This dissertation has been microfilmed exactly as received

MARKHAM, David Hogan, 1936-

THE DIMENSIONS OF SOURCE CREDIBILITY OF TELEVISION NEWSCASTERS.

The University of Oklahoma, Ph.D., 1965

Speech-Theater

University Microfilms, Inc., Ann Arbor, Michigan 
THE UNIVERSITY OF OKLAHOMA

GRADUATE COLLEGE

\title{
THE DIMENSIONS OF SOURCE CREDIBILITY \\ OF TELEVISION NEWSCASTERS
}

\author{
A DISSERTATION \\ SUBMITTED TO THE GRADUATE FACULTY \\ in partial fulfillment of the requirements for the \\ degree of \\ DOCTOR OF PHII,OSOPHY
}

BY

DAVID HOGAN MARKHAM

Norman, Oklahoma

1965 
THE DIMENSIONS OF SOURCE CREDIBILITY

OF TELEVISION NEWSCASTERS

APPROVED BY
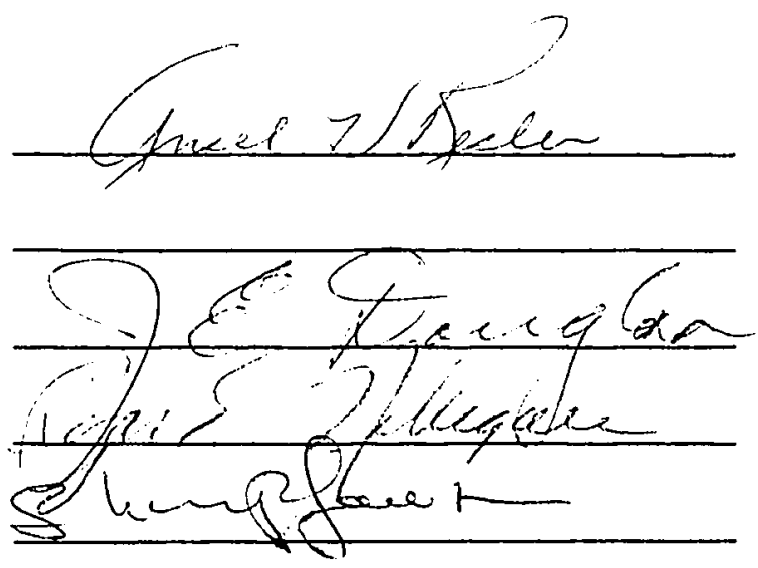

DISSERTATION COMMITTEE 
Filmed as received

without page(s) iii

UNIVERSITY MICROFIIMS, INC. 
TABLE OF CONTENTS

Page

LIST OF TABLES ...................

Chapter

I. DEFINITIONS OF SOURCE CREDIBILITY . . . . . . 1

II. SUMMARY OF PREVIOUS RESEARCH ....... 21

III. EXPERIMENTAL DESIGN AND RESULTS . . . . . . . 42

IV. DISCUSSION AND SUGGESTIONS FOR FUTURE RESEARCH . . . . . . . . . . . . 69

BIBLIOGRAPHY . . . . . . . . . . . . . . . . 85

Appendices

A. FIFTY-FIVE BIPOLAR ADJECTIVES ....... 93

B. TEST INSTRUMENT .................... 95

C. NEWSCAST SCRIPTS ............... 99

D. FOUR FACTOR ROTATION .......... 117

E. SIX FACTOR ROTATION ............. 119

F. EIGHT FACTOR ROTATION ......... 121

G. FIELD INSTRUMENT . . . . . . . . . . . . 123 


\section{LIST OF TABLES}

Table

Page

1. AGE OF THE SUBJECTS . . . . . . . . . . . 47

2. ORDER OF STIMULUS PRESENTATION ........ 50

3. CORRELATION MATRIX ............. 52

4. UNROTATED FACTORS ............. 59

5. TEN FACTOR SOLUTION DERIVED BY

VARIMAX ROTATION . . . . . . . . . . . . 64 


\section{CHAPTER I}

\section{DEFINITIONS OF SOURCE CREDIBILITY}

The concept of source credibility or ethos has always occupied a significant place in rhetoric. While a complete survey of the theory of ethical proof lies outside the scope of this study, the author will emphasize both the basic formulations of ethos by ancient rhetorical theorists, particularly Aristotle, and formulations by contemporary theorists, including theories derived from the behavioral sciences.

For the purposes of this study, the judgments an audience makes about the communicative ability of a speake $r$ will be designated as the perception of the communicator's "source credibility." In other words, the receiver's perception of the communicator at a given time, considered in terms of common or average aspects of an image shared by a group of receivers will be called "source credibility." Following Andersen and Clevenger, " the terms ethos and "ethical proof" will be used interchangeably with "source credibility."

${ }^{1}$ Kenneth Andersen and Theodo re Clevenger, Jr., "A Summa ry of Experimental Research in Ethos, "Speech Moncgraphs, XXX (1963), $59-78$. 
I. Ethos in Ancient Rhetoric

Pre-Aristotelian Rhetoricians. Aristotle was probably the first to apply the term ethos to the concept of the communicator by an audi-

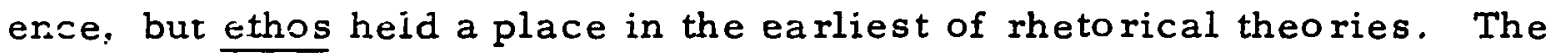
word ethos originally meant customs or usages, particularly those which were urique to one group of pecple as opposed to another. Later, the term came to mean character and evolved a connotation of socially approved characteristics. ${ }^{2}$

Corax and Tisias used the concept of ethos as an outg row th of the proem, the topics of probability, and the adaptation of the speech text by the professional speech writer to the intended speaker, audience, and message content. Isocrates stressed the role of character in the persuasive speech situation and the value of the speaker's reputation:

- . who does not know that words carry greater conviction when spoken by men of good replite than when spoken by men who live under a cloud, and that the a rgument which is made by a man's life is of more weight than that which is furnished by words? ${ }^{3}$

In the Gorgias, Plato criticized rhetoric as a false practice, used by men who were ignorant of the subjects about which they spoke. Plato

${ }^{2}$ William Sattler, "Conceptions cf Ethos in Rhetoric," (unpublished Ph. D. dissertation, Northwestern University, 1941), p. 5.

${ }^{3}$ George Norlin, trans. "Antidosis," Isocrates (London: Oxford University Press, 1938), p. 126. 
held that the fully-informed man, the philosopher, was the ideal human. 4 In the companion piece, the Phaedrus, Plato outlined a rhetoric in which good character, not the appea rance of good character, would be desirable in a rhetor. 5

Summarizing the concept of ethos p rior to Aristotle, Sattler noted that the theorists placed emphasis upon the appearance of good character, with little, but some, emphasis upon the importance of the "moral" speaker and the direct and indirect methods of application of ethical appeal as proof in the speaking situation. 6

Aristotle. Aristotle held that communication consisted of three parts, which he called ethos, logos, and pathos. Of ethos, he said:

It is not true, as some writers assume in their treatises that the personal goodness revealed by the speaker contributes nothing to his power of persuasion; on the contrary, his character may almost be called the most effective means of persuasion he possesses. 7

Aristotle further illustrated the importance of this concept of ethos when he w rote:

. . the orator must not only try to make the a rgument of his speech demonstrative and worthy of belief; . . .

${ }^{4}$ Lane Cooper, trans. Plato: Phaedrus, Ion, Gorgias, and Symposium, with Passages from the Republic and Laws (London: Oxford University Press, 1938), pp. 95-206.

${ }^{5}$ Ibid., pp. $7-71$.

${ }^{6}$ Sattler, pp. 328-329.

${ }^{7}$ Aristotle, Rhetoric, trans. by W. Rhys Roberts (New York: Modern Library, 1954), $1356^{\mathrm{a}}$. 
he must also make his own character look right and put his hearers, who a re to decide in the right frame of mind. It adds much to an orator's influence that his own character should look right and that he should be thought to entertain the right feelings toward his hearers; and also that his hearers themselves should be in just the right frame of mind. 8

The several expressions "character," "look right," and "be thought to entertain the right feelings" tend to indicate a total picture of the speaker as he appears to the audience during the speaking situation.

Although Aristotle recognized the prior existence of reputation, he did not treat this within the framework of the speaking situation involving modes of proof:

- . what the speaker did during the speech was of primary concern; what people thought of him before he spoke was not in itself directly related to the modes of persuasion. This distinction is defensible, perhaps, if we conceive of ethical proof as an artistic creation brought about by the speake $r^{\prime} s$ skill in asserting his intelligence, revealing his probity, and accommodating himself to his hearers. 9

The belief that the proofs of logos, pathos, and ethos were separate entities or distinct parts Aristotle implied in the emphasis he placed upon choice-making behavior in his section of the Rhetoric dealing with the forms of government and public speaking: "The qualities of individuals . . a re revealed in their deliberative acts of choice."10

${ }^{8}$ Ibid., $1377^{\mathrm{b}}$.

${ }^{9}$ Lester Thonssen and A. Craig Baird, Speech Criticism (New York: The Ronald Press Co., 1948), p. 385.

${ }^{10}$ Aristotle, $1366^{\mathrm{a}}$. 
Since the choices a speaker makes in forming his communication involve word choices, arguments, arrangement, style, and delivery, these choices will reflect the character, good will, and intelligence of the speaker. Sattler concluded that to Aristotle, ethos permeated the message and, "The speaker's ethos arises from choices evident in the invention, arrangement, style and delivery of the speech. "11 Further, Aristotle emphasized the many lises cf any one element or device in the message capable of creating logical and emotional proofs simultaneously (e.g., his discussion of the maxim. $)^{12}$ When Aristotle discussed the virtues of the speaker as means of creating an impression of intelligence and character, he also noted that good will and a friendly disposition we re closely related to the emotions. 13

In his summary of the Rhetoric, Pross noted that language, elements in a rrangement, emotion, and the entire structure of invention interrelated with ethos. ${ }^{14}$ Cope, in an introduction to the Rhetoric, noticed elements of ethos in invention, in devices designed to reveal the character of the speaker, in audience adaptation, and in techniques of style. 15

${ }^{11}$ Sattler, p. 92.

12 A ristotle, $1394^{\mathrm{a}}-1395^{\mathrm{b}}$.

13 Ibid., $1378^{\mathrm{a}}$.

14 Edward L. Pross, "A Critical Analysis of Certain Aspects of Ethical Proof," (unpublished Ph. D. dissertation, University of Iowa, 1942), pp. 16-17.

15 Edward M. Cope, An Introduction to Aristotle's Rhetoric (London: MacMillan and Co., 1867), pp. 110-113. 
Cicerc and Quintilian. Cicero and Quintilian prese rved almost intact the Aristotelian concept of ethos, although they added particular emphases. Cicero did rot place as much emphasis on ethos as did A ristotle, but errployed the concept largely under the term "character." Cicerc also treated ethos as a way of "winning the favor of the audience" 16 and placed more emphasis or pricr reputation of the speaker as a factor of ethos.

Quintilian tended to thirik of ethos as the attributes of "a good man skilled in speaking 17 and made many references to the persuasive power of ethos. ${ }^{18}$ However, Quintilian spent little time in dealing with specific techniques of ethical proof, but suggested that the "good man" would naturally deliver what was true and honorable. 19 Quintilian seemed to treat the whole concept of ethos as intermingled with the pathetic and logical modes of proof.

Both Cicero and Quintilian stressed the importance of audience adaptation, app rop riateness in the speaking situation, and, in contrast to Aristotle, paid less attention to the relationship of ethos and invention

\section{${ }^{16}$ Irving J. Lee, "Some Conceptions of Emotional Appeal in} Rhetorical Theory," Speech Monographs, VI (1939), 67.

${ }^{17}$ Quintilian, Institutio Orato rio, trans. by H.E. Butler, I (Cambridge: Ha rvard Press, 1953), p. 9.

$$
\begin{aligned}
& 18 \text { Ibid., II, } 9 . \\
& { }^{19} \text { Ibid., IV, } 361 .
\end{aligned}
$$


and more to the value of reputation before the speaking act. 20

\section{I1. Ethos from Ancient to Contemporary Rhetoric}

The period from the second to the twentieth centuries provided few innovations in the position given to ethos in earlier rhetorical systems.

During the decline and fall of the Roman Empire, rhetoric was practiced mainly as school room exercises, and in actual rhetorical use in society, ethos simply became the choice of a paid rep resentative.

Writers on homiletics did not use the word ethos; however, these writers, such as St. Aligustine in Book IV of De Doctrina Christiana, relegated ethos to the preacher's innate nobility of character and knowledge. Ethos was frequently talked about in terms of appropriateness in style and delivery. Ethos also continued to be associated frequently with character perception, but rarely as a device of proof. 21 Aristotle's view of ethos as being ar integral part of invention, interrelated with the elements of the message, was largely ignored.

The sixteenth and seventeenth centuries involved a renewed interest in classical rhetorical theories. Authors such as Fenelon noted the concept of ethos as a distinct method of proof, while writers such as Cox and Wilson implied an association of ethos with invention. However, ethos retained

20 Sattler, pp. 165-169.

$21_{\text {Ibid. }}$ pp. $231-234$. 
an association with character portrayal. 22 In the stylistic rhetorics, such as those of Sherry and Peacham, this character emphasis was evidert in devices to display the emotions.

Eighteenth and nineteerth century rhetorical theories showed a relatively full redevelopment of classical theories of ethos. The works of Campbell, Blair, and Whately widely quoted the concepts of Aristotle, Cicero, and Quirtilian. But Whately, for example, challenged Quintilian's advice that the good speaker must be a good man. 23 Blair strongly urged that the young ministe $r$ in his training not a rgue both sides of a question, for this practice might damage his reputation. 24

Ethos held a prominent position in the rhetorical theories of the time as attested by the fact that Whately devoled thirty pages of his treatise to a discussion of qualities of character, the problem of dealing with emotional opposition to the speaker, et cetera.

Despite the similarities between rhetoric of this period and classical rhetoric, the treatment of ethos was not always expressed in the same terminology. Campbell placed emphasis upon "sympathy, "which he defined as:

$22_{\text {Ibid. }}$ pp. $279-282$.

${ }^{23}$ Richard Whately, Elements of Rhetoric (New York: Sheldon and Co., 1846), p. 21 .

${ }^{24}$ Hugh Blair, Lectures on Rhetoric and Belles Lettres (Philadelphia: James Kay, Jun. and Brother, 1829), p. 287. 
- . the opinion entertained of him / the speaker 7 by the hearers, or the character which he bears with them.

Sympathy . . may be lessened several ways, chiefly by these two: by a low opinion of his / the speaker's intellectual abilities and by a bad opinion of his morale. 25

Ethos, as exemplified by Whately, was very often associated

with p roblems of audience aralysis.

- . it is requisite to consider who and what the hearers are; for when it is said that good Sense, good Principle, and Good-will, constitute the character which the speaker ought to establish of himself, it is to be remembered that every cne of these is to be considered in reference to the opinions and habits of the audience. To think very differently from his hearers, may often be a sign of the Orator's wisdom and worth, but they are not likely to consider it so. 26

During this period, writers in the homiletic tradition such as Campbell, Blair, and Whately, at least partially viewed the minister as an "inspired individual" and tended to place little emphasis on techniques to develop ethos, and these techniques tended to be thought of as dishonest. However, in the nineteenth century, particularly in America, increasing numbers of rhetorical authors stressed the development of techniques to promote ethos. 27 The rationale that such authors offered

${ }^{25}$ George Campbell, The Philosophy of Rhetoric (London: William Tegg and Co., 1850), pp. 96-97.

${ }^{26}$ Whately, p. 244 .

27 John P. Hoshor, "American Contributions to Rhetorical Theory and Homiletics," A History of Speech Education in Ame rica (New York: Appleton-Century-Crofts, Inc., 1954), pp. 129-152. 
for such "dishonest tricks" in homeletics often became exterded. 28

\section{Ethos in Contemporary Theory}

Contemporary theories of ethos have tended to retain the concept but have abandoned the term. Also, the concept of ethos, although not called by the name, has appeared in fields such as social psychology. Theorists have also noted the results of experimental research relative to communication and to ethos.

Rhetorical Theorists. Contemporary authors have placed emphasis upon the role of ethos in persuasion but have seldom used the term "ethical proof."29 However, in rhetoricai criticism of speakers, they have retained the concept under the heading of ethos and "ethical proof." 30 Since few authors have utilized the te rm ethos, the exact concept used by these authors has usually been unclear because they have not stated the elements of the concept nor explained the workings of ethical proof.

Writers who have focused on the subject of persuasion have tended to agree on the conceptual framework of ethos and have devoted more space to this concept than have writers of beginning communication

${ }^{28}$ See Edward T. Channing, Lectures Read to the Seniors in Harvard College (Boston: Ticknor and Fields, 1856), pp. 143-148.

${ }^{29}$ Winston L. Brembeck and William S. Howell, Persuasion (New York: Prentice Hall, Inc., 1952), pp. 247-248.

${ }^{30}$ For example, Wayland M. Parrish and Marie Hochmuth, American Speeches (New York: Longmans, Green and Co., 1954). 
texts. Brembeck and Howell, Minnick, ${ }^{31}$ and Oliver ${ }^{32}$ have all extensively remarked on the ethical features message elements. In scholarly instances of speech criticism, nearly every author has maintained that good character, good will, and authoritativeness have explicit or implicit effects upon the ultimate persuasive success of the speech.

These persuasion textbooks have tended to focus on "character" as a very near synonym for ethos. Oliver, Dickey, and Zelko stated that "in the long run... influence depends primarily upon character."133 Brembeck and Howell suggested that the word ethos may be "broadly translated as 'character'. " 34 Brigance suggested strong moral character, self-control, sincerity, and earnestness as basic to attaining ethos. 35

Some writers on communication have suggested that the term "character" is not broad enough to offer an explanation of ethos. The speech critic, James Winans, noted early in this century that some persons with an unsavory moral reputation have been very effective in

${ }^{31}$ Wayne C. Minnick, The Art of Persuasion (Boston: Houghton Mifflin Co., 1957).

${ }^{32}$ Robert T. Oliver, The Psychology of Persuasive Speech (New York: Longmans, Green and Co., 1957).

${ }^{33}$ Robert T. Oliver, Dallas C. Dickey, and Ha rold P. Zelko, Essentials of Communicative Speech (New York: The Dryden Press, 1949), pp. $173-174$.

34 Brembeck and Howell, p. 244.

${ }^{35}$ William N. Brigance, Speech Composition (New York: F.S. Crofts and Co., 1937), pp. 141-149. 
their persuasive efforts. 36 Sattler says that to limit ethos to character is a narrow definition of the concept. Such personal qualities as general intelligence, knowledge of the subject, app rop riateness of diction and pronounciation, and even appearance a re all a part of the "characte $r$ " of a communicating person. ${ }^{37}$ As Strother says: "In a word, 'ethos' is a speaker's personality as revealed by textual and extratextual materials. "38 Personality Theorists. The latter statement, along with many others cited above, suggests a tendency to identify the concept of ethos with that of personality, as employed in psychology. This app roach in regard to communication theorizing seems to be a current trend. Brigance described the personality of the speaker as part of persuasion. ${ }^{39}$ Oliver w rote:

Just as real a factor in persuasion as self-interest and social consciousness is the personality of the speaker. It is the channel through which all his appeals must be directed to the audience. 40

Sattler defined ethos as "totality of characteristic traits." 41

${ }^{36}$ James A. Winans, Public Speaking, rev. ed. (New York: The Century Co., 1917), pp. $314-315$.

37 Sattle r, pp. $7-8$.

${ }^{38}$ Edward S. Strother, "An Experimental Study of Ethos As Related to the Introduction in the Persuasive Speaking Situation, " (unpublished $\mathrm{Ph}$. D. dissertation, Northwestern University, 1951), p. 6.

${ }^{39}$ Brigance, pp. $240-241$.

${ }^{40}$ Oliver, The Psychology of Persuasive Speech, p. 105.

41 Sattle r, p. 6 . 
As Hall and Lindzey state,". . no substantive definition of personality can be applied with any generality. . personality is defined by the particular empirical concepts which are a part of the theory of personality emplcyed by the observer. "42 For the purposes of this paper, personality, as G.W. Allport defines it, ". . is the dynamic organization within the individual of those psychophysical systems that determine his unique adjistments to his envi ronment. "43 More simply, Ross Stagner explairs personality as ". . a way of looking at reality. "44 These same statements many communication theorists could use to explain ethos. For some theorists, the psychological definition of character more nearly app roximates some of the theories of ethos: "Character refers specifically to a person's conduct as evaluated by social standards.

Character is the moral and ethical side of personality. "45 This statement is comparable to Minnick's statement that 'known reputation. . character and personality revealed by the speaker as he utters the speech... and the coincidence of the speake $r^{\prime} s$ proposals with the rigid beliefs and

${ }^{42}$ Calvin S. Hall and Gardner Lindzey, Theories of Personality (New York: John Wiley and Sors, Inc., 1957), p. 9.

${ }^{43}$ G. W. Allport, Personality: A Psychological Interp retation (New York: Henry Holt and Company, Inc., 1937), p. 48.

${ }^{44}$ Ross Stagner, Psychology of Personality, third ed. (New York: McGraw-Hill, 1961), p. 9 .

45 Floyd L. Ruch, Psychology and Life, fourth ed. (Chicago: Scott, Foresman and Co., 1953), p. 30 . 
attitudes of the audience" are elemental variables in Minnick's concept of ethos. 46

Ethos has very often been treated as an intangible, not fully subject to control and investigation. Brigance has witten he could not teach others to acquire the personality necessary for maximum persuasiveness. 47 Minnick and Walter both have stressed that unconscious cues the speaker gives the audience are powerful variables of ethos. 48 This concept of covert and almost unsensible actions is often part of theories of ethos. Walter has suggested that the "number of small matters that reflect upon. . . ethos may well run into the hundreds." 49

The contemporary theorists have also stressed the situational aspect of ethos.

It is inevitable that the audience will form impressions of the speaker. . . from every conceivable factor entering into the speech situation. And they will react to him in terms of their own beliefs, customs, habits, and actions. 50

${ }^{46}$ Minnick, p. 113

${ }^{47}$ Brigance, pp. $140-141$.

${ }^{48}$ Minnick, p. 12l; and Otis M. Walter, "What You Are Speaks So Loud . . . " "Today's Speech, III (1955), 5.

49 Walter, pp. 4-5.

${ }^{50}$ Claude M. Wise, et. al., Foundations of Speech (New York: Prentice-Hall, Inc., 1941), p. 350 . 
Oliver has noted credibility elements in the occasion, the size of the audience, the sponsc ring group, et cetera.

in spite of the problems of the multi-dimensionality of ethos, the emphasis or audience adaptation, the minimal or unconsciously transmitted clies, and the linking of ethos to personality and character variables, some authors have prescribed highly specific techniques for creating ethos.

Ewbank and Auer suggest such specific items as the role of the communicator as a leader of a group, the use of citation of authorities, the use of good evidence and reasoning as keys to a persuasive ethical proof. 52 Winans lists "reputation, humor, fairness, personal magnetism, respect of audiences, moral character, modesty. "53 Minnick includes "physical energy and tonus; decisiveness; color, eccentricity, and uniqueness; and mental alertness, inteliigence, and knowledge. "54 Thonssen and Baird list certain techniques to promote three elements of ethos: probity of character; sagacity; and good will. 55

51 Oliver, pp. 106-107.

52 Henry L. Ewbank and J. Jeffery Auer, Discussion and Debate, second ed. (New York: Appleton-Century-Crofts, Inc., 1951), p. 246.

${ }^{53}$ Winans, pp. $305-328$

${ }^{54}$ Minnick, pp. $116-120$.

55 Thonssen and Baird, p. 387. 
Social Psychologists. Social psychologists have devoted much attention to "prestige" and other factors of ethos. But the psychological terms, although popular with contemporary communication theorists; have not been as poptilar with other spee ch critics as has classical rhetorical terminology. The basic concepts that the psychologist has used in measuring these ethical elements shows no significant departure from the classical or contemporary theories of ethos. Further, the implicit concepts of ethos employed by the social psychologist have been very similar to those explicitly stated in communication theory.

In the concepts of social psychologists, ethos has been closely identified with the concept of "prestige," usually created before the communication act. Experiments have frequently attributed messages to sources assumed or found to be different in prestige; then experiments have examined the differences in persuasiveness of the same message when attributed to these different sources. This rather simple theoretical position attempted to measure the effect of prior prestige but ignored any possible interaction between the source and the message. A few recent studies, particularly those using the semantic differential technique, have emphasized recip rocal effects in the linking of source and message.

Social psychologists have held the position that every source carries an image (or ethos) with any message. "The pronouncements of a person - . are experienced against the whole background of our relationship 
to that persen. "56 This view was reinforced by Merton's description of the Kate Smiti war bond drive: "Responses were also strongly influenced by previously established images of Smith and by personal ties to her. "57 Firther, "The effectiveness of what she had to say cannot be disassociated from these public images. 158

When explicitly stated by the psychologist, ethos has frequently been called leadership and leadership positions. Hovland, Janis, and Kelly found expertness and trustworthiness as important factors in persuasion. "These attitudes a re related to perceptions of the communi-

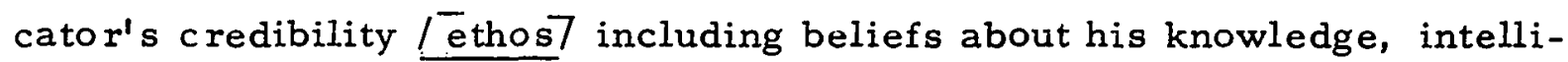
gence, and sincerity. 159

A close relationship between elements of ethos and logical forms of proof has been suggested:

The line between suggestion and rational advice is sometimes very difficult to determine. When a man of prestige gives an opinion or a suggestion, particularly when he is a specialist with formalized status, such as a physician, the opinion is not to be lightly dis regarded by any intelligent person. 60

${ }^{56}$ Muzafer Sherif, "An Experimental Study of Ste reotypes," Journal of Abnormal and Social Psychology, XXIX (1935), 371.

57 Robert K. Merton, Mass Persuasion: The Social Psychology of a War Bond Drive (New York: Harper and Brothers, 1946), p. 141.

58 Ibid., p. 177.

$59 \mathrm{Ca} \times 1$ I. Hovland, Irving L. Janis, and Ha rold H. Kelly, Communication and Persuasion (New Haven: Yale University Press, 1953), pp. 20-21.

60 Alfred R. Lindesmith and Anselm L. Strauss, Social Psychology, rev. ed. (New York: Henry Holt and Co., Inc., 1956), p. 455. 
Asch, Block, and Hertzman hold that judgments of communications are interrelated, that general attitudes affect each single judgment, and that "each singie judgment, as it occurs, directs and qualifies the character of succeeding judgments." 61 Young also stated that generalization of prestige and status from one field to another "is almost inevitable. "62

The prestige and authority of the speaker are held by some psychologists to be audience determined and not determined by the character of the speaker. "Prestige depends largely upon qualities ascribed to the leader by other persons," the leader assumes the traits and attitudes ascribed to him by the group he leads. 63

Much of the attention of experimental social psychologists centers on the conflict between two models of source credibility or prestige persuasion. One theory holds that "a change of evaluation consists of a change or response to the constant stimulus. "64 This position holds that

61 Solomon Asch, Helen Block, and Max Hertzman, "Studies in the Principles of Judgments and Attitudes: I. Two Basic Principles of Judgments," Journal of Psychology, V (1935), 219.

62 Kimball Young, Social Psychology, 2nd ed. (New York: F.S. Crofts and Co., Inc., 1947), p. 247.

${ }^{63}$ Ibid., pp. $246-247$.

${ }^{64}$ William B. Michael, Bernard G. Rosenthal, and Michael H. DeCamp, "An Experimental Investigation of Prestige Suggestion for Two Types of Literary Material," Journal of Psychology, XXVIII (1949), 303. 
the impact of source credibility and prestige is an "irrational and uncritical" response. 65

Representing the opposition to this theoretical position are Asch, J.P. Das, Rath, R.S. Das, and others. Their positions are that the prestige source or group makes up a frame of reference in which the initial stimulis is reinterp reted: "a change in the object of judgment, rather than in the judgment of the object. 166

McLaughlin surveyed the field of social psychology and discovered support for the Aristotelian theory of ethos. McLaughlin listed among his conclusions: (1) the communicative process is necessarily an interactive one between the listener and speaker, (2) prior prestige elements of ethos "cannot be separated realistically from the audience impressions during the speech," (3) the doctrine of free choices indicates a "lack of recognition of situational determinants," (4) "the moral dimensions of personality is $\langle\overline{\text { sic }}\rangle$ a means to ethical persuasion only when it comports with g roup norms of customary morality," (5) "apparent personal knowledge concerning the content of the speech as manifested in the social context"

${ }^{65}$ J.P. Das, R. Rath, and Rhea S. Das, "Understanding Versus Suggestion in the Judgment of Literary Passages," Journal of Abnormal and Social Psychology, LI (1955), 642.

${ }^{66}$ S.E. Asch, "Studies in the Principles of Judgments and Attitudes: II. Determination of Judgments by Group and Ego Standards, " Journal of Social Psychology, II (1940), 457. 
is very important, and (6) "good will toward the specific audience... conceived as adaptation to the interest of a specific audience situation" has crucial significance in communication. 67

Summary. The concept of ethos has continued to occupy an important position in the communication process. This position has been maintained by theorists in both rhetoric and social psychology. The word ethos, however, rarely occurs in contemporary speech textbooks, although preserved in speech criticism treatises, and never occurs in the writing of social psychologists. However, no discernable differences are noticeable between the psychologists' term "source credibility," which involves prestige, and the rhetorical concept of ethos.

In most contemporary communication theories, ethos has been conceived as an interaction between prior conceptions of the communicator held by the listener and almost all of the elements of the communication act, including content, delivery, appearance of the speaker, methods of communication, and others. The focus upon the audience's perception as the location of the major source of ethos has become increasingly important. Ethos or source credibility is held by persuasion theorists to be an important element in communication, but the exact method of operation and theoretical mechanisms by which ethos operates a re a subject of controversy among some theorists while totally ignored by others.

67 Teddy J. McLaughlin, "Modern Social Psychology and the Aristotelian Concept of Ethical Proof, " (unpublished Ph. D. dissertation, University of Wisconsin, 1952), pp. 171-172. 


\section{CHAPTER II}

\section{SUMMARY OF PREVIOUS RESEA RCH}

Since the literature pertaining to the experimental measurement of source credibility or ethos is extensive, only those studies closely related to the variables this study investigates are reported here. Although the authors of many studies reported did not conceive of the variabies in question as elements of source credibility, I include them here because they appear relevant to ethos defined as the "image" or perception of the speaker held by his audience.

\section{Fixed Ethos}

One of the eariiest pieces of research concerning ethos was conducted by social psychologists investigating the influence of the "prestige of the source" upon judgments. The most frequently used procedure was to find communication sources which differed in "prestige, likableness, credibility, etc. " as judged by the investigators, experimental subjects, or subject matter experts. "Messages" were attributed to these sources, and the resulting effect of prestige or credibility was measured by shift of opinion in the subject area or by changes 
in evaluation of the subject matter p resented. Ail of these experiments assumed an unchanging credibility during the communication. Some considered a few gross audience characteristics, e.g., sex, age, economic position; but most studies ignored these variables.

Arnett, Davidson, and Lewis used Harper's test of liberalism to assess the impact of very literal responses supposedly made by distinguished educators. Graduate sociology students reacted with highly significant shifts on the liberalism instrument. ${ }^{l}$ However, since there was no control group, other factors might have caused the shifts.

Kulp, in a replication of the Arnett, Davidson, and Lewis experiment, told graduate students that lay citizens or social scientists made consistently liberal markings on Harper's test of liberalism. Significant shifts occurred in both groups, but differences were noticeable in the effects of the two rating groups upon the shift of opinions. 2

Lewis experimented with credibility by offering subjects political slogans that Franklin Roosevelt and Herbert Hoover had supposedly ranked and by asking subjects to evaluate these rankings. No significant shifts occurred; but the author suggests that students rationalized the supposed

${ }^{1}$ Claude Arnett, Helen Davidson, and Hallett Lewis, "Prestige as a Factor in Attitude Changes," Sociology and Social Research, XVI (193 1), 49-55.

${ }^{2}$ David Kulp, "Prestige, as Measured by Single Experience Changes and Their Permanency, " Journal of Educational Research, XXVII (1934), 663-672. 
rank, and when effective, the subjects' ratings redefined a previously ambiguous situation. 3 The latte $r$ conclusion is presented with no statistical basis.

Lorge and Curtis had students rank sources, then presented messages with a choice of source, still later supplied the correct author. They found a significant tendency to change an evaluation to match a favorable source, but not a significant tendency to shift negatively to match an unfavo rable source. 4

Moos and Koslin tested the prestige suggestion of political leaders by presenting statements variously attributed to a conservative Republican and to a "Fair Deal" Democrat. The "sources" significantly altered the judgment of statements judged by the subjects to the "vague" but no effect was noticed on those statements judged to be "precise." 5

Hovland and Weiss presented messages alternately attributed to "high and low credibility sources." These sources were judged by the subjects on a scale of "trustworthiness" after the experimental message presentation. Info rmation recall showed no relation to credibility, but a

${ }^{3}$ Helen Lewis, "Studies in the Principle of Judgments and Attitudes: IV. The Operation of 'Prestige Suggestion', " Journal of Social Psychology, XIV (1941), 229-256.

${ }^{4}$ Irving Lorge with Carl Curtis, "Prestige, Suggestion, and Attitudes," Journal of Social Psychology, VII (1936), 386-402.

${ }^{5} \mathrm{Malcolm}$ Moos and Bertram Koslin, "Prestige Suggestion and Political Leadership, " Public Opinion Quarterly, XVI (1952), 77-93. 
significantly larger number shifted in opinion response to the high credibility source than to the low credibility source. 6

Marple discovered that "expert ratings" on a va riety of social and political content items altered subject's judgments. ${ }^{7}$ Saadi and Farnsworth found that very dogmatic statements were more likely to be accepted by the subjects when attributed to sources previsusly ranked as well-1iked. 8

Credibility effects also have been investigated in judgments of art, literature, religious belief, et cetera. Farnsworth and Misumi presented paintings, randomly attributing them to artists previously determined to be known or unknown to the subjects, and found a tendency to evaluate a picture more favorably when the name of the artist was known. 9 Be rnberg found that students significantly altered their opinion

${ }^{6}$ Carl Hovland and Walter Weiss, "The Influence of Source Credibility on Communication Effectiveness, "Public Opinion Quarterly, XV (1951), 635-650.

${ }^{7}$ Clare Marple, "The Comparative Susceptibility of Three Age Levels to the Suggestion of Group Versus Expert Opinion, " Journal of Social Psychology, IV (1933), 176-186.

${ }^{8}$ Mitchell Saadi and Paul Farnsworth, "The Degrees of Acceptability of Dogmatic Statements and Preferences for Their Supposed Makers," Journal of Abnormal and Social Psychology, XXIV (1934), $143-150$.

${ }^{9}$ Paul Farnsworth and Issea Misumi, "Further Data on Suggestion in Pictures, " American Journal of Psychology, XLIII (1931), 632. 
in accordance with positive and negative prestigious critical reactions. 10 Cole found that evaluations of abstract art by group leaders or by an art teacher failed to alter judgments unless these evaluations we re coupled with logical-appearing arguments or the actual presence of the teacher. 11

Sherif studied credibility effects in literature by rotating supposed authors of sixteen prose passages by Robert Louis Stevenson rated by experts as equal in quality. He found that ratings of the worth of the passages and the worth of the authors correlated between .46 and .53 for several college groups in the United States and in Turkey. ${ }^{12}$ Michael, Rosenthal, and DeCamp presented prose and poetry passages variously matched with ranked authors. They found no significant shift in evaluation of passages to match author evaluations. 13 Das, Rath, and Das using a design similar to Sherif's but with a smaller number of subjects, concluded that prestige of the author significantly affected the judgment of poetry. Stressing the factor of understanding weakened this effect sharply. 14

10 Raymond Bernberg, "Prestige Suggestion in Art as Communication," Journal of Social Psychology, XXXVIII (1953), 23-30.

${ }^{11}$ David Cole, "'Rational Argument' änd 'Prestige-Suggestion' as Factors Influencing Judgment, "Sociometry, XVIII (1954), 350-354.

12 Muzafer Sherif, "An Experimental Study of Ste rotypes, " Jou rnal of Abno rmal and Social Psychology, XXIX (1935), 370-375.

13William B. Michael, Bernard Rosenthal, and Michael DeCamp, "An Experimental Investigation of Prestige-Suggestion for Two Types of Litera ry Material," Journal of Psychology, XXVIII (1949), 303-323.

14 J.P. Das, R. Rath, and Rhea Das, "Undertaking Versus Suggestion in the Judgment of Lite rary Passages, " Journal of Abnormal and Social Psychology, LI (1955), 624-628. 
Donceel, Alimerra, and Birch presented a variety of psychological or psychological-appearing tests; the descriptions of personality they later supplied to the subjects were false. They were able to cause subjects to significantly alter their judgments of their own personality, even to the point of changing responses to the "test" items in order to coincide with the false descriptions of their own personalities. 15

Moore found that "expert judgments, " actually determined randomly, we re effective in altering judgments in grammar, ethics, and music. 16 Burtt and Falkenberg found ministers had a significant effect upon judgments in religious matters. ${ }^{17}$ And Duncker was able to alter children's food preferences by presenting a story in which the fictitious hero endorsed one food over the other. 18

All of the above studies used a source in conjunction with slogans, written messages, art works, et cetera, in presentations unlike speaking

${ }^{15}$ Joseph Donceel, Benjamin Alimerra, and Catherine Birch, "Influence of Prestige Suggestion on the Answers of a Personality Invento ry, " Journal of Applied Psychology, XXXIII (1949), $352-355$.

${ }^{16}$ Henry Moore, "The Comparative Influence of Majority and Expert Opinion," American Journal of Psychology, XXXIII (1921), 16-20.

17 Ha rold Burtt and Don Falkenberg, Jr. "The Influence of Majority and Expert Opinion on Religious Attitudes, "Journal of Social Psychology, XIV (1941), 169-178.

${ }^{18}$ Ka rl Duncker, "Experimental Modification of Children's Food Preferences through Social Suggestion," Journal of Abnormal and Social Psychology, XXXIII (1938), 489-507. 
situations. Furthermore, the experimenters treated "prestige, likeableness, credibility, "et setera, as if the ethos was unaffected by the message. The following studies, while continuing to hold ethos as unchanging, presented the messages in speech situations.

Kelman and Hovland presented a recording of the same message taped by diffe rent speakers using diffe rent delivery techniques and different introductory interviews, the changes designed to alter the "credibility, prestige, and likeableress" of the communicator. The high credibility source was so evaluated in rating by the subjects and significantly greater attitude shifts were induced by the high ethos source. 19 Unfortunately, many uncontrolled variables make it difficult to give definite reasons for the cause of the shift.

Paulson presented taped speeches on lowering the voting age to eighteen, attributing them to a college professor of political science or a university student. "Speeches by the professor" created significantly greater shifts of opinion than those "of the student" among the male college student subjects, although this was not true for the female college subjects. The investigators found no significant difference in amount cf retention between speeches. 20

19Hexbert Kelman and Carl Hovland, " 'Reinstatement' of the Communicato $r$ in Delayed Measurement of Opinion Change, "Journal of Abno rmal and Social Psychology, XLVIII (1953), $321-325$.

20 Stanley Paulson, "The Effects of the Prestige Speake $\dot{r}$ and Acknowledgement of Opposing Arguments on Audience Retention and Shift of Opinion," Speech Monog raphs, XXI (1954), 267-271. 
Haiman attributed a speech on socialized medicine to Eugene Dennis, Secretary of the Communist Party in America; to Thomas Parran, Surgeon General of the United States, and to a university sophomore. The speech was significantly more effective when attributed to Parran than when attributed to Dennis or the sophomore, and Parran was rated significantly more competent. Dennis and the sophomore did not differ significantly in persuasiveness. 21

The following studies, in addition to varying the source of the message, also added some introductory material intended to improve the source's "image" to the audience. While the introduction was presumed to alter the image of the speaker, the expected charge was still measured indirectly and simultaneously in terms of attitude shift on the issue treated in the speech which followed.

Strother followed some elements of Haiman's design with a larger sample of audiences. Again, Dennis was judged significantly less persuasive than Parran. An introduction of Dennis designed to present him as a more "likeable" person did not significantly increase his persuasiveness. The subjects wrote a significant number of negative evaluations of the "speech techniques" employed by Dennis, but did not write any negative comments about Parran's techniques. 22

21 Franklyn Haiman, "An Experimental Study of the Effects of Ethos in Public Speaking, "Speech Monog raphs, XXI (1949), 190-202.

${ }^{22}$ Edward Strother, "An Experimental Study of Ethos as Related to the Introduction in the Persuasive Speaking Situation, " (unpublished $\mathrm{Ph}$. D. dissertation, Northwestern University, 1951). 
Highlander asked college students to judge radio speeches with and without introductions designed to "establish the authority of the speakers." He found no significant differences in liking of the programs or information-gain between the two conditions. 23

Pross also presented a variety of speeches with and without introductions designed to establish the "character, reputation, and intelligence of the speaker." These introductions added only slightly to the persuasiveness. 24

Kersten studied the effect of introductions rated by experts as good or poor by the criteria of focusing attention on the speaker and on the subject and on building the speaker's prestige. She found that those who heard the speech with the "good" introduction showed greater attitude shifts than those who heard the speech with no introduction or with the undesi rable introduction. 25

In cont rast to the above studies, Annis and Meier attempted to create an image of a previously unknown source through "pianted"

${ }^{23}$ John Highlander, "Audience Analyzer Measurements and Informational Effects of Speaker Variables in Radio Talks, " (unputlished Ph. D. dissertation, University of Wisconsin, 1953).

${ }^{24}$ Edward Pross, "A Critical Analysis of Certain Aspects of Ethical Proof, " (unpublished Ph. D. dissertation, University of Iowa, 1942).

${ }^{25}$ Ba rbara Kersten, "An Experimental Study to Determine the Effect of a Speech Introduction Upon the Speech that Followed, " (unpublished M.S. thesis, South Dakota State College, 1958). 
editorials. They constructed messages designed to create uniavorable and favorable images. Both types of messages were effective in creating the intended perception; exposure to seven editorials proved as effective as exposure to fourteen in creating this desired perception. 26

\section{Variable Ethes}

Althcligh the studies dealing with internal or message-centered ethical proofs are less numerous than those dealing with a fixed corcept of ethos, the studies have concentrated on a limited number of message variables. Only those studies are summarized here which the author feels a re applicable to this study. Again. many experimeriters did not conceive their studies as concerning ethos and indirectly measured ethos as a shift of opinion toward or away from the position presented by the ccmmunicator.

The effect of citing authority within the message $f_{1}$ as been investigated. Sikkink presented a taped speech on lowering the voting age to eighteen, incorporating or excluding six authority quotations accomparied by "app rop riate qualifying remarks." No significant shifts of cpinion we re found. 27 In a similar experiment, Gilkinson, Faulson, and

26 Albert Annis and No rman Nieier, "The Induction of Opinion Through Suggestion by Means of 'Planted Content, " Journal of Social Psychology, V (1934), 65-81.

27 Donald Sikkink, "An Experimental Study of the Effects on the Listener of Anticlimax Order and Authority in an Argumentative Speech," Southe rn Speech Journal, XXII (1956), 73-78. 
Sikkink, lising a speech on NATO, found only a siight tendency to favor inclusion of authorities. 28

Catheart presented a number of taped speeches on the abolition of capital punishment. Speeches ir which all contentions were supported but not documented or we re supported, documented, and the source qualified as legitimate, proved significartly more persuasive than $a$ speech which merely presented generalizations. However, a speech which supported and documented by naming fersor, flace, and date was not significantly more persuasive than that presenting generalizations. No significant differences we re found on ratings of speaker competence among any of the four speeches. 29

Ludlum constructed two sets cf speeches containing partisar a rguments on political issues. One set ci: speeches was labeled "strägrtforward a rgumentative" while the other incorpc rated "credibility techniques" described as "acknowledging opposing a rguments, " "manifesting a high degree of integ rity, " "leading thoughts rather than forcing," "showing alleged facts consistent with known facts," and "showing the up-to-dateness of the material." The speeches were given by various

${ }^{28}$ Howa rd Gilkinson, Stanley Paulson, ard Donald Sikkink, "Effects of Order and Authority in an Argumentative Speech, "Quarterly Journal of Speech, XI (1954), 283-292.

${ }^{29}$ Robert Cathcart, "An Experimental Study of the Relative Effectiveness of Four Methods of Presenting Evidence, "Speech Monographs, XXII (1955), 227-233. 
communicators identified as leaders in the Young Democrats and Young Republicans. The "straight-forward argumentative speeches" were significantly more persuasive than the speeches incorporating credibility techniques. 30 Inclusion of the many variables makes it difficult, if not impossible, to identify the results of any one variable. Hoviand and Mandell found that failure to draw an explicit conclusion resulted in a speech significantly less persuasive than one in which the conclusion was explicitly stated. 31 This variable might have hidden the effects of the treatments in the Ludlum study. It is also possible that an argumentative speech on political issues delivered by a partisan could have had a credibility component for college students. In the absence of any direct measure of change in the image of the communicator, one or more of the credibility techniques coild have had a negative rather than a positive effect or the speaker's image. Pross constructed four speeches: two non-ethical (no attempts at ethical proof), one short and one long; two ethical, one short and one long. No significant differences were found except. that the long ethizal speech was significantly more persuasive than the short ethicai speech. The short ethical speech had almost no logical structure due to the technique employed to shorten it by "cutting" elements. If logical proof has a

${ }^{30}$ Thomas Ludlum, "Effects of Certain Techniques of Credibility Upon Audience Attitude, "Speech Monog raphs, XXV (1959), 278-284.

${ }^{31} \mathrm{Ca}$ rl Hovland and Wallace Mandell, "An Experimental Comparison of Conclusion Drawing of the Communicator and by the Audience," Journal of Abno rmal and Social Psychology, XLVII (1952), $581-588$. 
persuasive dimension for college students, the effect of ethical proof may have been hidden.

Strother added material to a speech to increase the ethical appeal of the supposed speaker, Eugene Dennis. Neither the addition of this material, with or without the "image building" introduction, sigrificantly increased the total persuasive effect of the speech.

Brehm and Lipsher presented statements of opinion with and without supporting materials. On two of three issues, the addition of the supporting statements significantly increased ratings of the "trustworthiness of the communicator." However, the variable on the third is sue was found to be nearly the same between the two treatments. 32 Ethos and the Cong ruity Principle. In contrast to the above studies, several recent communication experimenters have employed Osgood's cong ruity principle to explain the interaction of the message content and the speaker.

The general cong ruity principle may be stated as follows: Whenever two signs are related by an assertion, the mediating reaction characteristic of each shifts towa $r$ d cong ruence with that characteristic of the other, the magnitude of the shift being inversely proportional to intensities of the inter-acting reactions. This "shift" may be in intensity, direction, or both. 33

32 Jack Brehm and David Lipsher, "Communicator-Communicatee Discrepancy and Perceived Communicatory Trustworthiness," Journal of Personality, XXVII (1930), 353-361.

${ }^{33}$ Charles Osgood, George Suci, and Percy Tannenbaum, The Measurement of Meaning (Urbana: University of Illinois Press, $1 \overline{957}$ ), pp. 300-301. 
Using the cong ruity hypothesis and the evaluative scales of the semantic differential, Tannenbaum's prediction of direction of shift for source and assertion (message) was highly significant for written messages. Tannenbaum hypothesized that the amour.t of shift toward the source or assertion was inversely proportional to the original intensity of the attitude ir question. This hypothesis was supported at significant levels. 34

Berlo and Gulley used the congruity hypothesis in predicting attitude charges toward a speaker and message. The predicted charges in attitude toward both were significant, although not as highly accurate as Tannenbaum's predictions of attitude shifts corcerning written messages. Berlo and Gulley's predictions of direction of shift were 67 percent accurate for the speaker, 64 percent correct for the message. 35

Bettinghaus in an attempt to explain the differerces between the Tannenbaum and the Berlo and Gulley experiments; theorized that the increased number of stimuli, hence, variables, in the speech situation (as opposed to a written commuricationj contributed to the inaccuracy of Berlo and Gulley's prediction. Bettinghaus concluded that the congruity

${ }^{34}$ Percy Tannenbaum, "Initial Attitude Toward Source ard Concept as Factors in Attitude Change Through Communication, "Public Opinion Quarterly, XX (1956), 413-415; and Charles Osgood and Percy Tannenbaum, "The Principle of Cong ruity in the Prediction of Attitude Change," Psychological Review, LXII (1955), 42-55.

${ }^{35}$ David K. Berlo and Halbert E. Gulley, "Some Determinants of the Effect of Oral Communication in Producing Attitude Change and Lea rning," Speech Monog raphs, XXIX (1957), 10-20. 
hypothesis was a valid model for prediction of an oral communication, provided additional variables such as delivery and treatment of the message were considered. Also, shifts in cong ruity seem to be more a function of the listener's attitude toward the speaker than the initial attitude toward the speech topic. Further, the listener's attitude toward the speaker influenced his perception of the speaker's delivery, the reby confounding the cong ruity p rinciple. 36

By using galvanic skin responses as an instrument, Burdick and Barnes found that tension was created by states of imbalance between the source and the message, as the cong ruity hypotheses predicts. In a separate experiment, they found that a well-liked source created significant positive shifts of opinion. By a rousing a dislike for a previously liked source, the experimenters tended to lower opinion level shifts. 37

In contrasi to the above app roaches, Haiman concentrated on non-verbal stimuli. He found that sex, manner, educational level, and appearance could produce variations in ratings on such factors as "competence," "fairmindedness," "likableness." Only the variable of "competence" was found to be highly correlated with degree of opinion

${ }^{36}$ E rwin Bettinghaus, Jr., "The Ope ration of Cong ruity in the Oral Communication Situation, " (unpublished Ph. D. dissertation, University of Illinois, 1959).

${ }^{37}$ Harry Burdick and Alan Barnes, "A Test of 'Strain Toward Symmetry' Theories," Journal of Abnormal and Social Psychology, LVII (1958), 367-370. 
shifts. Haiman's results indicate that delivery elements not oniy affected judgments of speaker competence, but we re causally linked with perslásiveness.

\section{The Measurement of Ethos}

Only a few studies directly attempted to measure ethos or the perception of the speaker. Most of the studies that attempted to measure this image did it indirectly, by such means as measuring opinion shifts assumed attributable to ethical proof.

The majority of early experiments assumed a fixed or stable ethos. Occasionally, the "prestige" of the source appears to be treated as independent of the message content. Almost universally in studies of fixed or stable ethos, the commuricator is found tc affect the perception of the rressage, but the possibility of the message affecting the perception of the communicator is ignored.

Occasionally assumed differences in ethos were ccrroborated if the different sources produced different measurable effects. Lurie defined this method when he defined prestige as "... the change in scale value of certain items brought about by attaching the name of the symbol to these items. ${ }^{38}$ Lurie, by using this method, developed a scale for the measurement of prestige. In a similar study, Bowden,

${ }^{38}$ Walter Lurie, "The Measurement of Prestige and Prestige Suggestibility," Jourral of Social Psychology, IX (1938), 219-225. 
Caldwell, and West presented several identical messages worded to appear different and attributed these messages to a variety of groups as sources. The relative prestige of these groups was then measured by the number of subjects selecting messages "made by" these groups. 39 Another early measuring device of source credibility was the method employed by She rif and by Das, Rath, and Das. This method was the use of rank order of sources and/or messages. Correlations usually measured the effect of the prestige. Cole used a sociogram in an attempt to determine group leaders and "prestige sources" in his experimental g roupings.

In the above measurement techniques, prestige was assumed to vary with attitude or opinion change. In recent experimental findings, such as Tannenbaum's discovery that source and message have an interactive effect, the fixed and unchanging concept of ethos becomes untenable. The linear rating scale indicates that some elements of the speaker's image change without any effect on persuasiveness.

The linear rating instrument is composed of one or more unidimensional scales, such as employed by Haiman, Cathcart, and Brehm and Lipsher with such scales as "sincerity, " and "trustworthiness." These experimenters studied the effects of the message which altered one or more elements of the perception of the communicator.

${ }^{39}$ A. Bowden, Floyd Caldwell, and Guy West, "A Study in Prestige, "American Journal of Sociology, XL (1934), 193-203. 
Winile simultaneous measurement on several inear scales indisates that the experimenter is aware of the multidimensionality of the speakeris image, Walter was the first to use this idea explicitly in an expe rimert. He limited his work to the measurement of "moral characte $r^{\prime \prime}$ and constructed twenty-two items, using the Thurstone technique of scaling, to measure the "character" of the speaker. The completed tests correlated highly between a recalled and live speaker, and Walter judged them to be valid against the criterion measures of open-ended ard Iree-response. 40

One of the later techniques is the use of evaluative scales of the semantic differential to measure the perception of the speaker. Although several different sets of scale items have been used ir studies by Tannenbaum, Bettinghaus, and Berlo and Kumata, 41 the experimenters have limited themselves mainly to the evaluative dimension of semantic space. Hicwever, the originators of the semantic differential note the greater validity of a multiva riate measure. The scales of evaliation, potency, and activity (plus the unidentifiable scales), which Osgood generated, a re probably not applicable to all judgment situations.

40 Otis Walter, Jr., "The Measurement of Ethos," (urpublished Ph. D. dissertation, Northwestern University, 1948).

41 David K. Berlo and Hideya Kumata, "The Investigator: The Impact of a Satirical Radio Drama, " Journalism Quarterly, XXXIII (1956), 187-198. 
Mulivariate Measures of Variable Ethos. Presently communiaation experimenters are using the technique developed by Osgood et al in the semantic differential studies to discover generalized dimensions of ethes. The technique of factor analysis of bipolar adjective scales suggests that ethos car be thought of as occupying "judgmental space" just as Osgood theorized that meaning occupies "semantic space." Ir other words, a few theorists a re suggesting that a listener to a communication judges that communication (and the communicator) on the basis of several internally held criteria, e.g., honesty, trustworthiness, ability, et cetera. These theorists a re presuming that these criteria may be discovered and arranged into dimensions or "clusters" by the measin rement techniques of the semantic differential and factor analysis of these measurements. Andersen selected twenty-two bipolar adjective scales and asked linderg raduate students to judge a list of sixteen living speakers' names by using the scales designed in the manner of the semantic differential. 42 Andersen extracted by orthogonal rotation (factor analysis) two dimensions from his data--an evaluative scale (characterized by the adjective pairs "Honest-dishonest, " "moral-immoral, " "Fair-unfair," "Good-bad, " et cetera) and a dynamism factor (characterized by items such as "Interestinguninte resting, " "Strong-weak, " "Fast-slow, " Active-passive, " et cetera.)

${ }^{42}$ Kenneth Andersen, "An Experimental Study of the Interaction of Artistic and Non-Artistic Ethos in Persuasion," (unpublished Ph. D. dissertation, University of Wisconsin, 1961). 
In an unpublished study Berlo expanded the measurement of ethos using the Andersen technique. ${ }^{43}$ He used a much larger number of scale items, used more subjects, and used living speakers as the communicators to be judged (as did Andersen); but Berlo included in his list the topics that the speakers were presumably talking about, and also used a different technique of factor analysis. Berlo discovered essentially the same two dimensions as Andersen (the evaluative and dynamism factors). When one considers the difference between the two studies in the factor analysis methods the consequence of the findings a re similar. Berlo also found a third dimension-- a "good guy" construct.

Summary. Research has shown that perceived differences in the source of a communication-- personal judgments, literary passages, art works, speeches, et cetera --are frequently capable of altering the effect of these stimuli upon a perceiver. Such studies have generally been concerned with rather gross measurements of "like" or "dislike, "believable" or "unbelievable," et cetera, rather than specific perceptions of the source. The use of materials apart from the source and the message, such as "good will" introductions have not been effective in producing a measurable diffe rence in the perception of the message.

In research which concentrates upon the message, often the results are inconclusive because of the confounding of variables present in the

43 David K. Berlo, "An Empirical Test of a General Construct of Credibility, " (unpublished paper presented at SAA convention, New York City, December 29, 1961). 
experiment. Experimentation in the inclusion of authority evidence has not shown any measurable deg ree of greater communication effectiveness or persuasiveness. Experimentation employing the cong ruity hypothesis has been highly predictive, particularly when, in examining the oral communication situation, the experimenter took. into account the complex va riables of delivery and message treatment. In this research, experimenters have found that the image of the communicator and the content of the message interact--each affect the other.

Early measurement techniques largely ignored these interactive tendencies of the source and the message. Consequently, many of the early studies did not measure what they purported to examine. In the absence of an instrument to measure specifically the perception of the communicator, the specific operation of ethical proof tends to be unclear.

Some of the newer techniques of measurement, which offer a means of operationalizing ethical proof more exactly, are the unidimensional linear rating scales and the semantic differential.

However, the most fruitful measurement method to date seemingly is the construction of a semantic differential type of instrument for the specific task of measuring the perception of the speaker. At least two investigators have had similar results in using this type of measurement on the platform speaker. As yet, this technique has not been applied to a mass communication medium. 


\section{CHAP TER III}

\section{EXPERIMENTAL DESIGN AND RESULTS}

One of the major problems in attempting to measure ethos is the inability of the experimente $r$ to assume that the re is a single major variable in operation in the communication situation. Charles E. Osgood and his associates at the University of Illinois devised an instrument called the semantic differential which has made possible multidimensional measurement of attitudes. ${ }^{1}$ This measurement device uses bi-polar adjectives to define the termini of semantic dimensions. Osgood et al found that three major identifiable dimensions (evaluation, potency, and activity) appeared in judgments of various words or concepts. Other dimensions were found less prominently. However, these scales of evaluation, potency, and activity a re probably not applicable to all judgment situations. For, as Osgood says:

- . it is also evident that functional semantic space is to some deg ree modifiable in terms of what kinds of concepts a re being judged, i.e., the relative importance and relationship among factors may vary with the frame of reference of judgments. Certainly, specific scales may change their

${ }^{1}$ Charles E. Osgood, George J. Suci and Percy H. Tannenbaum, The Measurement of Meaning (Urbana: University of Illinois Press, 1957). 
meanings in the factoral composition sense, as a function of the concept being judged. And finally, it is clear that what we have called the three dominant factors do not exhaust the dimensions along which meaningful judgments are diffe rentiated. 2

The following is a description of the procedures followed and results obtained by the experimenter in the use of a semantic differential type instrument applied to a series of television newscasts. ${ }^{3}$

The Measuring Instrument. From previous semantic differential research, the experimenter selected one-hundred and fifteen bipolar adjective pairs which showed high factor loadings in the original semantic differential research, some attitude measurement studies employing this technique, ${ }^{4}$ and a communication study of platform speakers. ${ }^{5}$ Items that seemed to have face validity for this study were selected. The experimenter then submitted these pairs of adjectives to two members of the

2Ibid., p. 72 .

${ }^{3}$ The author is aware of some of the limitations and theoretical difficulties of the semantic differential type of attitudinal measurement. For a discussion of these difficulties see Donald Keith Da rnell, "A Technique for Determining the Evaluative Discrimination Capacity and Polarity of Semantic Differential Scales for Specific Concepts" (unpublished $\mathrm{Ph} . \mathrm{D}$. dissertation, Michigan State Universiry, 1964).

${ }^{4}$ Paul M. Kneldergaard, "Attitudes Towards Newscasters as Measured by the Semantic Differential: A Descriptive Case, "Journal of Applied Psychology, XLV (1961), 35-40, and Raymond G. Smith, "Development of a Semantic Differential for Use with Speech Related Concepts," Speech Monographs, XXVI (1959), 263-272.

${ }^{5}$ Kenneth Andersen, "An Experimental Study of the Inte raction of Artistic and Non-artistic Ethos in Persuasion" (unpublished Ph. D. dissertation, University of Wisconsin, 1961). 
English faculty of Northe rn Illinois University and asked them to discard "duplicate" or "near duplicate" items. These Erglish professors discarded items until fifty-five pairs remained. Due to the limits of computer storage, the experimenter limited the number of items to fifty-five for the factor analysis that fcllowed. The reader may examine the complete set of fifty-five items in Appendix A.

The author then placed these fifty-five items on separate, numbered cards. During this process, a flip of the coin decided that odd-numbered items should be reversed. Then by a table of random numbers, the experimenter placed the items into the order in which they appeared on the test instrument. A rep roduction of the test instrument, with the cove $r$ set of instructions, is Appendix B.

The test instrument consisted of one cover page upon which the subject recorded information regarding sex, classification, et cetera; one page of instruction; and three sets of fifty-five items, which the author arranged by Osgood's method. The author then mimeographed the instruments on eight and one-half by fourteen-inch paper.

The Stimuli. The author contacted three newscasters who occupied positions as news directors in television stations located in fairly la rge market areas and cosmopolitan centers. These newscasters were Mr. Dick John of WIIC, Pittsburgh, Pennsylvania; Mr. John Harrison of KOCO, Oklahoma City, and Mr. Ed Turner of KWTV, also in Oklahoma City. Mr. Turner presented a "joint" or "two man" newscast 
with Mr. Bruce Palmer of the KWTV staff. The author asked these newsmen to ship a videotaped newscast that was taken "off the air." In other words, the newscasters recorded a program that was aired to the general public; a newscast that was part of the normal broadcast day. One newscaster elected to send the experimenter a prepared newscast designed for agency use, but it differed in only two respects from his daily operations: the opening of the newscast mentioned an oil company as a sponsor, and a placard on the set identified that sponsor.

The experimenter instructed the newscasters to present only news of a local or regional interest from a "typical broadcast day" and not include news of a national nature because of the danger of a subject's familiarity with national news content which would bias with the subjects' judgments of the communication. A practical limitation influenced this decision also: there was necessarily a time delay in processing the newscast for film projection because of shipping and filming time. The experimenter felt that the time differential between news actually happening, providing the subject was awa re of the news, and the actual viewing of the newscast might cause an unp redictable and undesirable interaction between subject and stimulus. Therefore, the author decided to use only newscasts of local interest.

The reader will notice that the newscasters were geog raphically removed from the place of the experiment. Because of the distances between Oklahoma City, Pittsburgh, and the Chicago area (the home of 
most of the experimental subjects), the subjects of the experiment were not familiar with the newscasters. During the experimentation, none of the subjects signified any previous experience with any of the newscasters.

The newscasts were transferred from video tape to sixteen millimeter sound film by the kinescope process. This transfer was done by a New York City recording firm, and a film producer at Northern Illinois University judged the reproductions to be of first or second generation quality. In other words, the print quality was from good to excellent by filming standards. The experimenter then edited the film to withdraw all internal commercials, since he felt that these were extraneous to the stimuli measured. Each film was placed on an individual reel so that order of presentation could be randomized. A script, in television form, of each newscast is Appendix C.

Subjects. Five hundred and ninety-eight underg raduate students at No rthe rn Illinois University participated in the experiment. These students were all en rolled in the Speech 100 course (Fundamentals of Speech), which is required of all undergraduate students at Northern Illinois University. This course is usually taken in the freshman or sophomore year. The 598 subjects completed 596 test instruments. Of these 596, 287 were male, 306 were female, and 3 gave no answer. Table 1 gives the distribution of the subjects' ages. The median age of the subjects was 19 years. 
TABLE 1

AGE OF THE SUBJECTS

\begin{tabular}{lr}
\hline Age in Years & Frequency \\
\hline 16 & 1 \\
17 & 2 \\
18 & 117 \\
19 & 215 \\
20 & 36 \\
21 & 24 \\
22 & 9 \\
23 & 6 \\
24 & 1 \\
25 & 5 \\
26 & 2 \\
27 & 2 \\
28 & 4 \\
29 & 1 \\
30 & 1 \\
Above 30 & 16 \\
No answer & 4 \\
\hline
\end{tabular}

Experiment Administration. The 596 sutjects were presented the newscasts and the test instrument in 31 separate sessions. These sessions were regular class meetings of the section of Speech 100 in which the subjects were regularly enrolled. Section size ranged from 10 to 24 subjects with a median number of 19 subjects. All experimental sessions occurred between May 13 and June 4, 1964. Experimental session times ranged from 8:00 AM to 6:30 PM with each session lasting 43 to 51 minutes. The regular class room was the place of the experiment; all class rooms had the facility of being darkened for film projection. 
The experimenter was introduced to the class by the regular instructor. In all but two of the 31 sessions, the instructor then left the room. The experimenter then said the following words:

The Speech Department of Northern Illinois University is engaged in an experiment to try to determine how college students observe television newscasts. Mr. (name of instructor) has allowed me to come in today to ask your help in this experiment. This in no way affects your performance or grade in this class of Speech 100. As a matter of fact, Mr. (name of instructor) will not even see what you do today.

The test instrument was then passed out to the subjects. When the experimenter noticed that a majority of the students had completed filling out the first page, he asked them to turn to the second page and read the instructions aloud. After reading the first paragraph the experimente $r$ then said the following:

This is how we are going to do this. We will project a series of three newscasts. After each newscast, you will be asked to fill out a series of descriptive scales which allow you to describe the man or men you have just seen. This is how you will fill out the scales.

Then the experimenter read aloud the rest of the instructions. After the reading of the instructions was completed, the experimenter asked if the subjects had any questions. If none, the first newscast was sta rted.

All newscasts were projected by the same Bell and Howell Filmosound projector (model number 285). Sound controls were maintained at the same level for all projections, but the screen image 
size varied from 24 to 34 inches, horizontally measured, depending upon level of room illumination. All experimental rooms were of app roximately the same dimensions. Illumination of the rooms fluctuated because of differences in density of blackout curtains, differing times of day, different overcast conditions, and different locations of experimental rooms in regard to sun placement.

The order in which the newscasts were presented was determined by a roll of a die prior to the experimental session. Table 2 shows the orders and frequency of orders of newscast projection.

After the projection of each newscast, the experimenter said:

"Now I wish you would tell me what you think about (name of newscaster or newscasters). Please fill out the next two pages of the ballot." The experimenter then showed a large lettered card with the newscaster's name or newscasters' names. The experimenter then rewound the film, threaded the next newscast, and watched the subjects. When all of them had completed marking the test instrument, he said, "Now, the next (or final) newscast." When the subjects had completed filling in the test instrument for the third newscast, they were excused. Mathematical Procedures. After discarding three test instruments as unusable, the experimenter coded the responses in the margin of the instruments by assigning numbers of one to seven reading the blanks left to right. These numbers were then punched on IBM cards and a fifty-five by fifty-five correlation matrix (using the Pearsonian 
TABLE 2

ORDER OF STIMULUS PRESENTATION

\begin{tabular}{cccc}
\hline $\begin{array}{c}\text { Order of } \\
\text { Newscasts }\end{array}$ & $\begin{array}{c}\text { Number of } \\
\text { Subjects }\end{array}$ & $\begin{array}{c}\text { Number of Experi- } \\
\text { mental Sessions }\end{array}$ \\
1 & ABC & 158 & 8 \\
2 & ACB & 145 & 7 \\
3 & BAC & 49 & 3 \\
4 & BCA & 0 & 0 \\
5 & CBA & 96 & 5 \\
6 & CAB & 148 & 8
\end{tabular}


product moment) was generated by the use of an IBM 1620 (60 K Model II) computer. Table 3 is this correlation matrix.

The experimenter then extracted from this correlation matrix 10 unrotated factors by the use of Hotelling's iterative method of factoring as described by Thurstone. 6 These 10 factors account for $61.97 \%$ of the total variance of the correlation matrix and the solution lowe red the eigenvalue or characteristic latent root to .9062 .

At this point extraction was stopped. As Kaise ${ }^{7}$ points out, following his consideration of statistical significance, algebraically necessary conditions, psychometric reliability, and psychological meaningfulness, when the eigenvalues reach one and factors extracted. range in quantity from one-sixth to one-third of the total number of variables, factoring for all practical purposes is completed. ${ }^{8}$ Table 4 is this set of 10 un rotated factors.

Using the IBM 1620 computer again, the experimenter rotated the first four factors by Varimax rotation. 9 The author then rotated

${ }^{6}$ L. L. Thurstone, Multiple-factor Analysis: A Development and Expansion of the Vectors of the Mind (Chicago: University of Chicago Press, 1957), pp. 483-510.

${ }^{7}$ Hen ry F. Kaiser, "The Application of Electronic Computers to Factor Analysis, "Educational and Psychological Measurement, XX (1960), $141-151$.

${ }^{8}$ For a discussion of the difficult question "when to stop factoring," see, Harry Harman, Modern Factor Analysis (Chicago: University of Chicago Press, 1960), pp. 362-383.

9 Ibid., pp. $301-308$. 
TABLE 3

CORRELATION MATRIX

KEY

1. Kind-cruel

2. Wise-unwise

3. Unfair-fair

4. Unde rstandable-incomp rehensible

5. Fast-slow

6. Attractive-unattractive

7. Unplea sant-plea sant

8. Intelligent-unintelligent

9. Unautho ritative-autho ritative

10. Uno riginal-o riginal

11. Upset-calm

12. Careful-careless

13. Illogical-logical

14. Irrational- rational

15. Uninte resting-inte resting

16. Organized-disorganized

17. Small-large

18. Un reliable-reliable

19. Insincere-sincere

20. Consistent-inconsistent

21. Believable-unbelievable

22. Objective-subjective

23. Modest-boastful

24. Imp ressive-unimp res sive

25. Indecisive-decisive

26. Extroverted-introverted

27. Non-agg ressive-agg ressive

28. Uneducated-educated
29. Igno rant-expert

3C. Persliasive-linpersuasive

3i. Unfriendly-friendly

32. Skilled-unskilled

33. Urs sympathetic-sympathetic

34. Effective-ineffective

35. Relaxed-tense

36. Likable-unlikable

37. Trairied-untrained

38. Immoral-moral

39. Realistic-unrealistic

40. Uninfo rmed-info rmed

41. Strong-weak

42. Biased-openminded

43. Good-bad

44. Passive-active

45. Admirable-contemptible

46. Competent-incompetent

47. Unsociable-sociable

48. Experienced-inexperienced

49. Un reasonable-reasonable

50. Unsure-confident

5i. Dishonest-honest

52. Right-w rong

53. Tired-energetic

54. Gloomy-chee rful

55. Profound-superficial 
TABLE 3

CORRELATION MATRIX

\begin{tabular}{|c|c|c|c|c|c|c|c|c|c|c|c|c|c|c|}
\hline 1 & 2 & 3 & 4 & 5 & 6 & 7 & 8 & 9 & & 10 & 11 & & \multirow{2}{*}{\multicolumn{2}{|c|}{$\frac{13}{-.312}$}} \\
\hline$\overline{1 .}$ & -.444 & -.501 & .310 & .067 & .364 & -.417 & .329 & -.221 & & 252 & -.314 & & & \\
\hline 2. & & .565 & -.426 & -.088 & -.425 & .474 & -.565 & .459 & & 403 & .320 & & \multicolumn{2}{|c|}{.503} \\
\hline 3. & & & -.387 & -.064 & -.354 & .427 & -.422 & .360 & & 239 & .327 & & \multicolumn{2}{|c|}{.416} \\
\hline 4. & & & & .032 & .431 & -.478 & .510 & -.340 & & 280 & -.322 & & 67 & -.453 \\
\hline 5. & & & & & .107 & -.083 & .141 & -.109 & & 050 & .057 & & $27-$ & -.070 \\
\hline 6. & & & & & & -.670 & .495 & -.329 & & 418 & -.272 & & $05-$ & -.385 \\
\hline 7 . & & & & & & & -.549 & .410 & & 430 & .377 & & \multicolumn{2}{|c|}{.431} \\
\hline 8. & & & & & & & & -.500 & & 359 & -.358 & & 36 & -.555 \\
\hline 9. & & & & & & & & & & 348 & .289 & & \multicolumn{2}{|c|}{.469} \\
\hline 10. & & & & & & & & & & & .197 & & \multirow{2}{*}{\multicolumn{2}{|c|}{$\begin{array}{l}.315 \\
.365\end{array}$}} \\
\hline 11. & & & & & & & & & & & & & & \\
\hline 12. & & & & & & & & & & & & & \multicolumn{2}{|c|}{-.520} \\
\hline 14 & 15 & 16 & 17 & 18 & 19 & 20 & 21 & 22 & & 23 & 2 & 4 & 25 & 26 \\
\hline 1. -.308 & -.305 & .282 & -.143 & -.328 & -.406 & .247 & .323 & 197 & & .301 & 3 & 20 & .22 & .127 \\
\hline 2. .471 & .423 & -.397 & .238 & .501 & .431 & -.397 & -.463 & -.262 & & -.249 & -.4 & & .39 &. .174 \\
\hline 3. .428 & .334 & -.319 & .159 & .461 & 430 & -.328 & -.458 & -.312 & & -.332 & -.3 & & 28 & -.117 \\
\hline 4. -.418 & -.424 & .450 & -.185 & -.415 & -.378 & .397 & .438 & 20 & & .195 & .3 & 92 & -.33 & .208 \\
\hline 5. -.064 & -.159 & .062 & -.073 & -.104 & -.084 & .017 & .112 & .026 & & -.011 & .1 & 91 & -.15 & .168 \\
\hline 6..- .356 & -.601 & .349 & -.273 & -.369 & -.420 & .349 & .329 & .198 & & .175 & .6 & 10 & -.38 & .281 \\
\hline 7. .399 & .620 & -.389 & .255 & .403 & .513 & -.381 & $-.389^{\circ}$ & $-.24 c$ & & -.228 & -.5 & & .43 & -.272 \\
\hline 8. -.506 & -.481 & .517 & -.222 & -.507 & -.459 & .452 & .479 & .259 & & .231 & .5 & 01 & -.46 & .233 \\
\hline 9. . .403 & .400 & -.384 & .195 & .474 & .369 & -.367 & -.417 & -.249 & & -.193 & -.3 & & .36 & -.171 \\
\hline 10. . .312 & .499 & -.261 & .202 & .307 & .378 & -.261 & -.305 & -.157 & & -.184 & -.4 & & .35 & -.165 \\
\hline 11. .377 & .271 & -.347 & .081 & .339 & .381 & -.312 & -.330 & -.170 & & -.285 & -.2 & & .24 & -.054 \\
\hline 12. -.454 & -.374 & .523 & -.146 & -.455 & -.428 & .477 & .444 & .236 & & .289 & & 82 & -.36 & .162 \\
\hline
\end{tabular}

${ }^{a}$ Diagonal correlations of 1.000 omitted. 
TABLE 3 (Continued)

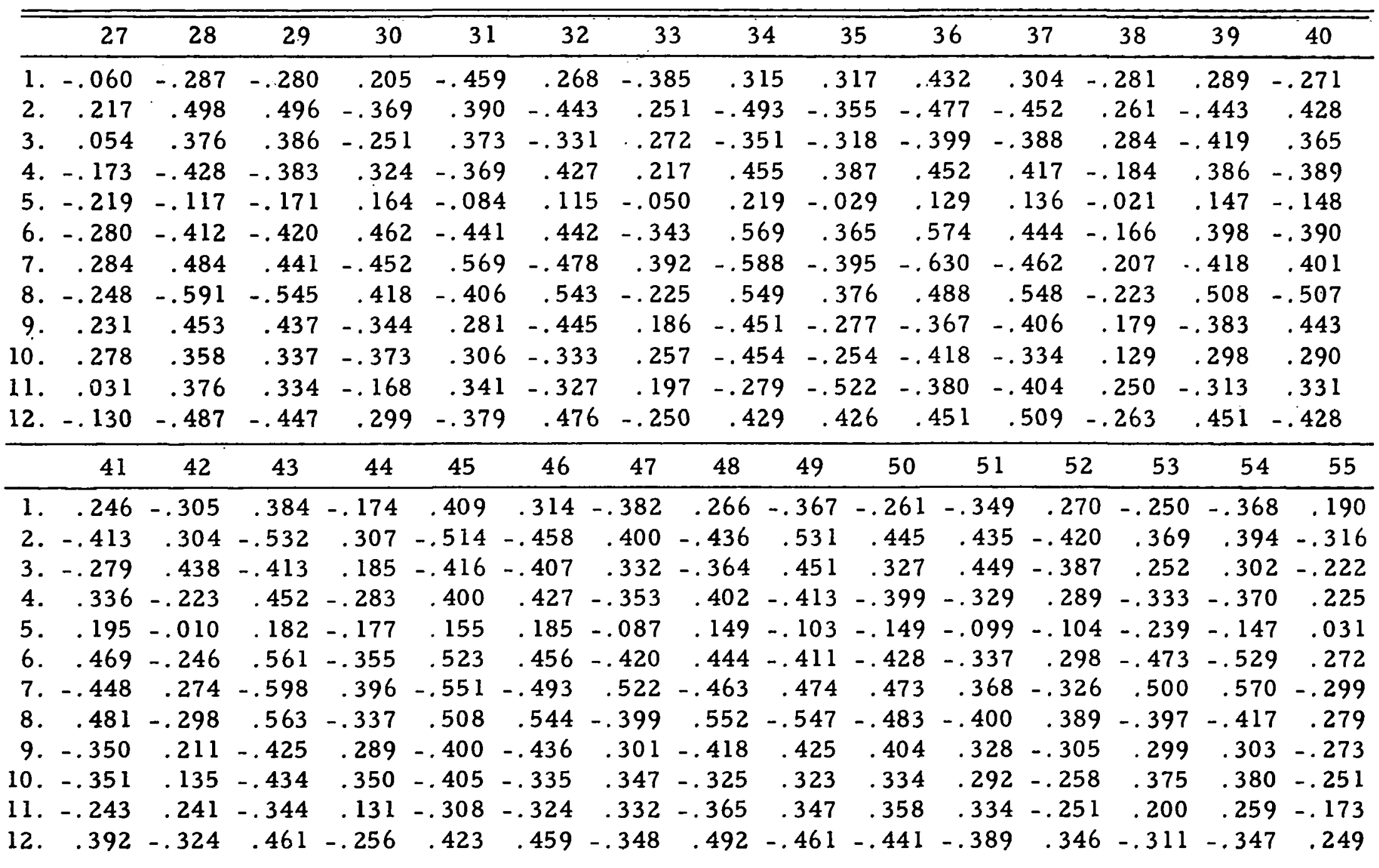


TABLE 3 (Continued)

\begin{tabular}{llllllllllll}
\hline 1 & 2 & 3 & 4 & 5 & 6 & 7 & 8 & 9 & 10 & 11 \\
\hline
\end{tabular}

13.

14.

15.

16.

17.

18.

19.

20.

21.

22.

23.

24.

\begin{tabular}{|c|c|c|c|c|c|c|c|c|c|c|c|c|c|}
\hline & 14 & 15 & 16 & 17 & 18 & 19 & 20 & 21 & 22 & 23 & 24 & 25 & 26 \\
\hline 13. & .619 & .392 & -.546 & .253 & .522 & .411 & -.524 & -.479 & -.252 & -.259 & -.393 & .407 & -.160 \\
\hline 14. & & .389 & -.445 & 191 & .506 & .429 & -.457 & -.518 & -.294 & -.292 & -.347 & .366 & -.145 \\
\hline 15. & & & -.389 & .256 & .375 & .491 & -.323 & -.347 & -.205 & -.120 & -.690 & .460 & -.263 \\
\hline 16. & & & & -.206 & -.448 & -.413 & .552 & .395 & .214 & .217 & .408 & -.386 & .197 \\
\hline 17. & & & & & .218 & .157 & -.157 & -.129 & -.146 & -.086 & -.286 & .232 & -.135 \\
\hline 18 & & & & & & .522 & -.449 & -.562 & -.287 & -.263 & -.386 & .357 & -.146 \\
\hline 19. & & & & & & & -.365 & -.455 & -.272 & -.268 & -.485 & .413 & -.202 \\
\hline 20 & & & & & & & & .463 & .228 & .236 & .357 & -.355 & .190 \\
\hline 21 & & & & & & & & & .311 & .294 & .365 & -.328 & .132 \\
\hline 22. & & &.$^{\prime}$ & & & & & & & .243 & .246 & -.225 & .072 \\
\hline 23. & & & & & & & & & & & .185 & -.140 & .002 \\
\hline 24 & & & & & & & & & & & & -.525 & .293 \\
\hline 25. & & & & & & & & & & & & & -.261 \\
\hline
\end{tabular}


TABLE 3 (Continued)

\begin{tabular}{|c|c|c|c|c|c|c|c|c|c|c|c|c|c|c|c|c|c|c|c|c|}
\hline & 27 & 28 & 29 & 30 & 1 & 2 & \multicolumn{2}{|c|}{33} & \multicolumn{2}{|c|}{34} & \multicolumn{2}{|c|}{35} & \multicolumn{2}{|c|}{36} & \multicolumn{2}{|r|}{37} & \multicolumn{2}{|c|}{38} & 39 & 40 \\
\hline 13. & 174 & 1 & 468 & 351 & .347 & $7-.4$ & & \multicolumn{2}{|c|}{-.484} & \multicolumn{2}{|c|}{-.371} & \multicolumn{2}{|c|}{-.437} & \multicolumn{2}{|c|}{-.452} & \multicolumn{2}{|c|}{.283} & -.488 & .480 \\
\hline 14 & .139 & & 26 & .250 & .333 & .403 & \multicolumn{2}{|c|}{.201} & \multicolumn{2}{|c|}{-.414} & \multicolumn{2}{|c|}{-.341} & \multicolumn{2}{|c|}{-.411} & \multicolumn{2}{|c|}{-.404} & \multicolumn{2}{|c|}{.252} & -.446 & .418 \\
\hline 15. & .372 & .415 & .472 & -.515 & .473 & $3-.462$ & \multicolumn{2}{|c|}{.328} & \multicolumn{2}{|c|}{-.524} & \multicolumn{2}{|c|}{-.336} & \multicolumn{2}{|c|}{-.581} & \multicolumn{2}{|c|}{-.457} & & $155 \quad-$ & -.394 & .396 \\
\hline 16. & -.199 & -.478 & -.411 & .354 & $1-.352$ & .474 & $4-.20$ & & .43 & & .36 & 68 & .4 & 14 & & $476-$ & -.1 & 183 & $.398-$ & -.412 \\
\hline 17. & .200 & .253 & .211 & -.243 & .168 & $8-.236$ & .09 & & -.32 & & -.17 & 73 & -.2 & 45 & & 194 & & 61 & -.166 & .203 \\
\hline 18. & .155 & .502 & .462 & -.297 & .332 & $2-.422$ & .23 & $34-$ & -.43 & & -.3 & 46 & -.4 & $32-$ & & 421 & & $244-$. & -.466 & 490 \\
\hline 19. & .215 & .441 & .464 & $1-.380$ & .544 & $4-.423$ & .39 & $94 \quad$. & -.46 & & -.37 & 74 & -.5 & 13 & & 428 & & $253-$. & -.412 & .416 \\
\hline 20 . & -.186 & -.439 & -.389 & .286 & -.347 & .404 & $4-.23$ & & .43 & & .37 & 72 & .4 & 04 & & 401 & & 205 & $.383-$ & -.394 \\
\hline 21. & -.098 & -.447 & -.432 & .299 & -.348 & .402 & $2-.20$ & & .41 & 11 & .35 & 53 & & 30 & & 457 & -.2 & 273 & $.549-$ & -.465 \\
\hline 22. & -.054 & -.221 & -.234 & .176 & -.183 & .210 & $0-.13$ & & .25 & 53 & & 98 & & 83 & & $241-$ & -.0 & 2 & .257 & -.191 \\
\hline 23. & .093 & -.257 & -.190 & .090 & -.250 & .183 & $3-.18$ & & .16 & 65 & .28 & 83 & & 86 & & $251-$ & -.2 & 4 & $.239-$ & -.188 \\
\hline 24 & -.392 &. .453 & -.513 & .595 & $;-.464$ & .508 & $8-.34$ & & .68 & 85 & .36 & 60 & & 12 & & $497-$ & -.1 & 0 & $.432-$ & -.407 \\
\hline & 41 & 42 & 43 & 44 & 45 & 46 & 47 & & 48 & & 47 & & $=$ & & 1 & 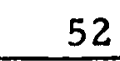 & & 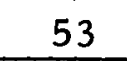 & 54 & 5 \\
\hline 13 & -.392 & 291 & 488 & 267 & 56 & & 28 & & 60 & & 0 & & 5 & .42 & & & & 324 & 345 & $5-$ \\
\hline 14. & -.296 & .289 & -.449 & 224 & -.422 & -.457 & .310 & -.43 & 33 & .51 & 14 & & 420 & .41 & 12 & -.363 & & .295 & .332 & $2-.257$ \\
\hline 15. & -.493 & .223 & -.617 & .452 & -.521 & -.489 & .451 & -.47 & 72 & .41 & 18 & & 144 & .34 & & -.298 & & .540 & .566 & $6-.3$ \\
\hline 16. & .373 & .258 & .433 & -.288 & .386 & .459 & .459 & -.29 & 93 & .47 & 74 & -.40 & 105 & -.41 & & -.352 & & .301 & $1-.355$ & 5 \\
\hline 17. & -.273 & .129 & -.261 & .214 & -.250 & -.239 & .169 &. .23 & 34 & .24 & 40 & & 30 & .15 & & -.152 & & .223 & 3.223 & $3-.183$ \\
\hline 18. & -.356 & .346 & -.456 & .277 & -.439 & -.457 & .338 & -.44 & 46 & .56 & 64 & & 466 & .50 & & -.422 & & .291 & .324 & $4-.267$ \\
\hline 19. & -.355 & .285 & -.500 & .346 & -.460 & -.463 & .476 & -.46 & 62 & .4 & 44 & & $\$ 26$ & .47 & & -.353 & & .401 & .454 & $4-.263$ \\
\hline 20. & .347 & -.239 & .408 & -.269 & .380 & .425 & -.314 & -.41 & 13 & -.45 & 54 & -.41 & 15 & -.36 & & .306 & & -.309 & $9-.334$ & 4.227 \\
\hline 21. & .306 & -.301 & .458 & -.252 & .423 & .495 & -.341 & & 34 & -.52 & 21 & -.43 & 36 & -.47 & & .419 & & -.283 & $3-.295$ & .242 \\
\hline 22 . & .202 & -.307 & .280 & -.075 & .237 & .271 & -.190 & & 47 & -.28 & 85 & -.21 & 10 & -.26 & & .235 & & -.158 & $3-.181$ & .235 \\
\hline 23. & .144 & -.339 & .236 & -.048 & .290 & .248 & -.225 & & 06 & $-.2 \varepsilon$ & 83 & -.23 & 34 & -.315 & & .257 & & -.129 & $7-.189$ & .140 \\
\hline 24. & .545 & -.288 & .650 & -.466 & .589 & .535 & -.441 & & 14 & -.43 & 39 & -.46 & 69 & -.37 & & .367 & & -.540 & -.550 & .370 \\
\hline
\end{tabular}


TABLE 3 (Continued)

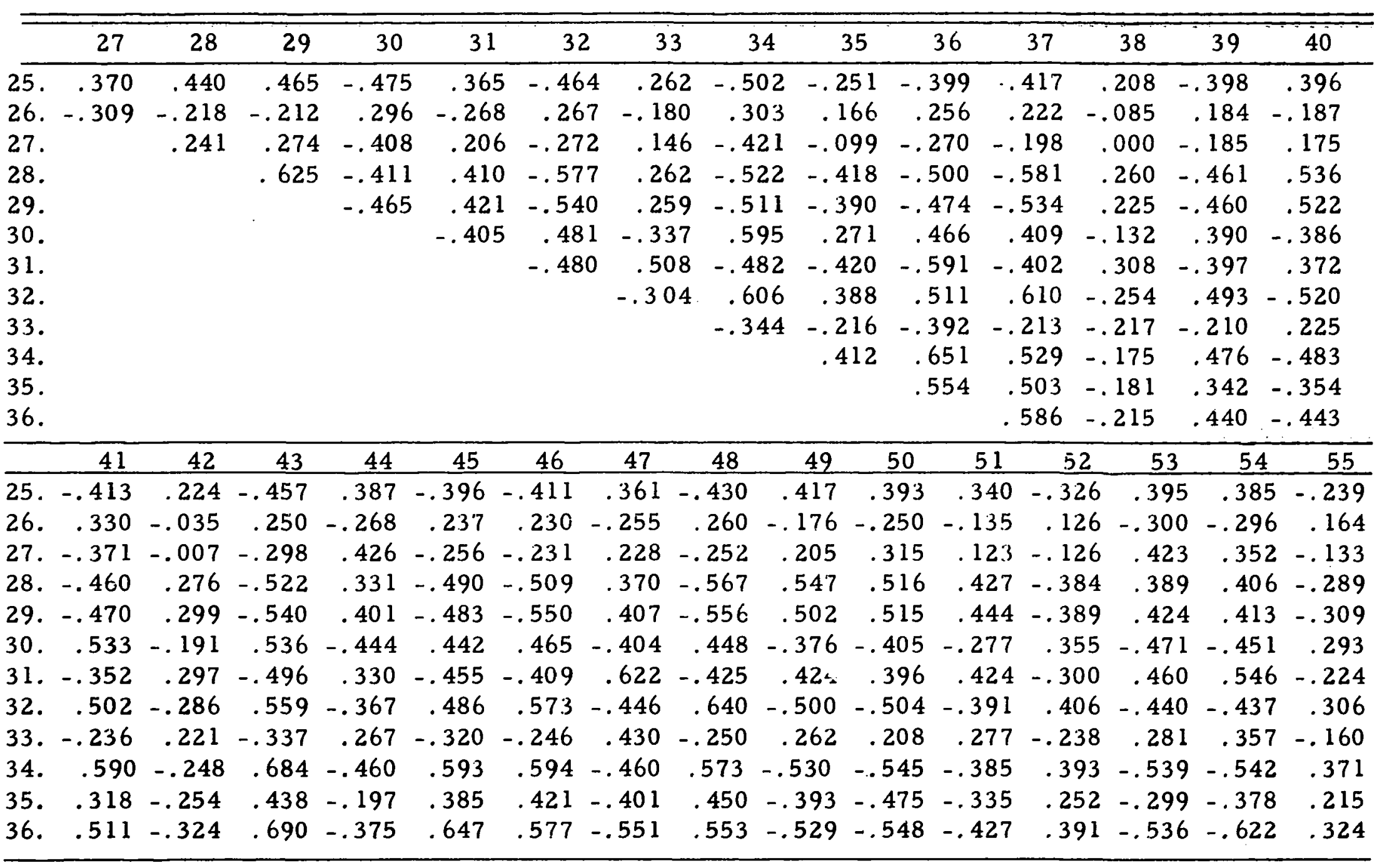


TABLE 3 (Continued)

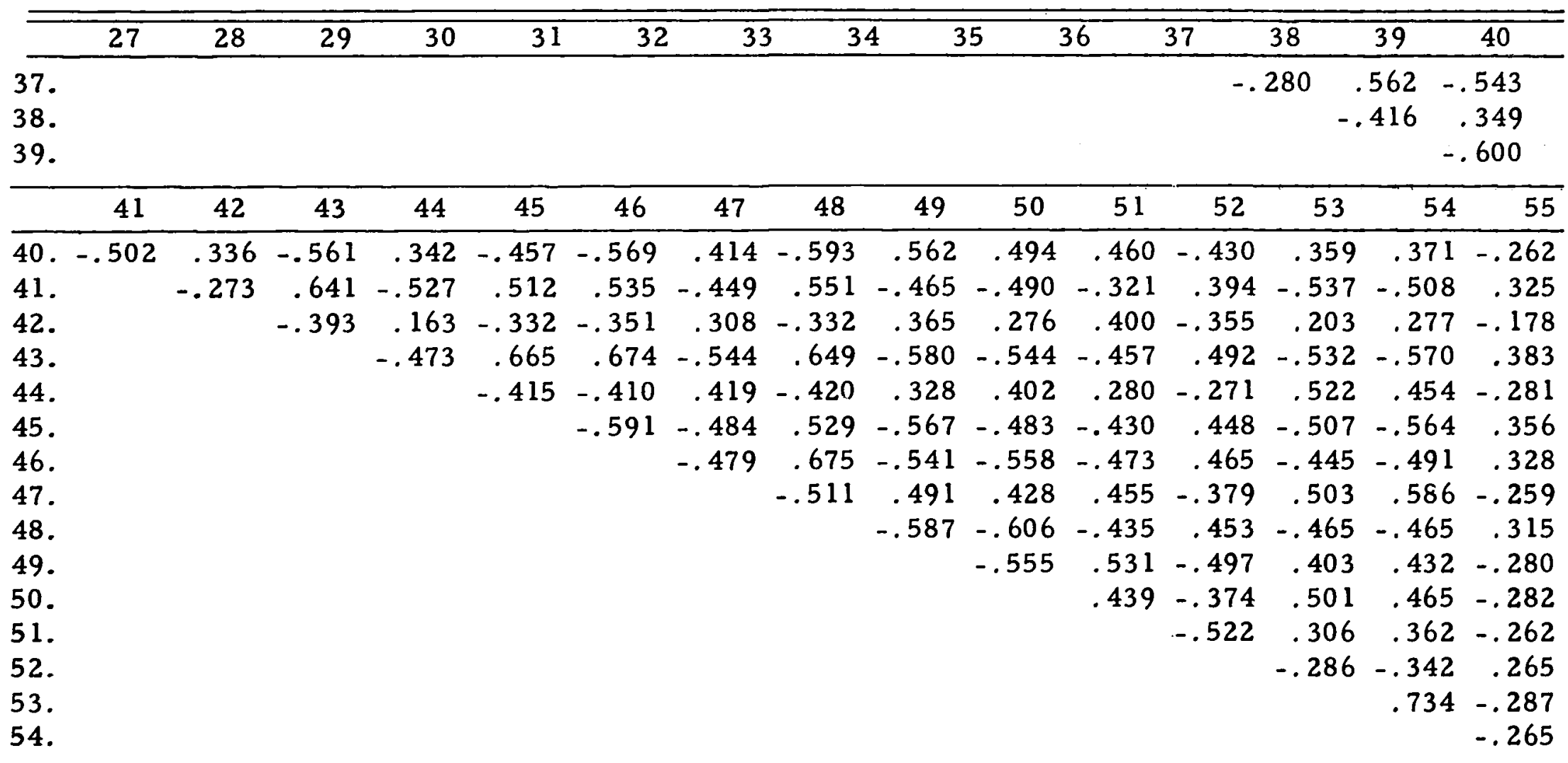


TABLE 4

UNROTATED FACTORS

\begin{tabular}{|c|c|c|c|c|c|c|}
\hline & Factors: & 1 & 2 & 3 & 4 & 5 \\
\hline 1. & Kind-cruel & .502 & .185 & -.467 & -.031 & -.139 \\
\hline 2. & Wise-unwise & -.684 & -.138 & -.002 & .042 & .266 \\
\hline 3. & Unfair-fair & -.580 & -.340 & .194 & -.045 & .281 \\
\hline 4. & Understandable-incomp rehensible & e. .604 & .095 & .037 & -.287 & .007 \\
\hline 5 . & Fast-slow & .183 & -.264 & .173 & .340 & -.131 \\
\hline 6. & Attractive-unattractive & .670 & -.221 & -.163 & -.185 & -.077 \\
\hline$?$. & Unpleasant-pleasant & -.729 & .148 & .241 & .217 & .059 \\
\hline 8. & Intelligent-unintelligent & .736 & .080 & .195 & -.140 & -.054 \\
\hline 9. & Unauthoritative-authoritative & -.587 & -.079 & -.238 & .099 & .196 \\
\hline 10 . & Uno riginal-o riginal & -.529 & .198 & .076 & .129 & .241 \\
\hline 11. & Upset-calm & -.491 & -.326 & .121 & .259 & -.320 \\
\hline 12. & Careful-careless & .646 & .252 & .071 & -.221 & .152 \\
\hline 13. & Illogical-logical & -.672 & -.249 & -.221 & .166 & .108 \\
\hline 14. & Irrational-rational & -.623 & -.297 & -.127 & .149 & .167 \\
\hline 15 . & Uninte resting-inte resting & -.699 & .323 & .090 & .141 & .121 \\
\hline 16. & Organized-disorganized & .618 & .139 & .212 & -.277 & .064 \\
\hline 17. & Small-large & -.334 & .150 & -.100 & .079 & .230 \\
\hline 18. & Un reliable - reliable & -.654 & -.286 & -.133 & .009 & .202 \\
\hline 19. & Insincere-sincere & -.671 & -.062 & .207 & .054 & .060 \\
\hline 20 . & Consistent-inconsistent & .590 & .185 & .159 & -.238 & .022 \\
\hline 21. & Believable-unbelievable & .632 & .324 & .107 & .037 & -.133 \\
\hline 22. & Objective-subjective & .364 & .206 & -.032 & .001 & -.338 \\
\hline 23. & Modest-boastful & .353 & .393 & -.265 & .021 & -.059 \\
\hline 24. & Imp ressive-unimp ressive & .736 & -.325 & -.056 & -.043 & -.152 \\
\hline 25 . & Indecisive-decisive & -.609 & .160 & -.136 & .009 & .119 \\
\hline 26. & Extroverted-introverted & .340 & -.331 & .033 & -.011 & .066 \\
\hline 27. & Non-aggressive-aggressive & -.369 & .541 & -.185 & .018 & .107 \\
\hline 28 . & Uneducated-educated & -.713 & -.091 & -.204 & .065 & -.090 \\
\hline 29. & Igno rant-expert & -.705 & .002 & -.175 & -.047 & -.038 \\
\hline 30 . & Persuasive-unpersuasive & .620 & -.369 & .061 & .052 & -.055 \\
\hline 31. & Unfriendly-friendly & -.648 & .064 & .434 & .018 & -.159 \\
\hline 32. & Skilled-unskilled & .719 & -.048 & .162 & -.010 & .192 \\
\hline 33. & Uns ympathetic-sympathetic & -.437 & .094 & .491 & -.022 & .016 \\
\hline 34. & Effective-ineffective & .776 & -.269 & .069 & -.054 & -.055 \\
\hline 35 . & Relaxed-tense & .571 & .158 & -.123 & -.264 & .381 \\
\hline 36. & Likable-unlikable & .771 & -.114 & -.227 & -.088 & .110 \\
\hline 37. & Trained-untrained & .725 & .071 & .155 & .022 & .286 \\
\hline 38. & Immoral-moral & -.370 & -.305 & .148 & -.379 & -.127 \\
\hline
\end{tabular}


TABLE 4 (Continued)

\begin{tabular}{llrrrrr}
\hline \hline & Factors: & 1 & 2 & 3 & 4 & 5 \\
\hline 39. Realistic-unrealistic & .683 & .176 & .143 & .281 & .054 \\
40. Uninformed-informed & -.683 & -.127 & -.220 & -.227 & -.145 \\
41. Strong-weak & .677 & -.288 & .141 & .159 & .078 \\
42. Biased-openminded & -.452 & -.299 & .188 & -.249 & .086 \\
43. Good-bad & .813 & -.126 & -.022 & .108 & .022 \\
44. Passive-active & -.541 & .403 & -.058 & -.147 & -.004 \\
45. Admirable-contemptible & .739 & -.083 & -.103 & .060 & -.065 \\
46. Competent-incompetent & .757 & .006 & .135 & .144 & .116 \\
47. Unsociable-sociable & -.655 & .106 & .339 & -.159 & -.199 \\
48. Experienced-inexperienced & .754 & -.009 & .188 & .125 & .275 \\
49. Unreasonable-resonable & -.735 & -.187 & -.080 & -.152 & .013 \\
50. Unsure-confident & -.700 & .028 & -.150 & -.021 & -.192 \\
51. Dishonest-honest & -.625 & -.281 & .102 & -.314 & .041 \\
52. Right-wrong & .576 & .176 & .021 & .390 & -.075 \\
53. Tired-energetic & -.636 & .413 & .097 & -.066 & -.069 \\
54. Gloomy-cheerful & -.677 & .319 & .264 & -.001 & -.091 \\
55. Profound-superficial & .438 & -.063 & .038 & .028 & -.159
\end{tabular}

Percent of variance accounted for: 
TABLE 4 (Continued)

UNROTATED FACTORS

\begin{tabular}{|c|c|c|c|c|c|c|}
\hline & Factors: & 6 & 7 & 8 & 9 & 10 \\
\hline 1. & Kind-cruel & -.092 & .162 & -.098 & .078 & -.203 \\
\hline 2 . & Wise-unwise & .031 & .031 & .165 & -.014 & .107 \\
\hline 3. & Unfair-fair & .003 & -.149 & .067 & -.122 & .093 \\
\hline 4. & Understandable-incomp rehens & $e-.084$ & .076 & -.054 & .055 & -.032 \\
\hline 5 . & Fast-slow & -.143 & .627 & -.224 & .072 & -.028 \\
\hline 6. & Attractive-unattractive & .069 & -.001 & -.129 & .135 & -.113 \\
\hline 7 . & Unpleasant-pleasant & .004 & .009 & .094 & -.105 & .037 \\
\hline 8. & Intelligent-unintelligent & -.062 & .053 & -.079 & .146 & -.037 \\
\hline 9. & Unauthoritative-autho ritative & .069 & .079 & .082 & -.052 & -.069 \\
\hline 10. & Uno riginal-original & -.007 & .327 & .236 & .090 & -.110 \\
\hline 11. & Upset-calm & -.020 & .047 & .069 & .049 & -.006 \\
\hline 12. & Careful-careless & -.051 & .051 & .082 & .068 & .001 \\
\hline 13. & Illogi.cal-logical & .133 & .014 & -.014 & .125 & .084 \\
\hline 14. & Irrational - rational & .102 & -.043 & .036 & .172 & -.061 \\
\hline 15. & Urinteresting-inte resting & -.028 & .081 & .146 & -.078 & -.073 \\
\hline 16. & Organized-disorganized & -.121 & .063 & .215 & -.015 & .012 \\
\hline 17. & Small-la rge & -.203 & .070 & -.169 & .240 & .700 \\
\hline 18. & Unreliable-reliable & .113 & -.029 & .042 & .112 & -.070 \\
\hline 19. & Insincere-sincere & .174 & .018 & -.017 & -.007 & -.197 \\
\hline 20. & Consistent-inconsistent & -.165 & .040 & .215 & -.191 & .111 \\
\hline 21. & Believable-unbelievable & -.091 & .077 & -.099 & -.045 & .203 \\
\hline 22. & Objective-subjective & .332 & .177 & .398 & .061 & .235 \\
\hline 23. & Modest-boastful & .201 & .101 & .089 & -.941 & .000 \\
\hline 24. & Imp ressive-unimp ressive & .114 & -.067 & -.036 & .133 & .028 \\
\hline 25 . & Indecisive-decisive & .188 & .094 & -.183 & -.109 & -.003 \\
\hline 26. & Ext rove rted-introverted & -.242 & .277 & .356 & .029 & -.109 \\
\hline 27. & Non-aggressive-aggressive & .221 & -.037 & -.092 & .196 & -.024 \\
\hline 28. & Uneducated-educated & .044 & .037 & .012 & -.075 & .102 \\
\hline 29. & Igno rant-expert & .028 & -.126 & .022 & -.120 & -.026 \\
\hline 30 . & Persuasive-unpersuasive & -.012 & -.127 & .138 & .196 & .017 \\
\hline 31. & Unf riendly-f riendly & .202 & -.032 & -.103 & -.052 & .012 \\
\hline 32. & Skilled-unskilled & -.008 & -.067 & .104 & .217 & -.062 \\
\hline 33. & Unsympathetic-sympathetic & .270 & .080 & -.213 & -.204 & -.020 \\
\hline 34. & Effective-ineffective & .079 & -.006 & -.014 & .070 & -.035 \\
\hline 35 . & Relaxed-tense & .195 & .062 & -.023 & -.107 & -.045 \\
\hline 36. & Likable-unlikable & .181 & .090 & -.082 & -.204 & .019 \\
\hline 37 . & Trained-untrained & .148 & .042 & -.056 & .169 & -.022 \\
\hline 38. & Immo ral-mo ral & .330 & .242 & -.007 & .030 & .227 \\
\hline
\end{tabular}


TABLE 4 (Concluded)

\begin{tabular}{llrrrrr}
\hline & Factors: & 6 & 7 & 8 & 9 & 10 \\
\hline 39. Realistic-unrealistic & -.050 & -.061 & -.045 & .092 & .005 \\
40. Uninformed-informed & .043 & .075 & .074 & -.090 & .068 \\
41. Strong-weak & .137 & -.004 & .072 & -.027 & -.056 \\
42. Biased-openminded & -.265 & -.093 & -.228 & -.050 & .016 \\
43. Good-bad & .192 & -.015 & -.084 & .061 & .020 \\
44. Passive-active & .098 & .121 & -.056 & .220 & -.104 \\
45. Admirable-contemptible & .170 & .032 & -.138 & -.067 & -.010 \\
46. Competent-incompeteint & .175 & .067 & -.048 & .061 & .046 \\
47. Unsociable-sociable & .075 & .052 & -.047 & .115 & -.055 \\
48. Experienced-inexperienced & .137 & .013 & .023 & .072 & .007 \\
49. Unreasonable-reasonable & .010 & .022 & .062 & .142 & .054 \\
50. Unsure-confident & -.071 & -.076 & .047 & .238 & -.030 \\
51. Dishonest-honest & .121 & .095 & -.019 & .151 & -.034 \\
52. Right-wrong & .047 & -.130 & .024 & -.023 & .035 \\
53. Tired-energetic & -.007 & -.115 & .041 & .290 & -.098 \\
54. Gloomy-cheerful & -.041 & -.109 & .034 & .241 & -.068 \\
55. Profound-superficial & .295 & -.247 & .213 & .007 & .131 \\
& & & & & & \\
& & & & & & \\
& & 2.16 & 1.81 & 1.73 & 1.66 & 1.64
\end{tabular}


the first 6,8 and all 10 factors by the same procedure. These analyses were done for exploratory investigation, but the 10 factor rotation is used for major discussion in the remainder of this paper. Appendices $D, E$, and $F$ contain the 4, 6, and 8 factor rotations; Table 5 is the 10 factor rotated solution.

Results of Mathematical Analysis. The rotation of 10 factors (accounting for $61.97 \%$ of total variance) identified the following factors, presented here in summary by selecting the highly loaded variables and listing them in descending order according to factor loading. 10

Factor 1 (38.80\% of total va riance): "Illogical-logical," "Irrational-rational, " "Un reliable-reliable, " "Inconsistent-consistent," "Unbelievable-believable," "Diso rganized-o rganized," "Unintelligentintelligent, " "Unautho ritative-autho ritative, " "Careless-ca reful, " ..... "Unwise-wise, " "Unoriginal-original, " and "Uneducated-educated."

Factor two (5.46\% of the total variance): "Unimpressiveimp ressive, " "Uninte resting-inte resting, " "Ineffective-effective, " "Tired-ene rgetic, " "Unpersuasive-persuasive, " "Gloomy-cheerful, " "Unoriginal-original, " "Bad-good, " "Passive-active," "Weak-strong," "Unattractive-attractive, " "Unpleasant-pleasant, " "Unlikable-likable, " and "Contemptible-admi rable."

10 For clarity in this summary, some variables a re "reversed" from the method of scale presentation; e.g., "Good-bad" may be reported as "Bad-good" to cor respond with the same polarity as "Unfair-fair." 
TABLE 5

TEN FACTOR SOLUTION DERIVED BY VARIMAX ROTATION

\begin{tabular}{|c|c|c|c|c|c|c|c|}
\hline & Factors: & 1 & 2 & 3 & 4 & 5 & 6 \\
\hline 1. & & .233 & -.128 & -.667 & .118 & .142 & 0, \\
\hline 2. & Wis & -.534 & .354 & & & & .117 \\
\hline 3. & Unfair-fair & -.438 & .108 & .444 & -.220 & .071 & -.311 \\
\hline \multirow[t]{2}{*}{4.} & Understanda & isible & & & & & \\
\hline & & .518 & -.255 & -.221 & .007 & .288 & .014 \\
\hline J. & $\mathrm{Fa}$ & .031 & -.177 & .000 & .074 & -.076 & -.022 \\
\hline 6. & tive & .261 & -.581 & -.341 & .000 & .230 & .035 \\
\hline 7 . & Unpleasant-ple & -.330 & .558 & .436 & -.016 & -.249 & -.055 \\
\hline 8. & igent & .592 & -.358 & -.128 & .169 & .244 & .062 \\
\hline 9 . & $U_{n}$ & -.568 & .338 & .011 & -.157 & -.031 & -.077 \\
\hline & Uno & -.311 & .619 & .143 & -.067 & .062 & .035 \\
\hline & $U_{p}$ & -.370 & .041 & .237 & -.122 & -.538 & -.001 \\
\hline & & .535 & -.141 & -.182 & .144 & .416 & .115 \\
\hline & & -.698 & .190 & .084 & -.205 & -.170 & -.070 \\
\hline & $\operatorname{Ir}$ & -.679 & .165 & .119 & -.1 & -.130 & -.153 \\
\hline & $U_{n}$ & -.289 & .717 & .237 & -.024 & -.129 & -.026 \\
\hline & Or & .593 & -.176 & -.064 & .061 & .297 & .106 \\
\hline & & -.132 & .248 & .018 & -.0 & -.036 & -.064 \\
\hline & $\mathrm{Un}_{\mathrm{n}}$ & -.646 & .199 & .127 & -.2 & -.069 & -.185 \\
\hline & & & .363 & &.- & -.128 & -.138 \\
\hline & & .609 & -.149 & -.066 & .0 & .226 & .128 \\
\hline & & .608 & -.173 & -.124 & .288 & .120 & .212 \\
\hline & & .252 & -.111 & -.062 & -.025 & .013 & .749 \\
\hline & & .213 & .051 & -.270 & & .233 & .405 \\
\hline & & .247 & -.729 & -.205 & & .124 & .155 \\
\hline & & -.3 & .436 & .119 & -.2 & .015 & -.063 \\
\hline & & .0 & -.237 & -.156 & -.008 & .073 & .008 \\
\hline & & -.154 & .549 & -.071 & .019 & .125 & .145 \\
\hline & $\mathrm{Ur}_{\mathrm{r}}$ & -.502 & .318 & .074 & -.238 & -.319 & -.023 \\
\hline 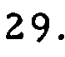 & & -.5 & 410 & 3 & -.313 & -.233 & -.084 \\
\hline & $\mathrm{Pe}$ & .163 & -.632 & -.1 & & .053 & .089 \\
\hline 1 & & -.156 & .348 & .600 & -.207 & -.283 & -.039 \\
\hline 2. & Ski & .337 & -.404 & -.083 & .324 & .357 & .062 \\
\hline & & -.039 & .270 & .636 & -.156 & -.004 & -.078 \\
\hline 4 & Ef $f$ & .331 & -.663 & -.125 & .141 & .223 & .107 \\
\hline & $\mathrm{Re}$ & .269 & -.191 & -.187 & .056 & .678 & .080 \\
\hline 6. & Likable-unlikable & .232 & -.554 & -.323 & .111 & .453 & .177 \\
\hline 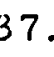 & Trained-untrained & .335 & -.350 & -.038 & .325 & .537 & .108 \\
\hline & Immo ral-moral & .161 & $-.06 C$ & .332 & -.678 & -.026 & .111 \\
\hline
\end{tabular}


TABLE 5 (Continued)

TEN FACTOR SOLUTION DERIVED BY VARIMAX ROTATION

\begin{tabular}{llrrrrr}
\hline \hline \multicolumn{1}{c}{ Factors: } & 1 & 2 & 3 & 4 & 5 & 6 \\
\hline 39. Realistic-unrealistic & .383 & -.274 & -.085 & .556 & .196 & .128 \\
40. Uninformed-informed & -.381 & .290 & .019 & -.538 & -.276 & -.030 \\
41. Strong-weak & .157 & -.586 & .031 & .297 & .252 & .131 \\
42. Biased-openminded & -.118 & .059 & .237 & -.329 & -.185 & -.553 \\
43. Good-bad & .265 & -.619 & -.156 & .309 & .320 & .209 \\
44. Passive-active & -.126 & .615 & -.005 & -.242 & -.012 & .029 \\
45. Admirable-contemptible & .277 & -.552 & -.214 & .266 & .257 & .195 \\
46. Competent-incompetent & .323 & -.450 & -.022 & .359 & .386 & .219 \\
47. Unsociable-sociable & -.079 & .438 & .401 &.- .356 & -.289 & -.072 \\
48. Experienced-inexperienced & .269 & -.421 & .023 & .402 & .481 & .139 \\
49. Unreasonable-reasonable & -.466 & .304 & .124 & -.448 & -.228 & -.145 \\
50. Unsure-confident & -.366 & .409 & -.029 & -.268 & -.416 & -.068 \\
51. Dishonest-honest & -.352 & .177 & .258 & -.570 & -.081 & -.196 \\
52. Right-wrong & .245 & -.261 & -.092 & .572 & .052 & .271 \\
53. Tired-energetic & -.133 & .659 & .127 & -.119 & -.217 & -.026 \\
54. Gloomy-cheerful & -.110 & .619 & .295 & -.097 & -.299 & -.078 \\
55. Profound-superficial & .148 & -.417 & .055 & .144 & .041 & .388 \\
& & & & & & \\
\hline
\end{tabular}


TABLE 5 (Continued)

TEN FACTOR SOLUTION DERIVED BY VARIMAX ROTATION

\begin{tabular}{|c|c|c|c|c|c|c|}
\hline & Factors: & 7 & 8 & 9 & 10 & Communality \\
\hline 1. & Kind-cruel & .137 & -.098 & -.016 & -.147 & .617 \\
\hline 2 . & Wise-unwise & -.089 & .132 & -.048 & .171 & .601 \\
\hline 3. & Unfair-fair & -.177 & .143 & -.073 & .109 & .622 \\
\hline \multirow[t]{2}{*}{4.} & Understandable-incomp rehe & asible & & & & \\
\hline & & .027 & .065 & .068 & -.042 & .478 \\
\hline 5 . & Fast-slow & .818 & .151 & -.010 & .029 & .737 \\
\hline 6. & Actractive-unattractive & .056 & -.011 & .134 & -.141 & .618 \\
\hline 7. & Unpleasant-pleasant & .000 & -.013 & -.068 & .061 & .685 \\
\hline 8. & Intelligent-unintelligent & .119 & .068 & .188 & -.052 & .645 \\
\hline 9. & Unautho ritative-authoritative & -.021 & .007 & -.106 & .007 & .482 \\
\hline 10 . & Uno riginal-o riginal & .171 & .198 & .067 & .015 & .584 \\
\hline 11. & Upset-calm & .178 & .071 & .060 & -.040 & .543 \\
\hline 12. & Careful-careless & -.054 & .137 & .079 & .014 & .576 \\
\hline 13. & Illogical-logical & .013 & -.082 & .041 & .166 & .644 \\
\hline 14. & Irrational-rational & -.022 & .013 & .143 & .049 & .591 \\
\hline 15 . & Uninteresting-interesting & -.022 & -.005 & -.063 & .000 & .677 \\
\hline 16. & Organized-disorganized & -.069 & .308 & .036 & -.042 & .593 \\
\hline 17 . & Small-la rge & .033 & -.114 & .004 & .852 & .828 \\
\hline 18. & Unreliable-reliable & -.074 & .014 & .095 & .024 & .602 \\
\hline 19. & Insincere-sincere & .040 & -.086 & .088 & -.170 & .574 \\
\hline 20 . & Consistent-inconsistent & -.109 & .278 & -.163 & .009 & .590 \\
\hline 21. & Believable-unbelievable & .125 & -.065 & -.079 & .139 & .604 \\
\hline 22. & Objective-subjective & .002 & .090 & .027 & .012 & .651 \\
\hline 23. & Modest-boastful & -.035 & -.140 & -.235 & -.106 & .450 \\
\hline 24. & Imp ressive-unimp ressive & .044 & .063 & .135 & -.065 & .713 \\
\hline 25 . & Indecisive-decisive & .032 & -.322 & -.138 & .035 & .520 \\
\hline 26. & Extroverted-introverted & .182 & .610 & .006 & -.089 & .507 \\
\hline 27. & Non-agg ressive-aggressive & -.118 & -.400 & .161 & .077 & .574 \\
\hline 28 . & Uneducated-educated & -.023 & -.119 & -.142 & 103 & .591 \\
\hline 29. & Igno rant-expe rt & -.080 & -.116 & -.144 & -.013 & .549 \\
\hline 30. & Persuasive-unpersuasive & -.016 & .277 & .213 & -.024 & .605 \\
\hline 31. & Unf riendly-f riendly & .041 & -.231 & .071 & -.059 & .695 \\
\hline 32. & Skilled-unskilled & -.008 & .246 & .258 & -.029 & .650 \\
\hline 33. & Unsympathetic-sympathetic & .141 & -.252 & -.063 & -.108 & .610 \\
\hline 34. & Effective-ineffective & .088 & .140 & .104 & -.118 & .699 \\
\hline 35. & Relaxed-tense & -.097 & -.006 & -.103 & -.064 & .639 \\
\hline 36. & Likable-unlikable & .073 & -.002 & -.072 & -.043 & .729 \\
\hline 37. & Trained-untrained & .099 & .063 & .195 & .005 & .694 \\
\hline 38. & Immo ral-mo ral & .096 & -.046 & .042 & .085 & .634 \\
\hline
\end{tabular}


TABLE 5 (CONCLUDED)

TEN FACTOR SOLUTION DERIVED BY VARIMAX ROTATION

\begin{tabular}{llrrrr}
\hline \multicolumn{1}{c}{ Factors: } & \multicolumn{1}{c}{7} & 8 & 9 & 10 & Communality \\
\hline 39. Realistic-unrealistic & .107 & .037 & .099 & .025 & .617 \\
40. Uninformed-informed & -.101 & -.062 & -.134 & .029 & .630 \\
41. Strong-weak & .111 & .216 & .021 & -.141 & .619 \\
42. Biased-openminded & -.040 & .010 & -.009 & .096 & .534 \\
43. Good-bad & .108 & -.006 & .058 & -.051 & .738 \\
44. Passive-active & .000 & -.058 & .214 & .003 & .568 \\
45. Admirable-contemptible & .130 & -.082 & -.076 & -.110 & .626 \\
46. Competent-incompetent & .167 & .044 & .071 & -.003 & .670 \\
47. Unsociable-sociable & .043 & -.151 & .212 & -.060 & .649 \\
48. Experienced-inexperienced & .088 & .152 &. .103 & -.004 & .721 \\
49. Unreasonable-reasonable &. .083 & .007 & .111 & .118 & .634 \\
50. Unsure-confident & -.105 & -.111 & .204 & .061 & .622 \\
51. Dishonest-honest & .000 & .000 & .190 & -.002 & .630 \\
52. Right-wrong & .033 & -.032 & -.026 & -.019 & .544 \\
53. Tired-energetic & -.164 & -.196 & .335 & .019 & .704 \\
54. Gloomy-cheerful & -.101 & -.137 & .313 & .026 & .717 \\
55. Profound-superficial & -.235 & .019 & .058 & -.056 & .435 \\
\end{tabular}


Factor three (3.51\% of the total variance): "Cruel-kind,"

"Uns ympathetic-sympathetic, " "Unf riendly-friendly, " "Unfair-fair," and "Unsociable-sociable."

Factor four $(2.73 \%$ of the total variance): "Immoral-moral,"

"W rong-right, " "Dishonest-honest, " "Unrealistic-rea!.istic, " and

"Uninfo rmed-informed."

Factor five (2.47\% of the total variance): "Tense-relaxed,"

"Upset-calm," "Untrained-trained, " "Unexpe rienced-expe rienced, "

"Unlikable-likable, " "Ca reless-ca reful, " and "Unsure-confident."

Factor six (2.16\% of the total variance): "Subjective-objective,"

"Biased-openminded," and "Boastful-modest."

Factor seven ( $1.81 \%$ of the total variance): "Slow-fast."

Factor eight ( $1.73 \%$ of the total variance): "Extrovertedintroverted."

Factor nine (1.66\% of the total va riance): "Tired-energetic."

Factor ten (1.64\% of the total variance): "Small-large."

Summary. In this experiment, 596 college students judged 3 television newscasters by marking for each newscast a 55 item semantic diffe rential type instrument under experimental conditions. These responses were correlated across subjects and newscasters and the resulting correlation matrix was factor analyzed by Hotelling's iterative technique and Varimax rotation. A total of 10 factors describing $61.97 \%$ of the subjects' reaction to the newscasters were extracted and rotated. 


\section{CHAP TER IV}

\section{DISCUSSION AND SUGGESTIONS FOR FURTHER RESEARCH}

This chapter will discuss the findings of the previous chapter, discuss the shortcomings of the experiment, compare the findings of this study with previous research, and suggest further research j.nto the ethos of television news communicators.

Factor Identification. The experimenter calls the first factor (with high loadings on the items "Illogical-logical, " "Ir rational-rational," "Unreliable-reliable, " "Inconsi stent-consistent, " "Unbelievable-believable, " "Disorganized-o rganized, " "Unintelligent-intelligent, " "Unauthoritativeauthoritative, " "Ca reful-careless, " "Unwise-wise, " "Uno riginal-original, " and "Uneducated-educated") a reliable-logic-evaluative factor. The data suggest that the subjects focused upon the message elements with questions regarding the logic and evaluation of the messages. This logic-evaluative factor was the largest, accounting for $38.80 \%$ of the total variance. This reliable-logic-evaluative factor corresponds rather completely to the evaluative factor in the original Osgood, Suci, and 
Tannenbaum studies ${ }^{l}$ in item simila rity and size of loading.

The author calls the second factor (with high loadings on the items "Unimp ressive-imp ressive," "Uninte resting-inte resting,"

"Ineffective-effective, " "Tired-energetic," "Unpersuasive-persuasive, " "Gloomy-chee rful, " "Uno riginal-o riginal, " "Bad-good," "Passive-active," "Weak-strong, " "Unattractive-attractive, " "Unpleasant-pleasant, " "Unlikable-likable," and "Contemptible-admirable") an activity factor. This factor suggests that the subjects made judgments about the newscaster's communicative attitude, or asked themselves the question, "Is the newscaster attempting to 'reach' me or talk to me?" This factor seems to relate to Bryant and Wallace's statement that the speaker must have". . a-vivid-realization-of-idea-at-the-moment-of-utterance. $" 2$ This factor was considerably smaller than the first accounting for $5.46 \%$ of the total variance.

The third factor is a "nice guy" factor (with high loadings on the items "Cruel-kind, " "Unsympathetic-sympathetic, " "Unf riendlyfriendly, "Unfair-fair, " and "Unsociable-sociable"). This factor strongly suggests a personality dimension of general good will and

${ }^{1}$ Charles E. Osgood, George J. Suci, and Percy H. Tannenbaum, The Measurement of Meaning (Urbana, Illinois: University of Illinois Press, 1957), pp. 70-71.

${ }^{2}$ Donald C. Bryant and Karl R. Wallace, Fundamentals of Public Speaking, third ed. (New York: Appleton-Century-Crofts, Inc., 1960), p. 192 . 
friendliness. Or, as Oliver says that of "confidence and ease." ${ }^{3}$ This factor is slightly smaller than factor two, accounting for $3.51 \%$ of the total va riance.

The author calls the fourth factor (with high loadings on the items "Immoral-moral, " "W rong-right," "Dishonest-honest," "Unrealistic-realistic, " and "Uninformed-informed") an abstract morality factor. This factor suggests that the subjects were concerned with the apparent truthfulness of the communication and the consistency of the communication. The subjects had no check on the validity of the content of the message, but seemed to make judgments based upon an abstract principle of honesty. This dimension is nearly the same size as factor three accounting for $2.73 \%$ of the total variance.

Factor five (identified by high loadings on the items "Tenserelaxed, " "Unlikable-likable," "Careless-ca reful, " and "Unsureconfident") may be called a skill factor. This factor has some similarity or cong ruence with facto $r$ number one, the reliable logic-evaluative dimension. The fifth dimension seems to relate to the audience's perception of the newscaste $r^{\prime}$ s ability to read, pronounce, a rticulate, and appear confident in the newscasting situation. 4 This factor is app roximately the same size as factor four; the fifth factor accounts for $2.47 \%$ of the total variance.

3 Robert T. Oliver, The Psychology of Persuasive Speech (New York: David McKay Company, Inc., 1957), p. 267.

${ }^{4}$ See She rman P. Lawton, The Modern Broadcaster (New York: Harper and Brothers, Publishers, 1961), p. 239. 
The experimenter calls factor six (with high factor loadings on the items "Subjective-objective," "Biased-openminded," and "Boastfulmodest") an openmindedness factor. This dimension suggests to the author that the subjects were concerned with the newscasters' personal attributes, which suggested the men's ability to evaluate data with as little personal bias as possible. This dimension is about the same size as factors four and five accounting for $2.16 \%$ of total variance.

Factor seven (with a high loading on the item "Slow-fást") is a speed factor. The data suggests that this is a relatively pure factor with little correspondence or congruence with the other nine dimensions, but the size of the factor (accounting for $1.81 \%$ of the total va riance) makes the importance of this dimension relatively insignificant.

The author calls factor eight (with a high loading on the item "Extroverted-introverted") an extroversion dimension which refers to the subjects' perceptions of the communicators as out-going personalities. This dimension is closely related to dimension three, the "nice guy" factor. However, because of dimension eight's smallness (accounting for $1.73 \%$ of the total variance), it is relatively unimportant.

The ninth factor (identified by the item "Tired-energetic") and factor ten (identified by the item "Small-la rge") a re not structurally clear enough for the author to identify. These two factors are quite small (factor nine accounting for $1.66 \%$ of the total variance and factor 
ten accounting for $1.64 \%$ of the total va riance).

In summary, the dimensions are identified by the author (in descending order of relative size) as (1) Reliable-logic-evaluation, (2) Activity, (3) "Nice guy," (4) Abstract morality, (5) Skill, (6) Openmindedness, (7) Speed, (8) Extroversion, (9) Unidentifiable, and (10) Unidentifiable.

Non-controlled Experimental Observation. During the experimental sessions the experimenter noticed some of subjects' behavior that seems to be indicative of influence upon the subjects' reactions to the experiments. First, the subjects seemed to show various deg rees of interest, but the majority of the student subjects were generally apathetic about the task set before them. As soon as the first film began, the subjects as a whole seemed to rouse, but interest soon dropped off. The experimenter noticed that their body positions (slouched in the chairs, heads dropped, etc.) seemed to indicate that their interest was very slight in either the films or the marking task that followed the films. To counter this observation however, only two of the original five hundred and ninty-nine ballots were discarded because of incomplete responses. Further, the author when coding the responses for IBM usage noticed that the schedules seemed to be legitimately marked; i.e., none of the subjects were marking the scales in consistently one place, nor in general, "playing games" with the scales.

Many of the subjects, mostly the male subjects, laughed a great 
deal at the two Oklahoma newscasts. The experimenter noted that this laughter seemed to be directed not at the newscasters themselves, but at the content of the messages. The mention of peculiar names and places in the state of Oklahoma seemed to a rouse most of this humorous response; e.g., "Byron Auchincloss of Chickasha," ". . Great Salt Plains Rese rvoir in Alfalfa County" ". . south of Barnsdall and on the Circle Mountain. . ." and ". . party chairman Smith Hester. . . " None of this laughter seemed to be directed at the Pittsburgh newscast. The author feels that since most of the subjects came from an urban area, they had a more favorable predisposition toward a la rge city newscast from Pittsburgh, than toward more rurally centered newscasts from Oklahoma. In other words, the subjects were familiar with metropolitian news stories.

Because of the absence of the regular classroom instructor from the experimental situation, and the unfamilia rity and casualness of the experimenter, many subjects, again mostly male, showed a gene ral boredom to the experimental task. A few of these subjects asked the experimenter when the "good parts" of the film were coming. "When are we going to see some sports news?" and gene rally suggested that they would rather be doing something else.

Afte $r$ the experimental sessions, both immediately and a few days later some subjects stopped to ask a few questions about the experiments. None of the subjects asked these questions during the actual course of 
the experiment. Their questions were similar to these: "What a re you trying to do or prove?" "Was this thing we did for some TV station?" and "What were all those adjectives about?" The author understands from colleagues who have done this type of research using a semantic differential type of instrument, the subjects' incredulity is often attached to the schedules; but this attitude does not seem to affect the subjects' responses.

Experimental Shortcomings. In addition to the above observations regarding the subjects' behavior, the author now briefly outlines some other difficulties of the study, which may influence the conclusions drawn. First, the lack of interest shown by the student subjects in regard to the newscasts was a problem. This lack of inte rest might have been caused by the fact that the news itself was uninteresting or to the fact that all of the subjects were college students who generally might have little interest in news, particularly television news, or more particularly television news with a strong local (i.e., Pittsburgh or Oklahoma City) interest.

Second, the subjects were entirely unfamiliar with the newscasters or the content of the news. One might suspect that a higher interest level and/or credibility influence would be ope rative if the subjects had some familiarity with the newscaster. However, as stated in the previous chapter, the author felt that the influence of the subjects' prior experience with the newscaster might effect their perception of 
the newscast. This possible deterimental influence might have become significantly greater because of the time differential between actual occurence of the news events and the time of film presentation in the expe rimental situation.

Next, the author is aware that one of the newscasts was done by two newscasters in a "team" newscast situation. Appendix C contains a script of this newscast, marked "Newscast $B . "$ The subjects were asked to make their judgments in the experimental sessions regarding both of these newscasters together, as a team. This "pooling" of newscasters might have influenced the judgments of the subjects in unknown ways, but since at least one major network news program uses this same technique of "team" newscasting, and all fifteen minute or longer network newscasts frequently use more than one reporter, the author felt that this newscast coincided both with reality and the viewing experience of the subjects.

Fourth, the sample of subjects by its nature was different from a "normal" or "average" sample of the television news audience. The subjects were all college students, mostly underclassmen, the refore younge $r$ than an "ave rage" viewer of television newscasts. More important, the subjects, because of college training and college attendance, were probably more intelligent and more critical of television news than the "no rmal" household viewer. These biases of the expe rimental group probably influenced the outcomes of the experiment. 
Finally, the physical situation of the experiment--using a classroom situation, having groups which were larger than the family and had existed for a period of time, and presenting the newscasts on film-p robably influenced the judgments of the subjects in some way.

Comparison with Similar Platform Studies. The author is familiar with only two studies in the judgment of communicators and communications that have used a technique similar to the technique of this study. These studies, by Andersen ${ }^{5}$ and Berlo, 6 both deal with platform speaking; Andersen presented to undergraduates a list of sixteen living speakers, while Berlo used several imaginary communication situations, e.g., Nikita Kruschev speaking on conditions in the Soviet Union.

Andersen found two dimensions of source credibility in his study: the evaluative scale, characterized by the scale items "Honest-dishonest," "Moral-immoral, " "Fair-unfair," "Sympathetic-unsympathetic," "Openminded-biased," "Good-bad," "Sincere-insincere, " "Reasonableunreasonable," and "Likable-unlikable;" the second factor, the dynamism factor, was characterized by the items "Interesting-uninteresting,"

5enneth Andersen, "An Experimental Study of the Interaction of Artistic and Non-Artistic Ethos in Persuasion" (unpublished Ph. D. dissertation, University of Wisconsin, 1961).

${ }^{6}$ David K. Berlo, "An Empirical Test of a General Construct of Credibility, " (unpublished paper presented at SAA convention, New York City, December 29, 1961). 
"Strong-weak, " "Fast-slow, " "Aggressive-non-agg ressive," and "Active-passive." Andersen used only twenty-two bipolar scales for analysis. 7 Factor one, the reliable logic-evaluative factor of the author's study corresponds highly with Andersen's first factor, with the exception that the study dealing with television newscasters seems to be more highly "skill" and "reason" oriented. Scale items such as "Irrationalrational," "Disorganized-organized," "Ca reful-careless," and "Uneducated-educated" support this view. One might note, however, that none of the latter scale items were included in Andersen's original twenty-two.

The second factor of the television study, the activity factor, corresponds with Andersen's dynamism factor. With the exception of one item, "Fast-slow," the television study's second factor includes all of the items of Andersen's dynamism. One should be cautious in this type of comparison, however, because of the difference between the two studies regarding number of scale items, mathematical treatment, and the fluctuating solutions of factor analysis.

Berlo carried out a similar study, ${ }^{8}$ using different speakers on a variety of communication contents, and he used a greater number of scales and more students than Andersen. Although the factor structure

${ }^{7}$ Andersen, pp. $73-75$.

${ }^{8}$ Be rlo. 
has not been published, preliminary inspection suggests that Be rlo found the same first two dimensions (evaluative and dynamism) as Andersen. Berlo also found a third dimension, what he calls a "nice guy" factcr. This factor, again if one keeps in mind the differences of mathematical treatment, et cetera, corresponds to the third factor (the "nice guy" dimension) of this television study.

The remaining six identifiable factors of the television study-the abstract morality factor, the skill factor, the open mindedness factor, the speed factor, and the extroversion factor--were not discovered by the two previously mentioned studies although the experimenter used all of Andersen's scale items and many of Berlo's items. The author suggests that the difference between these studies was due to the medium of television and the content of news communication.

Conclusions. The first conclusion is that television news is a peculiar type of communication, which is open to finer and more discrete judgments than other types of informative or persuasive communications. The larger number of factors of this study, compared to p revious platform speaking studies, supports this conclusion. One might speculate that viewers of television news communication, when asked to evaluate television news, change the basis of their judgments from the set of judgments used to evaluate othe $\mathbf{r}$ communications.

The second conclusion is that people (college students in this experiment) a re more critical of the "morality" displayed in television 
news than in public speaking, i.e., they show more concern for the perceived correctness, honesty, and forthrightness of the television newscaster than the public speaker. Support of this conclusion is that the public speaking studies did not suggest the abstract morality and the openmindness factor as separate structures, but the analysis of Berlo and Andersen included items suggestive of this dimension in the evaluative factor. The data suggest that the subjects of this experiment had a pre-conceived notion of what was "correct" in the news they heard, or they judged some criterion of "honesty" such as consistency of some dimensions as style or delivery. A person might not question the "honesty" or "morality" of a public speaker if he mispronounced a word, was hesitant in his delivery, or offered some inconsistency within the message; but a television newscaster might become suspect if he did these things, because the television audience seems sensitized to a dimension of "morality." One could further speculate that because of the prior experience of truthfulness that television (with the exception of commercials) has among the general Ame rican public, people might make demands upon the honesty of television news.

Thirdly, the author suggests that people seem to make more discrete and concerned judgments about the communicative skill of a television newscaster than of a platform speaker. The skill, extroversion, and speed factors were not discovered in the two previous factor analytic studies, although the extroversion factor of this study is very suggestive 
of a portion of Berlo's "nice guy" factor and is related to the "nice guy" factor of this television study. One could speculate on the reason for this dimension of skill by saying that most Ame ricans (particularly college age people) have been exposed to very professional communicators via the broadcast media. The network newscasters have established in the public's mind criteria of communicative skill which are probably used by the public to judge local newscasters.

The speed dimension is relatively pure when compared to the other dimensions of this study in the sense that the other scale items are not significant in the speed factor structure. However, since the factor accounts for only $1.81 \%$ of the total variance, in the context of the total factor structure, the speed dimension becomes relatively insignificant as a serious judgmental item. This speed factor could be considered a major portion of a skill dimension, but the factor analytical separation of this dimension suggests that people are interested in rate of delivery in listening to television news, but the factor is a minor judgmental crite ria.

In summary, television news communication seems to be a more highly structured type of communication. Viewers of news communication seem to make more numerous and more sophisticated judgments than they would in a face-to-face communication situation. These conclusions are not in conflict with Andersen's and Berlo's findings, but are rather additional findings. 
Suggestions for Further Research. In a replication of this study, the author suggests that videotape reproduction of the newscasts be used rather than sixteen millimeter sound film. The videotape medium would be more similar to the actual television newscast than projection on a screen.

The author suggests that a field study be attempted using the same scale items and having subjects in the privacy and familiarity of thei $r$ own homes make judgments about a news program or news $p$ rograms being actually broadcast from a television station. This approach could lead to fruitful conclusions both in the areas of difference between a field study and a laboratory study such as this in both numbers of factors and quality of factor structure.

From this laboratory study, the author has constructed an instrument that could be used in the field measurement of television newscasters. The instrument was constructed by selecting a number faccording to the size of the variance) of items from the first eight factors, and randomizing them. This field instrument is rep roduced in Appendix G. The field surveyor would select a sample of interviewees and present the instrument to them. The responses would be scored according to a scale of seven to one according to the "desirability" (e.g., "Fair") to "undesirability" (e.g., "Unfair") of each bi-polar item. These scores would be added to accumulate a total score which could be used to evaluate the credibility of the newscaster in question. 
If this study is replicated in a laboratory situation, control for material might be attempted, eithe $r$ in quality of news items presented or in exact word-for-word replication across two or more news communicators. Another experimental design could have the same informational material presented via television and in a face-to-face communication in order to test the suggested conclusion that the television medium (or channel in the communication theory sense) heightens the judgmental responses of the listeners.

In this study, the author is aware that the subjects had no familiarity with the newscasters or the material presented. One might be interested in a group of subjects' (1) responses to a newscaster the subjects had previously viewed, (2) the variety of responses according to the amount of prior experience with the newscaster, and (3) responses in relation to familiarity with the material presented in the television $\mathrm{p}$ rog ram. Finally, an expe rimenter might attempt some measurement of interest in the material presented in a television newscast and relate the interest to the responses subjects might make on the instrument or a similar instrument, used in this study. In the a rea of subject interest, an experimenter should investigate the relationship between general news interest as expressed in the reading of magazines, newspapers and in listening to radio, et cetera, and his judgments of television news. One might suspect that a person who had sophistication and experience with other media might not tend to make judgments in the areas of 
abstract morality and openmindedness dimensions.

Summary. In this chapter the ten factors the author extracted from the data he identified in order of descending importance as logicevaluative, activity, "nice-guy," abstract-morality, skill, openmindedness, speed, extroversion, and two unidentifiable dimensions. A seemingly important experimental difficulty was the lack of subjects' interest in the news material; however, the author could draw no conclusions about the effect of this va riable upon the experiment. The author made a. comparison between this study and two other studies involving public speakers judged with semantic differential type instruments. This comparison suggests that television news communication is a type of speech judged by the listener along more bases of judgment than that in the public speaking situation. One must realize that this conclusion is not in conflict with the previous studies, but coincides with previous knowledge by adding to the dimensions previously discovered. The chapter concludes with suggestions for future research. 


\section{BIBLIOG RAPHY}

\section{Books}

Allport, G. W. Personality: A Psychological Interpretation. New York: McGraw-Hill, Inc., 1961 .

Aristotle. Rhetoric. Translated by W. Rhys Roberts. New York: Modern Library, 1954.

Blair, Hugh. Lectures on Rhetoric and Belles Lettres. Philadelphia: James Kay, Jun. and Brother, 1829.

Brembeck, Winston L., and Howell, William S. Persuasion. New York: Prentice Hall, Inc., 1952.

Brigance, William N. Speech Composition. New York: F.S. Crofts and Co., 1937.

Bryant, Donald C., and Wallace, Karl R. Fundamentals of Public Speaking. Third edition. New York: Appleton-Century-Crofts, Inc., 1960.

Campbell, George. The Philosophy of Rheto ric. London: William Tegg and Co., 1850 .

Channing, Edward T. Lectures Read to the Seniors in Harvard College. Boston: Ticknor and Fields, 1856.

Cooper, Lane, translator. Plato: Phaedrus, Ion, Gorgias, and Symposium, with Passages from the Republic and Laws. London: Oxford University Press, 1938.

Cope, Edward M. An Introduction to Aristotle's Rhetoric. London: Macmillan and Co., 1867.

Ewbank, Henry L. and Auer, J. Jeffery. Discussion and Debate. Second edition. New York: Appleton-Century-Crofts, Inc., 1951. 
Hall, Calvin S. and Lindzey, Gardner. Theories of Personality. New York: John Wiley and Sons, Inc., 1957.

Harman, Harry. Modern Factor Analysis. Chicago: University of Chicago Press, 1960 .

Hovland, Carl I., Janis, Irving L., and Kelley, Harold H. Communication and Persuasion. New Haven: Yale University Press, 1953.

Lawton, She rman P. The Modern Broadcaster. New York: Harper and Brothers, Publishers, 1961 .

Lindesmith, Alfred R. and Strauss, Anselm L. Social Psychology.

Revised edition. New York: Henry Holt and Co., 1956.

Merton, Robert K. Mass Persuasion: The Social Psychology of a War Bond Drive. New York: Harper and Brothers, 1946.

Minnick, Wayne C. The Art of Persuasion. Boston: Houghton Mifflin Co., 1957.

Norlin, George, translato. Isocrates. London: Oxford University Press, 1938 .

Oliver, Robert T., Dickey, Dallas C., and Zelko, Ha rold P. Essentials of Communicative Speech. New York: The Dryden Press, 1949.

- The Psychology of Persuasive Speech. New York: Longmans, Green and Co., 1957.

Osgood, Charles, Suci, George, and Tannenbaum, Percy. The Measurement of Meaning. Urbana: University of Illinois Press, 1957 .

Parrish, Wayland M. and Hochmuth, Marie. American Speeches. New York: Longmans, Green and Co., 1954.

Ruch, Floyd. Psychology and Life. Fourth edition. Chicago: Scott, Foresman and Co., 1953.

Stagner, Ross. Psychology of Personality. Third edition. New York: McG raw-Hill, 1961 .

Thonssen, Lester and Baird, A. Craig. Speech Criticism. New York: The Ronald Press Co., 1948. 
Thurstone, L.L. Multiple-factor Analysis: A Development and Expansion of the Vectors of the Mind. Chicago: University of Chicago Press, 1957.

Quintilian. Institutio Oratorio. Translated by H.E. Butler. Cambridge: Ha rvard Press, 1953.

Whately, Richard. Elements of Rhetoric. New York: Sheldon and Co., 1846.

Winans, James A. Public Speaking. Rev. ed. New York: The Century Co., 1917.

Wise, Claude, et al. Foundations of Speech. New York: Prentice-Hall Inc., 1941 .

Young, Kimball. Social Psychology. 2d ed. New York: F.S. Crofts and Co., Inc., 1947.

\section{Articles}

Andersen, Kenneth and Clevenger, Theodore, Jr. "A Summary of Experimental Research in Ethos," Speech Monographs, XXX (1963), 59-78.

Arnett, Claude, Davidson, Helen, and Lewis, Hallett. "Prestige as a Factor in Attitude Changes," Sociology and Social Research, XVI (1931), 49-55.

Asch, Solomon, Block, Helen, and Hertzman, Max. "Studies in the Principles of Judgments and Attitudes: I. Two Basic Principles of Judgments," Journal of Psychology, V (1935), $217-224$.

- "Studies in the Principles of Judgments and Attitudes: II. Determination of Judgments by Group and Ego Standards," Journal of Social Psychology, II (1940), 455-453.

Berlo, David K. and Kumata, Hideya. "The Investigator: The Impact of Satirical Radio Drama," Journalism Quarterly, XXXIII (1956), $187-198$.

and Gulley, Halbert E. "Some Determinants of the Effect of Oral Communication in Producing Attitude Change and Learning," Speech Monographs, XXIX (1957), 10-20. 
Bernberg, Raymond. "Prestige Suggestion in Art as Communication," Journal of Social Psychology, XXXVIII (1953), 23-30.

Bowden, A., Caldwell, Floyd, and West, Guy. "A Study in Prestige," Ame rican Journal of Sociology, XL (1934), 193-203.

Brehm, Jack and Lipsher, David. "Communicator-Communicatee Discrepancy and Perceived Communicatory Trustworthiness, " Journal of Personality, XXVII (1930), 353-361.

Burdick, Harry, and Barnes, Alan. "A Test of 'Strain Toward Symmetry' Theories," Journal of Abrormal and Social Psychology, LVII (1958), $367-370$.

Burtt, Harold and Falkenberg, Don, Jr. "The Influence of Majority and Expert Opinion on Religious Attitudes," Journal of Social Psychology, XIV (1941), 169-178.

Cole, David. "'Rational Argument' and 'Prestige-Suggestion' as Factors Influencing Judgment," Sociometry, XVIII (1954), 350-354.

Das, J.P., Rath, R., and Das, Rhea S. "Understanding Versus Suggestion in the Judgment of Literary Passages," Journal of Abno rmal and Social Psychology, LI (1955), 624-628.

Donceel, Joseph, Alimerra, Benjamin, and Birch, Catherine. "Influence of Prestige Suggestion on the Answers of a Personality Inventory, " Journal of Applied Psychology, XXXIII (1949), 352-355.

Duncker, Karl. "Experimental Modification of Children's Food Preferences th rough Social Suggestion," Journal of Abno rmal and Social Psychology, XXXIII (1938), 489-507.

Farnsworth, Paul and Misumi, Issea. "Further Data on Suggestion in Pictures," American Journal of Psychology, XLIII (193 1), 632.

Haiman, Franklyn. "An Experimental Study of the Effects of Ethos in Public Speaking," Speech Monographs, XVI (1949), 190-202.

Hoshor, John P. "American Contributions to Rhetorical Theory and Homiletics," A History of Speech Education in Ame rica. New York: Appleton-Century-Crofts, Inc., 1954, pp. 129-152.

Hovland, Carl and Mandell, Wallace. "An Experimental Comparison of Conclusion Drawing of the Communicator and by the Audience," Jou rnal of Abnormal and Social Psychology, XLVII (1952), 581-588. 
, and Weiss, Walter. "The Influence of Source Credibility on Communication Effectiveness, " Public Opinion Quarterly, XV (1951), 635-650.

Kaiser, Henry F. "The Application of Electronic Computers to Factor Aralysis," Educational and Psychological Measurement, XX (1960), $141-\overline{151 \text {. }}$

Kelman, Herbert and Hovland, Carl. "'Reinstatment' of the Communicator in Delayed Measurement Measurement of Opinion Change," Journal of Abnormal and Social Psychology, XLVIII (1953), $321-325$.

Kneldergaard, Paul M. "Attitudes toward Newscasters as Measured by the Semantic Differentiai: A Descriptive Case," Journal of Applied Psychology, XLV (1961), 35-40.

Kulp, David. "Prestige, as Measured by Single Experience Changes and Their Permanency," Journal of Educational Research, XXVII (1934), 663-672.

Lee, Irving J. "Some Conceptions of Emotional Appeal in Rhetorical Theory, "Speech Monog raphs, VI (1939), 66-70.

Lewis, Helen. "Studies in the Principle of Judgments and Attitudes: IV. The Operation of 'Prestige Suggestion.' " Journal of Social Psychology, XIV (1941), 229-256.

Lorge, Irving with Curtiss, Carl. "Prestige, Suggestion, and Attitudes," Journal of Social Psychology, VII (1936), 386-402.

Lurie, Walter. "The Measurement of Prestige and Prestige Suggestibility," Journal of Social Psychology, IX (1938), 219-225.

Marple, Clare. "The Comparative Susceptibility of Three Age Levels to the Suggestion of Group Versus Expert Opinion, " Journal of Social Psychology, IV (1933), 176-186.

Michael, William B., Rosenthal, Benard G., and DeCamp, Michael H. "An Experimental Investigation of Prestige Suggestion for Two Types of Literary Material, " Journal of Psychology, XXVIII (1949), 303-323.

Moore, Henry. "The Comparative Influence of Majority and Expert Opinion," American Journal of Psychology, XXXIII (1921), 16-20. 
Moos, Malcom and Koslin, Bertram. "Prestige Suggestion and Political Leadership," Public Opinion Quarterly, XVI (1952), 77-93.

Osgood, Charles, and Tannenbaum, Percy. "The Principle of Congruity in the Prediction of Attitude Change," Psychological Review, LXII (1955), 42-55.

Paulson, Stanley. "The Effects of the Prestige Speaker and Acknowledgment of Opposing Arguments on Audience Retention and Shift of Opinion, " Speech Monographs, XXI (1954), 267-271.

Saadi, Mitchell and Farnsworth, Paul. "The Degrees of Acceptability of Dogmatic Statements and Preferences for Their Supposed Makers," Journal of Abnormal and Social Psychology, XXIV (1934), $143-150$.

Sherif, Muzafer. "An Experimental Study of Ste reotypes," Journal of Abnormal and Social Psychology, XXIX (1935), 370-376.

Smith, Raymond G. "Development of a Semantic Differential for Use with Speech Related Concepts," Speech Monographs, XXVI (1959), 263-272.

Tannenbaum, Percy. "Initial Attitudes Toward Source and Concept as Factors in Attitude Change Through Communication, " Public Opinion Quarterly, XX (1956), 413-415.

Walter, Otis M. "What You Are Speaks So Loud . . .," Today's Speech, III (1955), 3-6.

\section{Unpublished Materials}

Andersen, Kenneth. "An Experimental Study of the Interaction of Artistic and Non-artistic Ethos in Persuasion." Unpublished Ph. D. dissertation, University of Wisconsin, 1961.

Berlo, David K. "An Enqpi rical Test of a General Construct of Credibility," Unpublished paper presented at SAA convention, New York City, December 29, 1961.

Bettinghaus, Erwin, Jr. "The Operation of Cong ruity in the Oral Communication Situation, "Unpublished Ph. D. dissertation, University of Illinois, 1959. 
Darnell, Donald Keith. "A Technique for Determining the Evaluative Discrimination Capacity and Polarity of Semantic Differential Scales for Specific Concepts," Unpublished Ph. D. dissertation, Michigan State University, 1964.

Highlander, John. "Audience Analyzer Measurements and Informational Effects of Speaker Variables in Radio Talks," Unpublished Ph. D. dissertation, University of Wisconsin, 1953.

Kersten, Barbara. "An Experimental Study to Dete rmine the Effect of a Speech Introduction upon the Speech that Followed, " Unpublished M.S. thesis, South Dakota State College, 1958.

McLaughlin, Teddy J. "Modern Social Psychology and the Aristotelian Concept of Ethical Proof," Unpublished Ph.D. dissertation, University of Wisconsin, 1952.

Pross, Edward L. "A Critical Analysis of Certain Aspects of Ethical Proof." Unpublished Ph. D. dissertation, University of Iowa, 1942 .

Sattler, William. "Conceptions of Ethos in Rhetoric." Unpublished Ph. D. dissertation, Northwestern University, 1941.

Strother, Edward S. "An Experimental Study of Ethos as Related to the Introduction in the Persuasive Speaking Situation." Unpublished Ph. D. dissertation, Northwestern University, 1951.

Walter, Otis, Jr. "The Measurement of Ethos." Unpublished Ph. D. dissertation, Northwestern University, 1948. 
APPENDICES

$+$ 


\section{APPENDIX A}

SCALE ITEMS

Item

Source $^{a}$

1. Active Passive

2. Admirable Contemptible

A \& $O$

3. Aggressive Non-aggressive

A

4. Attractive Unattractive

A

5. Authoritative Unauthoritative

6. Believable Unbelievable

7. Calm Upset

8. Careful Careless

9. Cheerful Gloomy

10. Competent Incompetent

A

11. Confident Unsure

12. Consistent Inconsistent

13. Decisive Indecisive

14. Dishonest Honest

A

15. Educated Uneducated

16. Effective Ineffective

17. Energetic Tired

18. Experienced Inexperienced

19. Expert Ignorant

20. Extroverted Introverted

21. Fair Unfair

22. Fast Slow

23. Friendly Unfriendly

24. Good Bad

O

25. Honest Dishonest

26. Imp ressive Unimpressive

A \& $O$

$A \& O$

A \& $O$

0

A

"Key to sources: " $A$ " signifies that the item came from Kenneth Andersen's dissertation, "An Experimental Study of the Interaction of Artistic and Non-artistic Ethos in Persuasion" (University of Wisconsin, 1961); "O" signifies that the item came from Osgood, Suci, and Tannenbaum's The Measurement of Meaning (Urbana: University of Illinois Press, 1957). 
APPENDIX A (Concluded)

$\underline{\text { Item }}$

Source

27. Informed Uninformed

28. Intelligent Unintelligent

29. Interesting Uninteresting

A

30. Kind Cruel

31. Large Small

32. Likable Unlikable

O

33. Logical Illogical

34. Modest Boastful

35. Moral Immoral

$A \& O$

A

36. Objective Subjective

37. Openminded Biased

38. Organized Disorganized

39. Original Unoriginal

40. Persuasive Unpersuasive

41. Pleasant Unpleasant

42. Profound Superficial

4.3. Rational Irrational

44. Realistic Unrealistic

45. Reasonable Unreasonable A

46. Relaxed Tense

47. Reliable Unreliable

O

48. Right Wrong

49. Sincere Insincere

A

A

A

0

50. Skilled Unskilled

51. Sociable Unsociable

52. Strong Weak

53. Sympathetic Unsympathetic

A

54. Understandable Incomprehensible

55. Wise Unwise

A

A \& 0

A

A 
APPENDIX B

TEST INSTRUMENT

STUDY OF CITIZEN'S OPINION ON TELEVISION NEWSCASTERS

This is part of a scientific study aimed toward better understanding of how people feel about televisicn newscasters. It is not undertaken with a view of meddling in your privite piniors. If you have any doubts or reservationis or this sccre, please feel perfectly free not to put your rame or this sheet.

$\begin{array}{ll}\text { Name } & \text { Male___ Female } \\ \text { Classification } & \text { Miajor }\end{array}$

TURN PAGE AND GO AHEAD 


\section{APFENDIX B (Continued)}

\section{INSTRUCTIONS}

The purpose of this study is to measure the impressions of newscasters to various people by having them judge them against a series of descriptive scales. In taking this test, please make your judgments on the basis of what these measures mean to you. You are to rate the concept of $\epsilon$ ach of these scales in order.

Here is how you are to use these scales:

If you feel that the newscaste $r$ is very closely related to one end of the scale, you should place your check-mark as follows:

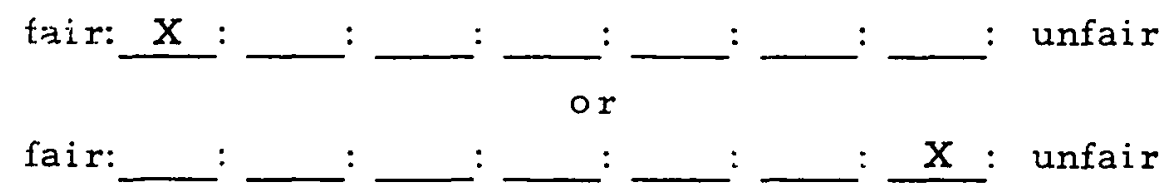

If you feel that the newscaster is quite closely related to one or the other end of the scale (but not extremely), you should place your check-mark as follows:



If the newscaster seems only slightly related to one side as opposed to the other side (but not really neutrali, then you should check as follows:

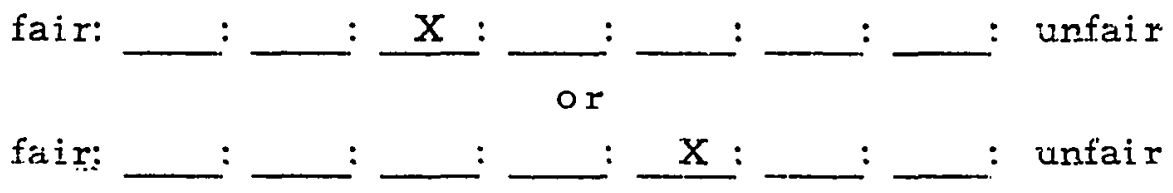

If you consider the newscaster to be neutral on the scale, both sides of the scale equally associated with the concept, $O r$ if the scale is completely irrelevant, unrelated to the concept, then you should place your checkmark in the middle space.

fair: $: \mathrm{X}:$ : : unfair

IMPORTANT: (1) Place your check-marks in the middle of the spaces, not on the bounda ries.

(2) Be sure you check eve ry scale for every concept; do not omit any.

(3) Neve $r$ put more than one check-mark or a single scale.

(4) Do not lock back and forth through the items; make each item a separate and independent judgment.

(5) Your first impression, the immediate "feeling s" about the items, is what we want. TURN PAGE AND GO AHEAD 
APPENDIX B (Continued)

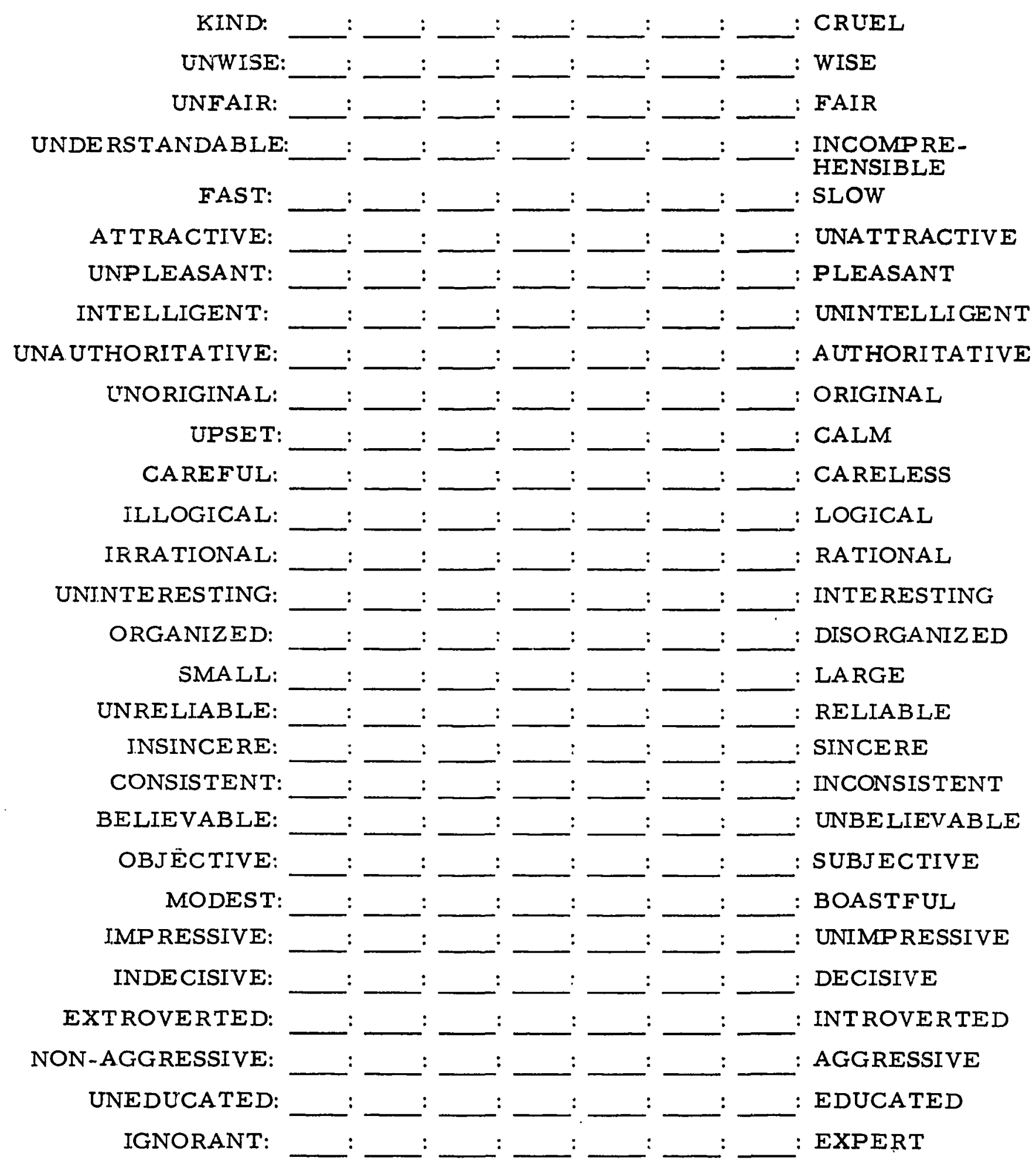


APPENDIX B (Concluded)

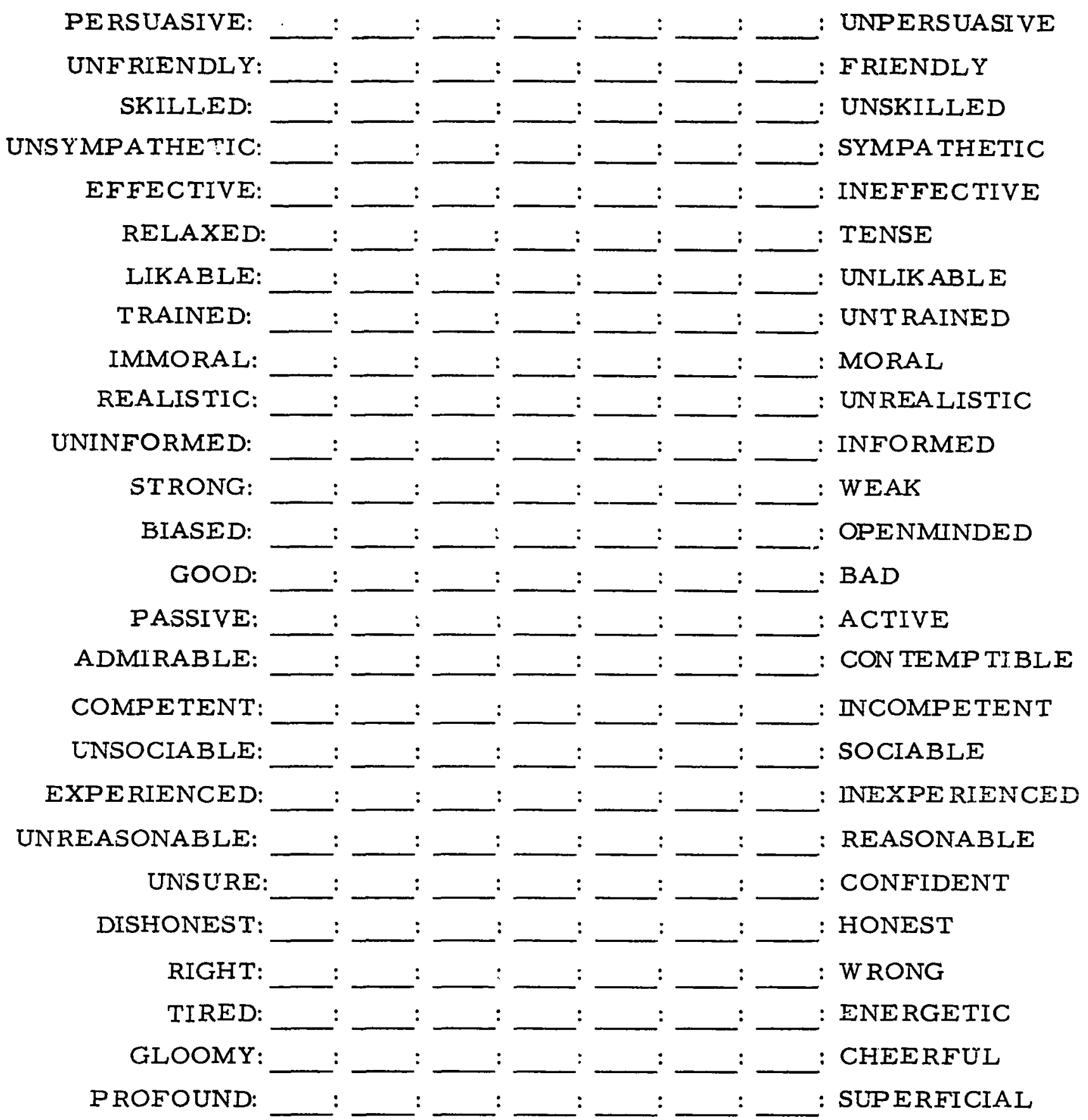

DO NOT TURN PAGE UNTIL ASKED 


\section{APPENDIX C}

The following are the scripts of the three newscasts used in this experiment. The scripts were taken from the actual films used in the experiment, i.e., with most of the commercial material removed.

\section{NEWSCAST A}

FADE IN ON:

FILM CLIP. SUPER LOGOS:

Dateline 64;

Six O'Clock Report;

Dick John.

DICK JOHN: HEAD SHOT.

JOHN. SEATED AT

DESK

PUSH IN

TO

\section{CHEST SHOT}

\section{BOOTH ANNOUNCER:}

Dateline, 64. Monday, January twentieth, 1964--the Six O'clock Report with WIIC's News Director Dick John.

\section{JOHN:}

Hello, everybody. Welcome again to the Tri-State Report, Dateline 64.

Abe Zeid went on trial today in criminal court charged with shooting and attempting to hijack a Hill District bartender a year ago this month. Zeid and his alleged accomplice, William Cody, a re charged with shooting it out with bartender William Carter. Carter and Zeid were both critically wounded in the shooting and hospitalized for weeks.

Mon roeville's forme $r$ tax collector, Andrew Cummings, was sentenced to jail today for his involvement in the fatal automobile accident back in 1961. Cummings was sentenced to from thiee to twenty-three months in jail. He had been sick and was sentenced while seated in a wheel chair in the courtroom. His attorney indicated that he would appeal.

Pittsburgh Safety Director, James Dillion, and Police Supe rintendent, James Schlusser, held their much publicized meeting today as an outg row th of Schlusser's shakeup last week of the city's Sex, Vice, and Racket Squad without first consulting Dillion. For a report, here is newsman Rej Pavonitz. 


\section{APPENDIX C (Cortinued)}

FILM CLIP:

CHEST SHOT. PAVONITZ

CHEST SHOT. HEAD SHOT.

JOHN: HEAD SHOT

FILM CLIP.

(Swearing in Scene)

\section{PAVONITZ:}

Pittsburgh Safety Director James Dillion today handed Superintendent of Police James Schlusser a verbal slap across the knuckles today for allegedly trying to re-organize the ci $y^{\prime}$ s Sex and Na rcotic Squad without his-Dillion's--permission. Mr. Schlusser received his reprimand here in the office of Safety Director Dillion during a closed meeting. He was told: One. That any orders he had given to reorganize the Sex and Narcotics Squad a re now out the window. Two. He was also told that he would not make any statements with Safety Director Dillion. He was also told to report here to Safety Director Dillion's office twice a week to discuss the operations of the Sex and Narcotics Squad.

Both men refused to comment for television following their meeting. But the word here at City Hall is that this was but the latest round in a skirmish between the two men as to who is going to run the Pittsburgh police department. If this is true, then there is no question who was the victor in this latest bout. This is Rej Pavonitz reporting from the City-County Building.

\section{JOHN:}

United Mine Worker's official August Libby was sentenced to three years in prison and fined five thousand dollars today for income tax evasion. His attorneys immediately said that they would appeal the sentencing.

Allegehney County's Assistant Chief of County Detectives, Joseph J. O'Niel, was sworn in today by provonotary Davey Roberts. O'Niel was sworn in this afternoon two weeks after his appointment because he had to wait for an official termination of service from the 
APPENDIX C (Continued)

JOHN: CHEST SHOT

JOHN: HEAD SHOT
Federal Bureau of Investigation. A native Pittsburgher, the fifty-three year old O'Niel had spent eighteen of his twenty-one years with the FBI in Pittsburgh. He was congratulated by Chief of County Detectives George Collet, District Attorney Robert Dugan, and his wife and two daughters.

Digan also made two cther special appointments today. One involving a Pittsburgh Pirate baseball player. And Red Donaly will have the details on that story in a few minutes.

The re were several developments on the political scene today. Governor Scranton denied that he ever promised to serve out his four year term as governor, although he said he thought it would be a good idea to do so. State Demosratic leaders met in Harris burg this afternoon with officials of the state AFL-CIO to discuss potential candidates for the Democratic nomination for the U.S. Senate. They a re a number of possible candidates and former governor David Lawrence discusses them among othe $r$ things on tonight's special report a little bit later on Dateline 64.

Couniy Commissioner Blair Gunther said today that $h \in$ will be a candidate for the delegation of the GOP convention in San Francisco. He says he'll run whether or not he has organization support. And over in Philadelphia Ha rold Stassen says he's going to be a candidate for the GOP Presidential nomination. It'll be the fourth time that he's tried.

The Pennsylvania Milk Commission held the first of three days of hearings in Pittsburgh today, amid reports that it is going to be asked to raise milk prices about three cents. Here is a report from newsman Matt Mathews. 


\section{APPENDIX C (Continued)}

FILM CLIP: MATHEWS: SHOULDER SHOT.

STEFANO: CHEST SHOT.

MATHEWS: SHOULDER SHOT.

That's the dairyman's point of view. However, the city and county a re fighting this milk increase, or whatever it may be, have their own opinion of it. Here is city solicitor David Craig.

CRAIG: HEAD SHOT.
MATHEWS:

Will the re be a milk increase this year or not? Nobody seems to $\mathrm{kr}_{\mathrm{i}} \mathrm{cw}$ here at the Milk Commissior hearings. Nobody wants to take the blame for taking the initiative in trying to get one. The Greate $r$ Pittsburgh Dairyman's Association says its after three thirgs. They want a lower price for farmers to make them more competitive. In that way they will sell more milk. It wants to make an adjustment in large sales. It does not say it wants to have an increase in milk costs. In fact Attorney Ralph B. Stefaro has this to say.

STEFANO:

We're not asking for any raise whatsoever in the street price of milk. It can be said that the dairies a re not making very much money. And some adjustments will have to be made in the order, but not necessarily an increase in the street pirice.

\section{MATHEWS:}

\section{CRAIG:}

They, certainly judging from the exhibits they have submitted, a re asking for an increase in - - an increase in the consumer price and from the exhibits submitted, I would think they have not proved the basis for that increase. For example, the milk companies admit paying lower prices for the milk that they purchased out of state, yet in order to show 


\section{APPENDIX C (Continued)}

that they lost money, they are using the higher prices which they would have paid in Pennsylvania if they had bought that milk in Pennsylvania. So, the--uh--cast of--cast changes, but the plot remains the same and the mystery deepens.

MATHEWS: SHOULDER SHOT.

\section{MA THEWS:}

So far the dairymen have been painting a pretty bleak financial picture and the milk commission has the prerogative of raising prices even if it is not specifically asked for. However, the preceding days will tell us if they are going to ask for an increase or not. As of right now, the re has been no specific request for an increase of milk prices. This is Matt Mathews reporting from the Rocsevelt Hotel.

\section{JOHN:}

JOHN: CHEST SHOT.

And that's the Tri-state Report, Dateline 64. In one minute, Red Donaly.

FADE TO BLACK. 


\section{APPENDIX C (Cortinued)}

NEWSCAST B

TAKE: PALMER AT DESK.

PALMER:

Good Evening. And they a re off and running in the 1964 Oklahoma Sweepstakes. In other words, another election year got under way today with a long, long line formed to the right. For what this first day of the political year produced, here's Ed Turner.

TURNER: CHEST SHOT. TURNER:

Well, it produced some excitement all day long on the fourth floor of the state capitol as the big, well-known, the small and the lesser known names walked down the corridor to p resent a one-hundred dollar cerified check or a petition bearirg so many names to file for state office.

DISSOLVE TO FILM CLIP One-hundred Democrats and ten Republicans (Filing scenes) came in person or mailed in their applications today. Election Board Secretary Frank Eernell estimates that five-hundred persons will have filed by five o'clock Friday afternoon.

The first person on hard was Byron Auchincloss of Chickasha. He is running for the Republican nomination for Congress in the Sixth District. Auchincloss has had someone at the election board since last week dssuring him first place. The biggest narre of the morning was Bud Wilkinson, the OU coach turned Republican Senate candidate. Wijkinson immediately left Oklahoma City for the Panhandle where he launched his campaign toright in Boise City. This afternoon state senator Fred Harris of Lawton accompanied by wife LaDonna filed on the Democratic ticket for U.S. Senate. Harris heads for Eastern Oklahoma and then to the Panhandle--a furious pace he has kept up for months.

In other developments, state Democratic Party Co-chairman Grace Hudlin of Hulbert filed 
APPENDIX C (Continued)

DISSOL VE TO TURNER:

CHEST SHOT.

PALMER: AT DESK.

FILM CLIP. (Police station scenes)
TURNER (Continued):

for the Senate and Patricia Andersen of Tulsa filed for the house. The two women the re. John White of Oklahoma City became the first Negro this year to file for office--a house seat from the Eastern part of Oklahoma City. The eleven Senate seats from Oklahoma City drew the expected landslide of candidates which will g row as the week continues.

The two principal candidates for state Democratic Party chairman both claim strong support today in the wake of those county meetings last Satizday. Roy Powers of Oklahoma City said he has the support of twentyfive to fifty counties but he did not name any of them. Smith Hester of Purcell said he had wide-spread support and he named fourteen counties which have endorsed him. The Chairman will be selected by the State Central Committee. Bruce.

\section{PALMER:}

Oklahoma City Police arrested three yourg men this afternoon and said that the $y$ think the arrests cleared up at least six recent a rmed robberies in the city.

In $j$ ail this evening on armed robbery charges a re twenty-two year old Rczzario McGrip of two elever Northeast Fourth Street, eighteen year old Jack L. Martin and twenty-two year old Cecil Burke both of two-eleven Harrison Avenu.e. Detectives said that several weeks of leg work led them to Burke ${ }^{i}$ s residence which they were searching when Martin appeared this afternoon. When they spotted the officers they tried to run but were arrested. All three $w \in r e$ shown on the afternoon line-up and officers said several recent holdup victims identified them. The officers said that the three admitted 


\section{APPENDIX C (Continued)}

PALMER: AT DESK.

DISSOLVE TO FILM CLIP. (Hospital construction scenes).
PALMER (Continued):

under/ questioning to six a rmed holdups at four grocery stores and two liquor stores. The detectives quoted Martin as saying nonchalantly, "I'll have a long, grey beard by the time I get out of this." Three young girls with the young men when they were arrested were booked by police on charges of vag rancy.

And two charges of murder and assault with the intent to kill have been filed against Second Lt. Gerald Cameron of Fort Sill in Comanche County District Court at Lawton. Lt. Cameron is accused of killing four year old James Gibbs, $J r$. , the son of a fellow officer, last Thursday at Gibbs' home. He was also accused of attacking the boy's mother.

Husky concrete pillars thrusting skyward are the first evidences of a three-quarter--three million dolla $r$ construction prog ram that will double the bed capacity of Oklahoma City's Baptist Memorial Hospital. After six weeks of work atop the six story hospital building on Northwest Highway, most of the supports for the first of four new floors are in place. When the whole construction $p$ rog ram is complete, some fourteen months from now, Baptist's two-hundred bed capacity will have been doubled and will soar ten stories high. Most of the new patient accommodations will be $p$ rivate and two-bed rooms, although two two-room suites and two one-and a half-room suites will be added. A twenty-six bed psychiatric unit will be provided in the construction prog ram. While the work proceeds on the windy roof of the hospital, anothe $r$ construction phase is excavating for a building service a rea that will be extended eastward from the present building at the basement, first, second and third floor levels. The present value of the hospital with its nursing school and doctor's medical center is estimated at five-million dollars. 


\section{APPENDIX C (Continued)}

\section{PALMER (Continued):}

DISSOL VE TO FILM CLIP. (KWTV construction).

PALMER AT DESK.

TURNER: CHEST SHOT.
And early this morning, workers began the last major portion of construction on KWTV's mammoth new studio. The pouring of twenty and a half cubic yards of cement for the studio floor. Varying in depth from one to three inches the cement covers fifty-four-hundred squa re feet of floor space. When concrete pouring is completed later this evening the floor will be covered with siesmog raph paper for a fifteen day curing period. The smooth finished floor will be covered with a plastic base sealer to protect the surface against moisture, cracks and dust. When the floor is completed and cured, then the engineers will move in to install wiring and lights and all the othe $r$ electronic gear that will be needed to put this new addition to KWTV's plant in service in May. Ed.

\section{TURNER:}

Senator Barry Goldwater will not--repeat, will not--be coming to Oklahoma City to keynote the state Republican convention this Saturday. The on-again, off-again trip he re is off again. State GOP Chairman Bill Burkett said that a Goldwater aide told him by phone today the Senator could not get from North Carolina to the city in time for the Oklahoma convention. Earlier, a spokesman for the Goldwater Club in the state said the Arizona Senator would be here.

U.S. Senate candidate Raymond Gary said today Democrats have questioned his party loyalty at county meetings last Saturday and placed hypocrisy above integ rity. The forme $r$ governo $x$ referred to reports that resolutions were passed at some county Democratic meetings criticizing his role in the 1962 general election campaign, in which Gary had refused to actively support 


\section{APPENDIX C (Continued)}

TURNER (Continued):

PALMER: CHEST SHOT. FILM CLIP. (geese capturing scenes). the nominee, Bill Atkinson. And Senator $\mathrm{J}$. Howard Edmondson has canceled speaking engagements in Stillwater, Edmond, and Osage county to return to Washington tomorrow to work on agriculture legislation. The senator was in Bartlesville tonight and will return to Washington tomor row with Interior Secretary Stuart Udall.

\section{PALMER:}

Another phase of a project to study the habits of a certain kind of Oklahoma tourist was completed early this morning on the shores of Great Salt Plains Reservoir in Alfalfa County. The tourist or tourists, rather-are the big Canadian Reeser Geese and varieties of ducks that swa rm to the Great Salt Plains Wildlife Refuge. And this morning as clouds of birds settled into the refuge, they became the unwitting objects of a dramatic kind of trapping.

Rockets attached to a sixty by forty foot net were fired. The big net flew out to settle over some of the birds. In this case twenty-five of the Canadian geese and eighteen Pintail ducks. That was a small catch. Sometimes the men of the National Fish and Wildlife Service catch as many as two-hundred to be banded according to age and sex and then released. The object of the continuing study in which almost one-thousand birds have been netted and banded is to determine their migratory flight path. The birds, next year, at anothe $r$ netting operation like this will show where they have been.

Manager Richard Hitch of the Wildlife Refuge records in his little book all the details which a re available to wildlife service officers at cther favorite nesting grounds of ducks and geese across the country. While it may be a frightening operation for the birds for the 
APPENDIX C (Continued)

DISSOLVE TO PALMER: AT DESK.
PALMER (Continued):

moment, as soon as the bands are attached they a re freed and off they go to rejoin those who avoided the net, this time.

For an hour and a half this afternoon, an intensive air and $g$ round search was under way in the Cookson Hills of Eastern Oklahoma for an airplane that reported crashed near Vian in Sequoyah County. Ernest Summers of Vinita told the Highway Patrol that he saw a la rge, obsolete plane with four engines smoking and flying at low altitude. Three Highway Patrol cruisers, several sheriff's cars, and two planes were sent to the area. The FAA advised that they had no planes overdue. After an hour and a hilf the search was called off. Officers said the report was possibly an error since it is not uncorımon for a plane to appear to fall behind a hill and not re-appear again. Ed.

\section{TURNER:}

Finally, this one-hundred dollar filing fee to run for state office is certainly a discouraging barrier to some potential statesmen like Ray Parr or me. The trouble is that if Ray or I had one-hundred dollars we wouldn't go into politics--we would become investment brokers. The state election board has collected nearly eleven-thousand dollars in filing fees in one day--and that's a lot of money to pay out for the privilege of being cussed. Goodnight, Bruce.

\section{PALMER:}

TWO SHOT: AT DESK.

Goodnight, Ed. And that's thirty for the Oklahoma News on Monday, Februa ry twentyfourth. I'll be back in sixty seconds with tonight's $\mathrm{KWTV}$ edito rial. 
APPENDIX C (Continued)

\section{BOOTH ANNOUNCER:}

LOGO: Oklahoma Report. KWTV's Oklahoma Report with Bruce Palmer and Ed Turner is a six o'clock Monday through Friday presentation.

LOGO: KWTV Newsfilm. Newsfilm by KWTV News.

TAKE BLACK. 


\section{APPENDIX C (Continued)}

NEWSCAST C

FADE IN ON HARRISON

AT DESK.

SUPER: Skelly Oklahoma

News; Skelly emblem

LOGO: SKELLY SIGN

HARRISON AT DESK.

\section{BOOTH ANNOUNCER: \\ (TELETYPE NOISE UNDER):}

And now, the Skelly Oklahoma News. Brought to you by Skelly Oil Company, and your Oklahoma Skelly dealer, who say, "Test drive three tankfuls of Skelly Keotane and see if you don't ag ree that today the best additives make the best gasoline."

(TELETYPE OUT)

And now for an uninter rupted report of the news, here is channel five's news director, John Harrison.

\section{HA RRISON:}

An attorney for twenty-nine Negro and white civil rights demonstrators, charged with trespassing in the latest racial dispute in Tulsa, entered pleas of not guilty in Municipal Court in Tulsa, today. Non-jury trials were set for May the sixth. All of the demonstrators arrested last night at the second restaurant demonstration in Tulsa this week. Were released to the custody of the attorney.

Oklahoma City integ ration leade $\mathrm{r}$ Clair Lupe $\mathrm{r}$ was arrested in anothe $r$ integ ration sit-in in Tulsa recently--fired a teleg ram to the governor today accusing him of ignoring racial inequities in this state. The governor had this reaction.

FILM CLIP:

BELLMON:

SHOULDER SHOT. BELLMON

Apparently Miss Lupe $r^{\prime}$ s dissatisfaction has resulted from the arrest of a group of demonstrators in Tulsa who were held to be in violation of the Tulsa municipal trespass law. As far as I can find out at this time, the re are no state laws that could have been violated, and--uh--there seems to be no action that the state administration can take. This 
APPENDIX C (Continued)

BELLMON (Continued):

HARRISON: CHEST SHOT.

administration has been active in trying to obtain equal rights for all our citizens and in areas where the state has a responsibility and authority, we will certainly continue in this direction. In as far as the Tulsa situation is concerned, apparently it will wind up in court and the court will make the decision as to whe the $r$ or not the Tulsa municipal law is legal and whether it must be upheld by the courts or whether the rights of the citizens over there have been imposed upon.

\section{HARRISON:}

Ir. regard to recent county commissioner's complaints that the purchase order law is too complex, the governor said this:

\section{BELLMON:}

FILM CLIP: SHOULDER SHOT. BELLMON

HARRISON: CHEST SHOT

To say that the law should be followed or should be changed. As long as it's on the books, I feel that the county commissioners have the legal responsibility of obeying the law and attempting to--uh--conduct their business as the law provides. Mr. Dale Cook on our staff is now examining the reports that have come in connection. with the use of purchase orders and we may have a report to make on our findings in a short time. At this time we have not been able to complete our investigation and have no position on Mr. Eddy's statement.

\section{HA RRISON:}

The gove rnor planned today to use tufted carpeting in Western Hills Lodge to solve a fuss over the carpeting at Lake Murray Lodge. The State Planning and Resources Board recently app roved a bid to pay sixteen-thousand two-hundred dollars to Carpet City of Oklahoma City for some Axminster type carpet to 
APPENIIX C (Continued)

\section{HARRISON (Continued):}

redecorate Lake Murray Lodge. This carpet is not made in Oklahoma. It rejected bids on carpet offered by two other firms. Bellmon said that the two bids were on tufted ca rpeting. The governor said that board members, Chairman Charles Monroe and Director Hugh Jones believe the Axminster type will wear longer and be easier and cheaper to maintain.

The Oklahoma Education Association has filed four initiative petitions with the Secretary of State. The petitions a re aimed at boosting state financing for teacher's salaries and other school functions by a potential amount of forty-seven million dollars per year. The twenty-three thousand teacher organization has set a goal of three-hundred thousand signatures by the time school is out in May. The OEA will have until July the first to complete the circulation of the petitions. The number of valid signatures required to gua rantee a vote of the people on the issues will range from fiftysix thousand to one-hundred and six thousand. Secretary of State Jim Bullard assigned the following numbers to the petitions. State question four-twenty-one is to boost the present five mil eme rgency levy to fifieen mils and change its name to "Local Support Levy." State question four-twenty-two to raise the state guaranteed base for teacher's salaries to seventy-five percent of the national average. State question four-twenty-three to make the transportation a rea of the school the taxing and administration a rea which would eliminate hundreds of small districts that have no high school. State question four-twenty-four to give county superintendents additional duties and increase their state guaranteed pay.

Highway Director Frank Lyons unveiled a plan today seeking to purchase highway rights-of-way years in advance and thereby lower the costs. 
APPENDIX C (Continued)

\section{LYONS:}

FILM CLIP: CHEST SHOT AT DESK. LYONS
HARRISON: CHEST SHOT.
Well, we've been talking a long time back and forth on the possibility of establishing an advance right-of-way prog ram. It simply means this--we would like to see a revolving fund established where it would be possible to buy right-of-way several years in advance of the time that it was actually needed. Then replenish this fund from time to time so we could use it over and over. Uh. Representative Jim Burnam of the State and Federal Government's Committee has talked to us and he is very much interested in this and we are just going over the possibilities of savings by having an advanced right-of-way buying prog ram.

For example, here ir Oklahoma City we started buying right-of-way on the Cross Town in fifty-nine. It was estimated that right-of-way would cost--oh--on the order of six-hundred and eighty-thousand dollars. We suspended that and in sixty-three we picked it up again and began to buy right-of-way again three and half years later, we found the cost had gone up some seven-hundred and seventy thousand doilars more, or almost a million--about a million-fou $r$. So, by buying i.t ahead of time it allows the people to know where they are going to have their right-ofway, it allows them to be certain that a road is going to come through the re, and---uh--we think that it would help in--uh--the rise of speculation and that sort of stuff and help the state get the most for their money.

\section{HA RRISON:}

High winds a re farning a prarie fire ove $r$ an estimated sixty-thousand acres of grassland in the Osage Hills area this afternoon. Fire fighters have expressed no immediate hope of bringing the flames under control. Other smaller fires were reported south of Barnsdall 
APPENDIX C (Continued)

HARRISON (Continued):

and on the Circle Mountain west of Bartlesville. Voluntee $r$ ranch units, fire units from Bartlesville, Pawhuska, and Barnsdall a re battling the flames along a two to three mile front. Firefighters say that they plan to let the fire burn cut and were concentrating their efforts on saving a few threatened buildings. A backfire was set late this afternoon in an attempt to save the home and outbuildings of Frank Garner near the Willow rock Ranch. A Girl Scout camp near Osage Hills State Park was also reported in the path of the fire.

FILM CLIP:

(Grass fire scenes).

A fire at Southeast forty-fourth and High this afternoon did very little actual damage to property--no injuries were reported--but the windswept smoke endangered traffic on roads nearty and police dispatched several units to slow down traffic in the area. Winds this afternoon in Oklahoma City were gusting as high as a rourd fifty miles an hour and the re was fear at ore point that the fire might get out of control. Traffic on interstate thirtyfive was slowed to a snail's pace for a period of time by the smoke, and everybody pitched in to keep the flames under control.

HARRISON: CHEST SHOT. The main street of Stillwater is taking on a new look with the addition of the First National Bank building ard its modern

FILM CIIP:

(New bank scenes). a rchitecture. Construction on the new bank began in September of 1963. The completion date, according to bank president Vic Thompson, should be in July of 1964. The old bank building will be to rn down and replaced by a parking lot. The cost of the new structure is estimated to be about a half a million dollars. The $\mathrm{H}$ and W Construction of Stillwater is doing the building, which will be three stories and a basement. One phase of the new bank's service will be a all new IBM bookkeeping system. 
APPENDIX C (Concluded)

HARRISON: AT DESK

HARRISON (Continued):

\begin{abstract}
A Democratic unity proposal by US Senate candidate Fred Harris drew favorable response from state senate party chairman Smith Hester and U.S. Senator Howard Edmondson, today. The third major candidate of the race, former governor Raymond Gary, could not be reached during the day for comment. Gary's answer is conside red significant because of his refusal to support Democrat W.P. "Bill" Atkinson for governor in the 1962 general election.
\end{abstract}

I'll be back with the weather in just a moment.

FADE TO BLACK. 
APPENDIX D

FOUR FACTOR SOLUTION DERIVED BY VARIMAX ROTATION

\begin{tabular}{|c|c|c|c|c|c|c|}
\hline & Factors: & 1 & 2 & 3 & 4 & Communality \\
\hline 1 . & Kind-cruel & .212 & -.083 & -.632 & .233 & .506 \\
\hline 2. & Wise-unwise & -.502 & .287 & .273 & -.281 & .489 \\
\hline 3. & Unfair-fair & -.408 & .046 & .415 & -.387 & .492 \\
\hline 4. & Understandable-incomp rehensible & .568 & -.260 & -.259 & .027 & .458 \\
\hline 5. & Fast-slow & -.105 & -.366 & .187 & .262 & .249 \\
\hline 6. & Attractive-unattractive & .327 & -.533 & -.409 & .021 & .559 \\
\hline 7 . & Unpleasant-plea sant & -.380 & .497 & .516 & -.042 & .660 \\
\hline 8. & Intelligent-unintelligent & .635 & -.380 & -.133 & .198 & .606 \\
\hline 9. & Unautho ritative-autho ritative & -.542 & .303 & .031 & -.175 & .417 \\
\hline 10 . & Uno riginal - o riginal & -.261 & .448 & .269 & -.022 & .342 \\
\hline 11. & Upset-calm & -.527 & -.007 & .378 & -.090 & .430 \\
\hline 12. & Careful-careless & .649 & -.169 & -.246 & .158 & .536 \\
\hline 13. & Illogical-logical & -.699 & .210 & .110 & -.214 & .591 \\
\hline 14. & Irrational-rational & -.644 & .132 & .177 & -.227 & .516 \\
\hline 15 . & Uninte resting-inte resting & -.306 & .644 & .334 & -.032 & .621 \\
\hline 16. & Organized-disorganized & .665 & -.256 & -.109 & .059 & .524 \\
\hline 17. & Small-large & -.214 & .322 & .033 & -.008 & .151 \\
\hline 18. & Un reliable-reliable & -.591 & .171 & .154 & -.353 & .528 \\
\hline 19. & Insincere-sincere & -.377 & .312 & .452 & -.235 & .500 \\
\hline 20 . & Consistent-inconsistent & .628 & -.199 & -.143 & .098 & .465 \\
\hline 21. & Believable-unbelievable & .562 & -.127 & -.163 & .398 & .518 \\
\hline 22. & Objective-subjective & .303 & -.045 & -.185 & .219 & .176 \\
\hline 23. & Modest-boastful & .277 & .139 & -.406 & .298 & .350 \\
\hline 24. & Impressive-unimp ressive & .294 & -.679 & -.296 & .128 & .653 \\
\hline 25. & Indecisive decisive & -.357 & .501 & .087 & -.170 & .416 \\
\hline 26. & Extroverted-introverted & .072 & -.466 & -.062 & .000 & .227 \\
\hline 27. & Non-aggressive-agg ressive & -.058 & .670 & -.085 & .070 & .465 \\
\hline
\end{tabular}


APPENDIX D (Concluded)

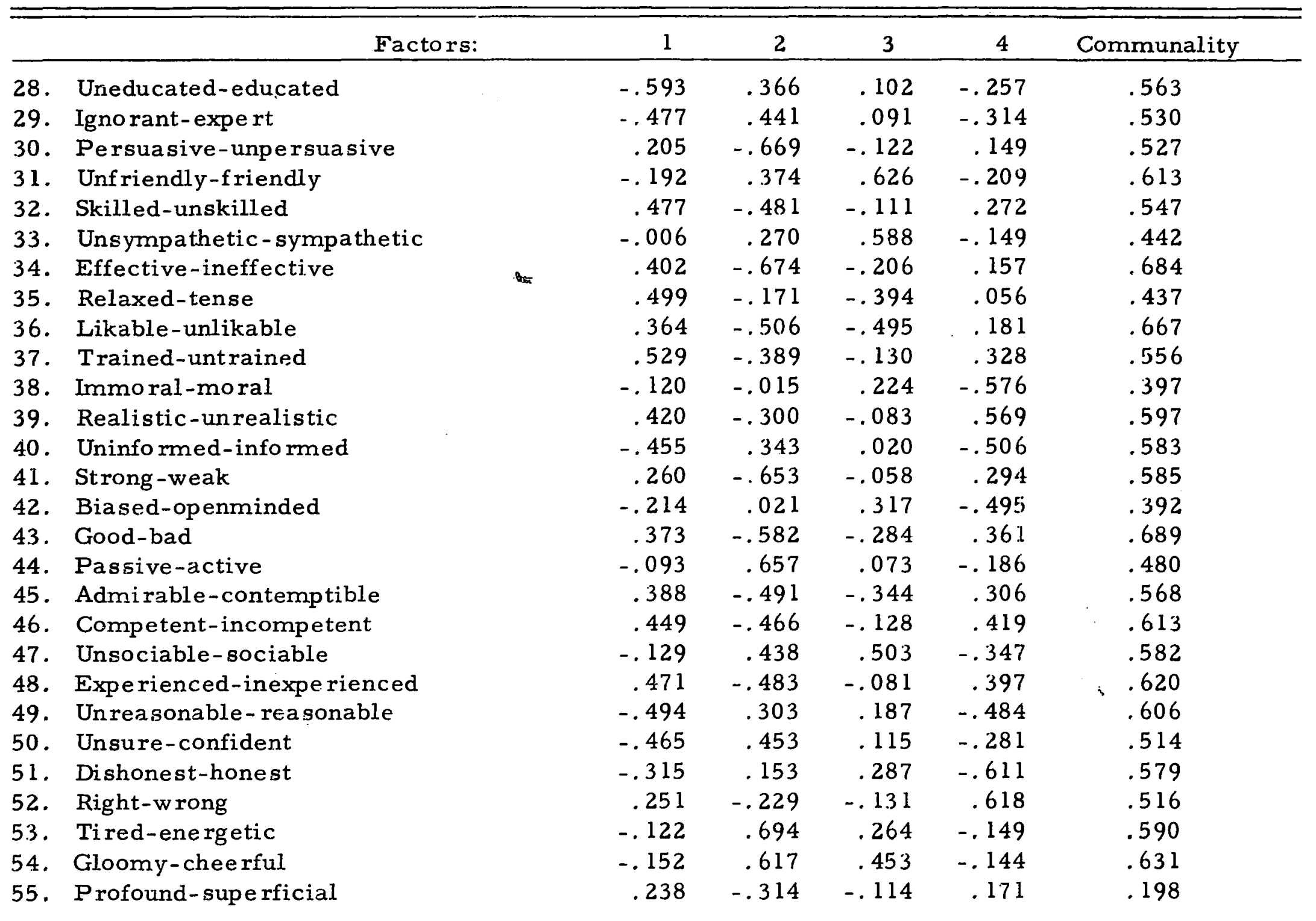


APPENDIX E

SIX FACTOR SOLUTION DERIVED BY VARIMAX ROTATION

\begin{tabular}{|c|c|c|c|c|c|c|c|c|}
\hline & Facto rs: & 1 & 2 & 3 & 4 & 5 & $6 c$ & Communality \\
\hline 1. & Kind-cruel & -.234 & -.072 & -.621 & .140 & .057 & .253 & .533 \\
\hline 2. & Wise-unwise & .518 & .279 & .245 & -.198 & -.028 & -.337 & .561 \\
\hline 3. & Unfair-fair & .420 & .038 & .383 & -.270 & .005 & -.415 & .571 \\
\hline 4. & Understandable-incomp rehensible & -.540 & -.234 & -.220 & .005 & .247 & .094 & .465 \\
\hline 5. & Fast-slow & .011 & -.377 & .098 & .295 & -.214 & -.039 & .287 \\
\hline 6. & Attractive-unattractive & -.281 & -.517 & -.336 & -.040 & .219 & .245 & .570 \\
\hline 7. & Unpleasant-pleasant & .348 & .477 & .456 & .020 & -.237 & -.221 & .664 \\
\hline 8. & Intelligent-unintelligent & -.612 & -.353 & -.101 & .174 & .212 & .167 & .613 \\
\hline 9. & Unautho ritative-authoritative & .561 & .295 & .017 & $\ldots 142$ & -.034 & $\therefore 192$ & .461 \\
\hline 10. & Uno riginal-o riginal & .280 & .453 & .235 & .039 &. .001 & -.244 & .400 \\
\hline 11. & $U_{\text {Fiset-calm }}$ & .395 & -.064 & .296 & -.074 & -.525 & -.047 & .533 \\
\hline 12. & Careful-careless & -.572 & -.123 & -.193 & -.142 & .391 & .087 & .562 \\
\hline 13. & Illogical-logical & .705 & .188 & .097 & -186 & -.138 & $\ldots 154$ & .620 \\
\hline 14. & Irrational-rational & .654 & .115 & .157 & -.175 & -.092 & $\ldots .221$ & .555 \\
\hline 15. & Uninte resting-interesting & .288 & .634 & .284 & .016 & -.153 & -.217 & .637 \\
\hline 16. & Organized-disorganized & -.635 & -.224 & -.082 & .065 & .278 & .025 & .542 \\
\hline $1 ?$. & Small-la rge & .175 & .328 & -.046 & .060 & -.017 & -.317 & .245 \\
\hline 18. & Unreliable - reliable & .618 & .156 & .152 & -.299 & -.037 & -.248 & .582 \\
\hline 19. & Insince re ..since re & .405 & .291 & .463 & -.194 & .127 & -1.30 & .534 \\
\hline 20 . & Consistert-inconsistent & -.624 &. .172 & -.135 & .098 & .213 & .026 & .493 \\
\hline $2 l$. & BElievable-linbeljevible & -.568 & -.105 & -.157 & .347 & .087 & .236 & .544 \\
\hline 22. & Objective-subjective & -.227 & -.047 & -.060 & .073 & .019 & .581 & .402 \\
\hline 23. & Modest-boastful & -.182 & .162 & $\ldots .309$ & .183 & .201 &, 406 & .394 \\
\hline 24. & Impressive-unimp ressive & -.255 & -.668 & $\ldots .228$ & .063 & .154 & .311 & .689 \\
\hline 25 . & Indecisive-decisive & .417 & .493 & .124 & $\ldots 175$ & -.010 & -.040 & .465 \\
\hline 26. & Extroverted-irstroverted & $\ldots .137$ & -.459 & -.130 & .060 & .030 & -.197 & .290 \\
\hline 27. & Non-agg ressive-agg ressive & .159 & .682 & $\ldots .012$ & .013 & .113 & .146 & .525 \\
\hline
\end{tabular}


APPENDIX E (Concluded)

\begin{tabular}{|c|c|c|c|c|c|c|c|c|}
\hline & Factors: & 1 & 2 & 3 & 4 & 5 & 6 & Communality \\
\hline 28. & Uneducated-educated & .538 & .326 & .069 & -.254 & -.311 & -.102 & .573 \\
\hline 29. & Igrorant-expert & .438 & .407 & .070 & -.306 & -.240 & -.134 & .532 \\
\hline 30 . & Persuasive-unpersuasive & -.203 & $\cdots .657$ & -.113 & .143 & .108 & .112 & .531 \\
\hline 31. & Unf riendly-friendly & .194 & .338 & .646 & -.195 & -.267 & .005 & .680 \\
\hline 32. & Skilled-unskilled & -.398 & -.434 & -.076 & .286 & .379 & .059 & .584 \\
\hline 33. & Unsympathetic-sympathetic & .084 & $.2 € 1$ & .650 & -.127 & -.016 & .015 & .515 \\
\hline 34. & Effective-ineffective & -.349 & -.651 & -.144 & .119 & .235 & .236 & .693 \\
\hline 35 . & Relaxed-tense & -.298 & -.107 & -.254 & .028 & .661 & .133 & .621 \\
\hline 36. & Likable-unlikable & -.234 & -.46 .3 & -.383 & .112 & .441 & .297 & .713 \\
\hline 37. & Trained-untrained & -.371 & -.327 & -.038 & .322 & .534 & .156 & .660 \\
\hline 38. & Immoral-moral & .189 & -.046 & .337 & -.600 & -.032 & .095 & .523 \\
\hline 39. & Realistic-unrealistic & -.388 & -.260 & -.089 & .555 & .201 & .164 & .603 \\
\hline 40 . & Uninfo rmed-informed & .402 & .297 & .018 & -.517 & -.282 & -.094 & .606 \\
\hline 41. & Strong -weak & -.176 & -.620 & -.005 & .284 & .281 & .183 & .610 \\
\hline 42 . & Biased-openminded & .111 & $\ldots .004$ & .224 & -.377 & -.177 & $\ldots 483$ & .471 \\
\hline 43. & Good $\cdots$ bad & -.264 & -.544 & -.193 & .298 & .338 & .347 & .727 \\
\hline 44. & Passive-active & .120 & .644 & .106 & -.211 & -.067 & .005 & .490 \\
\hline 45 . & Admirable-contemptible & -.255 & -.463 & -.259 & .225 & .251 & .373 & .601 \\
\hline 46. & Competent-incompetent & -.325 & -.419 & $\ldots .045$ & .384 & .387 & .275 & .657 \\
\hline 47 . & Unsociable-sociable & .088 & .395 & .502 & -.333 & $\ldots 309$ & -.061 & .627 \\
\hline 48. & Expe rienced-inexpe rienced & -.326 & -.423 & -.007 & .399 & .498 & .147 & .715 \\
\hline 49. & Unrea sonable - rea sonable & .435 & .26 .7 & .163 & -.442 & -.214 & -.246 & .606 \\
\hline 50 . & Unsure-confident & .359 & .405 & .055 & -.280 & -.408 &. .121 & .556 \\
\hline 51. & Dishonest-honest & .329 & .123 & .318 & -.566 & -.084 & -.206 & .596 \\
\hline & Right wrong & -.255 & -.203 & -.124 & .563 & .083 & .304 & .524 \\
\hline 53. & Tired-energetic & .090 & .671 & .244 & -.146 & -.218 & -.080 & .595 \\
\hline 54. & Gloomy-cheerful & .094 & .588 & .407 & -.112 & -.294 & -.145 & .641 \\
\hline 5.5. & Profound-supe rficial & -.147 & -.305 & -.005 & .082 & .135 & .413 & .311 \\
\hline
\end{tabular}




\section{APPENDIX F}

EIGHT FACTOR SOLUTION DERIVED BY VARIMAX ROTATION

\begin{tabular}{|c|c|c|c|c|c|c|c|c|c|c|}
\hline & Factors: & 1 & 2 & 3 & 4 & 5 & 6 & 7 & \multicolumn{2}{|c|}{8 Commu - } \\
\hline$i$. & Kind-cruel & -.288 & -.115 & -.621 & .081 & .092 & 192 & 132 & -.130 & .569 \\
\hline 2. & Wise-unwise & .562 & .361 & .218 & -.190 & .045 & -.161 & $\ldots .066$ & .159 & .589 \\
\hline 3 . & Unfair-fair & .484 & .100 & .377 & $\ldots 198$ & $\ldots .041$ & -.346 &. .156 & .158 & .598 \\
\hline 4. & Understandable-incomp rehensible & $e-.535$ &. .255 & -.207 & -.012 & .275 & .031 & .006 & .051 & .474 \\
\hline 5. & Fast-slow & -.060 & -.183 & .025 & .062 & .070 & -.029 & .816 & .131 & .731 \\
\hline 6. & Attractive-unattractive & -.296 & -.584 & -.317 & -.032 & .212 & .078 & .035 & -.060 & .587 \\
\hline 7. & Unpleasant-pleasant & .358 & .543 & .434 & .007 & -.070 & -.078 & .008 & .030 & .673 \\
\hline 8. & Intelligent-unintelligent & -.616 & -.372 & -.085 & .149 & .212 & .073 & .082 & .048 & .622 \\
\hline 9. & Unauthoritative-autho ritative & .517 & .342 & -.009 &. .155 & -.230 & -.065 & .001 & .019 & .474 \\
\hline 10 . & Uno riginal-o riginal & .300 & .591 & .184 & -.065 & .244 & .044 & .159 & .235 & .564 \\
\hline 11. & Upset-calm & .373 & .010 & .274 & -.104 & -.044 & -.007 & .174 & .069 & .540 \\
\hline 12. & Ca reful-careless & -.545 & -.139 & -.179 & .132 & .409 & .114 & -.071 & .135 & .571 \\
\hline 13. & Illogical-logical & .701 & .214 & .074 & -.182 & -.161 & -.107 & .033 & -.076 & .621 \\
\hline 14. & Irrational-rational & .671 & .155 & .138 & -.148 & -.127 & -.156 & -.023 & .010 & .558 \\
\hline 15. & Uninte resting-inte resting & .299 & .698 & .258 & -.015 & -.134 & $\ldots 019$ & -.021 & .041 & .665 \\
\hline 16. & Organized-disorganized & -.587 & -.196 & -.070 & .053 & .293 & .110 & -.086 & .308 & .593 \\
\hline 17 . & Small-la rge & .168 & .385 & -.068 & .038 & .021 & -.288 & .088 & -.066 & .279 \\
\hline 18. & Un reliable-reliable & .644 & .189 & .135 & -.267 & -.071 & -.179 & -.074 & .017 & .584 \\
\hline 19. & Insincere-sincere & .410 & .314 & .446 & -.198 & -.128 & -.090 & .014 & -.066 & .535 \\
\hline 20 . & Consistent-.irsconsistent & -.583 & -.148 & -.122 & .090 & .226 & .113 & -.097 & .286 & .541 \\
\hline 21. & Believable-unbelievable & -.603 & -.134 &. .147 & .298 & .134 & .164 & .134 & -.061 & .560 \\
\hline 22 . & Objective-subjective & -.245 & -.100 & -.056 & .001 & .011 & .712 & .002 & .104 & .592 \\
\hline 23. & Modest-boastful & -.215 & .077 & -.302 & .138 & .208 & .433 & -.012 & -.134 & .413 \\
\hline 24. & Imp ressive-unimp ressive & -.264 & -.730 & -.204 & .084 & .127 & .159 & .033 & .012 & .695 \\
\hline 25. & Indecisive-decisive & .385 & .464 & .106 & -.202 & .009 & -.058 & .048 & -.292 & .508 \\
\hline 26. & Extroverted-introverted & -.087 & -.283 & -.163 & -.018 & .058 & .030 & .181 & .584 & .494 \\
\hline 27. & Non-aggressive-aggressive & .128 & .576 & $\ldots .005$ & .020 & .113 & .144 & -.138 & -.365 & .535 \\
\hline
\end{tabular}


APPENDIX F (Concluded)

\begin{tabular}{|c|c|c|c|c|c|c|c|c|c|c|c|}
\hline & Fact & & 1 & 2 & 3 & 4 & 5 & 6 & 7 & 8 & $\begin{array}{c}\text { Commu } \\
\text { nality }\end{array}$ \\
\hline 28. & Uneducated-educated & & .520 & .343 & .050 & -.261 & -.321 & -.049 & .006 & -.097 & .575 \\
\hline 29. & Igno rant-expe rt & & .430 & .416 & .055 & -.304 & -.248 & -.071 & -.062 & -.091 & .534 \\
\hline 30 . & Persuasive-unpersuasive & & -.174 &. .654 & -.094 & .184 & .065 & .079 & -.031 & .230 & .566 \\
\hline 31. & Unf riendly-friendly & & .177 & .320 & .643 & $\ldots 195$ & -.259 & -.039 & .014 & -.191 & .692 \\
\hline 32 . & Skilled-unskilled & & -.358 & -.431 & -.059 & .307 & .366 & .066 & -.039 & .216 & .599 \\
\hline 33. & Unsympathetic-sympathetic & & .066 & .248 & .640 & -.161 & .020 & -.060 & .123 & -.215 & .567 \\
\hline 34. & Effective-ineffective & & -.345 & -.679 & -.127 & .120 & .226 & .127 & .072 & .094 & .693 \\
\hline 35. & Relaxed-tense & & -.272 & -.171 & -.242 & .026 & .664 & .110 & -.090 & -.015 & .625 \\
\hline 36. & Likable-unlikable & & -.246 & -.525 & -.373 & .088 & .444 & .191 & .087 & -.041 & .728 \\
\hline 37. & Trained-untrained & & -.356 & -.352 & -.030 & .303 & .550 & .107 & .074 & -.023 & .665 \\
\hline 38. & Immo ral-moral & & .186 & -.045 & .320 & -.654 & -.014 & .072 & .089 & -.023 & .582 \\
\hline 39. & Realistic-un realistic & & -.398 & -.275 & -.076 & .547 & .213 & .115 & .098 & .016 & .609 \\
\hline 40 . & Uninfo rmed-informed & & .398 & .305 & .004 & -.519 & -.294 & -.034 & -.082 & -.038 & .617 \\
\hline 41. & Strong-weak & & -.159 & -.613 & .001 & .277 & .265 & .153 & .109 & .174 & .615 \\
\hline 42. & Biased-openminded & & .139 & .056 & .220 & -.323 & -.170 & -.569 & -.042 & .018 & .531 \\
\hline 43. & Good-bad & & -.280 & -.609 & -.176 & .291 & .330 & .214 & .107 & -.049 & .734 \\
\hline 44. & Passive-active & & .095 & .613 & .095 & -.247 & -.036 & .048 & -.038 & -.218 & .508 \\
\hline 45. & Admirable-contemptible & & -.290 & -.537 & -.244 & .203 & .255 & .218 & .139 & -.121 & .621 \\
\hline 46. & Competent-incompetent & ; & -.332 & -.445 & -.039 & .346 & .404 & .209 & .161 & .018 & .664 \\
\hline 47. & Unsociable-sociable & & .077 & .401 & .495 & -.349 & -.286 & -.060 & -.005 & -.111 & .632 \\
\hline 48. & Expe rienced-inexpe rienced & & -.303 & -.428 & .000 & .386 & .501 & .132 & .079 & .127 & .716 \\
\hline 49. & Unreasonable-reasonable & & .471 & .306 & .146 & -.426 & -.203 & -.170 & -.088 & .028 & .610 \\
\hline 50 . & Unsure-confident & & .348 & .403 & .0 .51 & -.250 & -.429 & -.075 & -.126 & -.091 & .564 \\
\hline 51. & Dishonest-honest & & .351 & .156 & .301 & -.567 & -.084 & -.189 & -.029 & .017 & .605 \\
\hline 52. & Right-w rong & & -.249 & -.256 & -.105 & .570 & .067 & .261 & .043 & -.052 & .542 \\
\hline 53. & Tired-energetic & & .089 & .634 & .252 & -.110 & -.227 & -.020 & -.217 & -.152 & .610 \\
\hline 54. & Gloomy-chee rful & & .098 & .585 & .410 & -.084 & -.295 & -.082 & -.152 & -.092 & .654 \\
\hline 55. & Profound-superficial & & -.132 & -.420 & .034 & .156 & .057 & .372 & -.236 & .003 & .418 \\
\hline
\end{tabular}




\section{APPENDIX G}

FIELD INSTRUMENT

The following page is a suggested instrument for use in the field or in the laboratory for the measurement of the credibility of television newscasters. The author constructed the field instrument by taking highly loaded items from each of the first eight factors of this study, randomizing all and reversing some items.

This field instrument could be used as follows: (1) The sample of the population under consideration should be given the following schedule. (2) The subjects should then observe at least two prescribed newscasts at prescribed times. (3) The subjects should immediately record their reactions on the instrument after observing each newscast. (4) The surveyor would then sum the items across subjects and scale. (5) A comparative figure then could be drawn between the newscasters in question.

A cover sheet including instruction (similar to the one in Appendix B) should be used with this field instrument. 
APPENDIX G (Concluded)

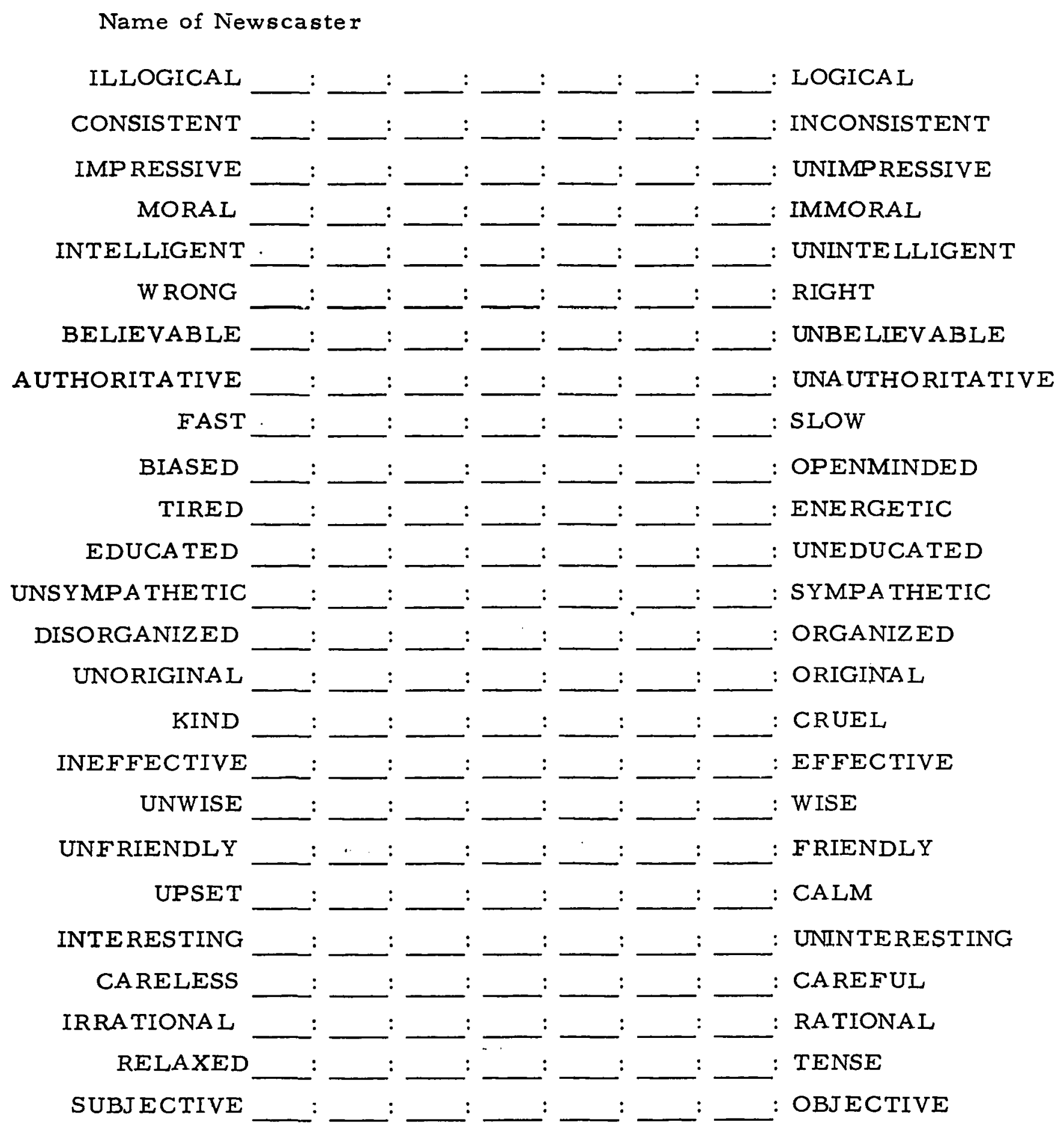



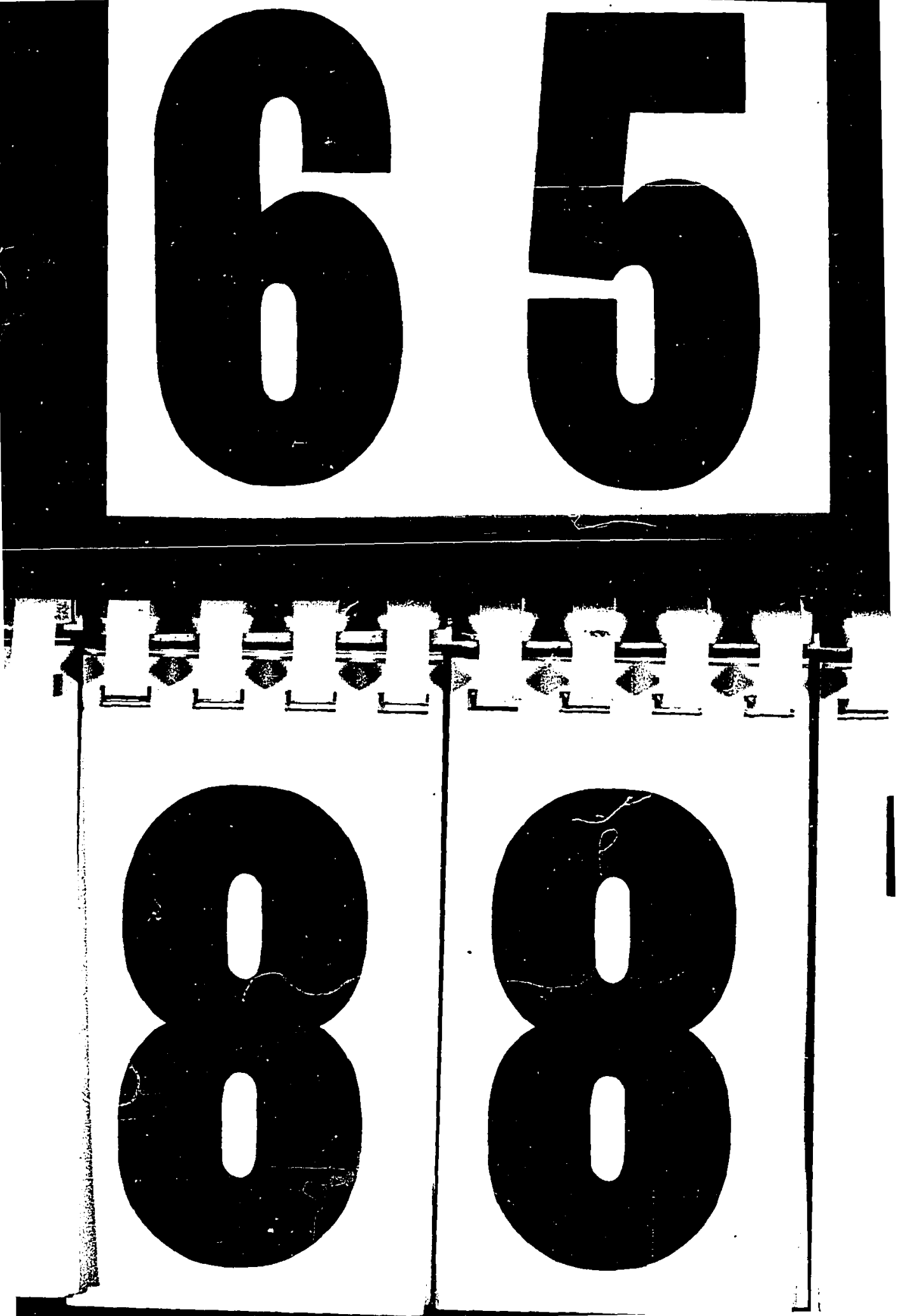
